Florida International University FIU Digital Commons

6-19-2018

\title{
Eating Frequency and the Role of Snacking on Body Weight of WIC Preschool Children
}

Andrea Charvet

achar065@fiu.edu

DOI: 10.25148 /etd.FIDC006837

Follow this and additional works at: https://digitalcommons.fiu.edu/etd

Part of the Community Health and Preventive Medicine Commons, Dietetics and Clinical Nutrition Commons, Food Studies Commons, Health Policy Commons, Maternal and Child Health Commons, Public Health Education and Promotion Commons, and the Social Welfare Commons

\section{Recommended Citation}

Charvet, Andrea, "Eating Frequency and the Role of Snacking on Body Weight of WIC Preschool Children" (2018). FIU Electronic Theses and Dissertations. 3796.

https://digitalcommons.fiu.edu/etd/3796 


\title{
FLORIDA INTERNATIONAL UNIVERSITY
}

\author{
Miami, Florida
}

EATING FREQUENCY AND THE ROLE OF SNACKING ON BODY WEIGHT OF WIC PRESCHOOL CHILDREN

A dissertation submitted in partial fulfillment of the requirements for the degree of DOCTOR OF PHILOSOPHY in

DIETETICS AND NUTRITION

by

Andrea Charvet 
To: Dean Tomás Guilarte

Robert Stempel College of Public Health and Social Work

This dissertation, written by Andrea Charvet, and entitled Eating Frequency and the Role of Snacking on Body Weight of WIC Preschool Children, having been approved in respect to style and intellectual content, is referred to you for judgment.

We have read this dissertation and recommend that it be approved.

$\begin{array}{r}\hline \text { Adriana Campa } \\ \hline \text { Catherine Coccia } \\ \hline \text { Boubakari Ibrahimou } \\ \hline \text { Fatma G. Huffman, Major Professor }\end{array}$

Date of Defense: June 19, 2018

The dissertation of Andrea Charvet is approved.

Dean Tomás Guilarte Robert Stempel College of Public Health and Social Work

Andrés G. Gil Vice President for Research and Economic Development And Dean of the University Graduate School

Florida International University, 2018 
(C) Copyright 2018 by Andrea Charvet All rights reserved. 


\section{DEDICATION}

I dedicate this dissertation to my mother and father, who raised me giving the best they had on themselves. It is said we are only able to fully understand our parents after we have children. This work is also dedicated to my beautiful children, who taught me how to live. From them I learned how to enjoy the simplest things, how to live for the well being of others, and how to someway find the strength to never give up. And I would have struggled to get here if I did not have such a supportive and wonderful man by my side. I will always be thankful. To my sister, who inspired me to always pursue science, and to my grandmother, who inspired me to always pursue love. Thank you God for the opportunity of life. 


\section{ACKNOWLEDGMENTS}

I wish to thank the members of my dissertation committee for the guidance provided during all steps of this research, and the many professors who all placed a building block, or many, when building who I am today. Going back in time I would like to thank Dr. Victoria Castellanos for planting the seed in me that would one day grow to become the researcher I am today. My sincere gratitude goes to my major professor, Dr. Fatma Huffman. Your unlimited support and your loving and caring heart made everything better. I also wish to thank the WIC program at the Florida Department of Health in Broward County, FL, in special Rebecca Hacker and Reginald Shagoury, for believing in me, and all the WIC families who participated in this study. You all made this possible. I thank the Dietetics and Nutrition Research Foundation for the generous support provided to conduct my study. Finally, I would like to thank the National Institute of General Medical Sciences, Research Initiative for Scientific Enhancement (NIGMS RISE) Program for their 4 years of support, making this work possible, and the hard working NIGMS RISE team at FIU.

A.C. was supported by NIH/NIGMS R25 GM061347. The content of this work is solely the responsibility of the authors and does not necessarily represent the official views of the National Institutes of Health. 


\title{
ABSTRACT OF THE DISSERTATION \\ EATING FREQUENCY AND THE ROLE OF SNACKING ON BODY \\ WEIGHT OF WIC PRESCHOOL CHILDREN
}

\author{
by \\ Andrea Charvet \\ Florida International University, 2018 \\ Miami, Florida

\section{Professor Fatma G. Huffman, Major Professor}

The objective of this study was to understand the influence of eating episodes and snack quality on body weight of children ages 3-4.9 years participating in the Broward County Special Supplementation Nutrition Program for Women, Infants, and Children (WIC). Additional objectives were to evaluate obesity risk factors and to examine the effect of childcare arrangements on body weight. Data was collected from 7 Broward County Health Department WIC clinics over 4 months via a researcher-administered questionnaire. Additional data was extracted from the WIC data system. BMI-for-age percentiles were used to categorize children by weight according to Centers for Disease Control (CDC) guidelines, which were further categorized into under/normal weight and overweight/obese. There were 197 participants included (45.7\% boys), 3.6\% of the children were underweight, $64.4 \%$ normal weight, $16.8 \%$ overweight, and $15.2 \%$ were obese. Most children consumed 3 meals $(97.5 \%)$ and 2 to 3 snacks per day $(33.0 \%$ and $37.1 \%$ respectively), with a significantly higher intake of snacks on the weekends when compared to weekdays $(\mathrm{p}=0.001)$. Children consumed more nutritious snacks more often $(66 \%)$ than the nutrient-poor snacks $(33.5 \%)$. We observed a marginally significant trend 
in which the WIC preschool children that more frequently consumed nutrient-poor snacks had a higher prevalence of overweight/obesity $(\mathrm{p}=0.090)$. In multivariate analyses, the children who consumed more than 4-oz of sugar sweetened beverages (SSB) per day, exercised for less than 1 hour per day, and had a higher birth weight had increased odds of being overweight/obese. Race and ethnicity were not predictive of body weight status, but Blacks or African Americans were at a higher risk for many of the risk factors. Children spent on average 20 hours per week under some type of nonparental care arrangement. There was no significant relationship between childcare and weight status. Our findings indicate that WIC children are at a greater risk for overweight and obesity, however there is potential for successful prevention interventions addressing prevalent risk factors. Longitudinal studies including a large sample of racial and ethnic diverse preschool children from low socioeconomic families could help elucidate the results from our study.

This study was approved by FIU IRB (Protocol Approval \#15-0369) the State of Florida Department of Health IRB (Protocol Title: Meal Frequency and the Role of Snacking on Weight of Minority Preschool Children). 


\section{TABLE OF CONTENTS}

CHAPTER

PAGE

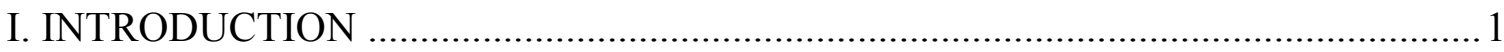

Prevalence of childhood overweight and obesity .................................................2

Incidence of childhood overweight and obesity ………..................................... 4

Impact of obesity ................................................................................................

Risk factors for childhood overweight and obesity ...............................................

Eating frequency and body weight status ........................................................

Snack quality and body weight status ............................................................ 8

Childcare arrangements in early ages...............................................................

The Special Supplementation Nutrition Program for Women, Infants, and

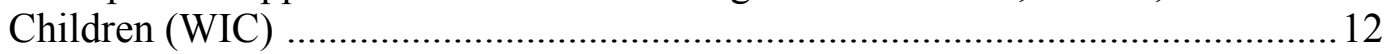

Specific Aims and Hypotheses ............................................................................ 14

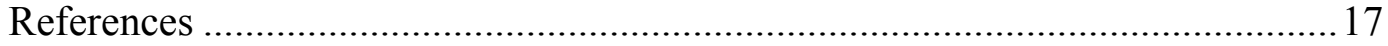

II. THE RELATIONSHIP OF EATING FREQUENCY AND BODY WEIGHT

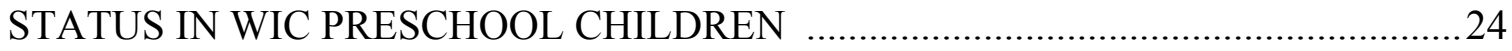

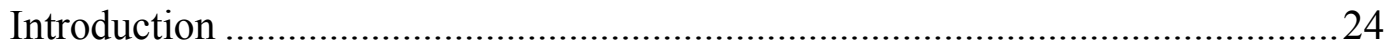

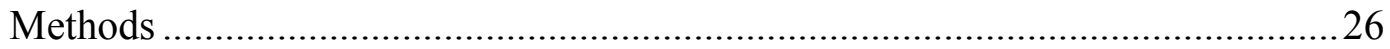

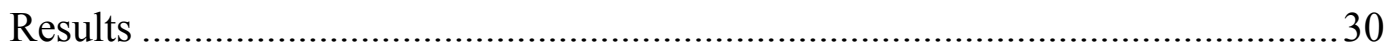

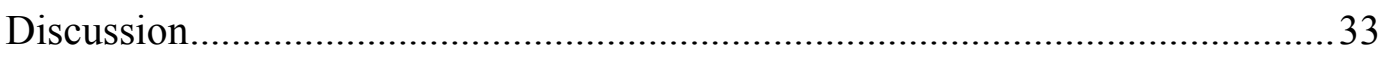

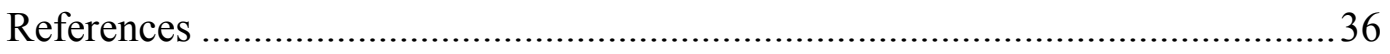

III. THE ROLE OF SNACK QUALITY ON BODY WEIGHT STATUS OF WIC

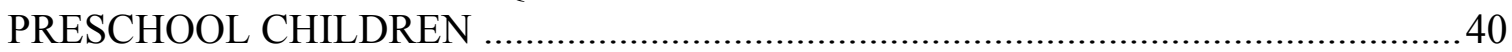

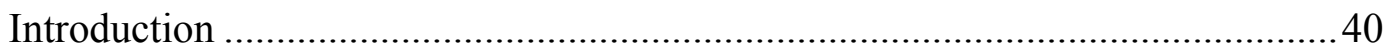

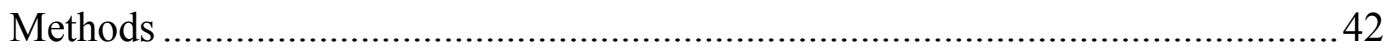

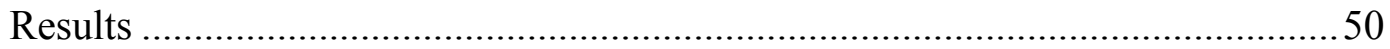

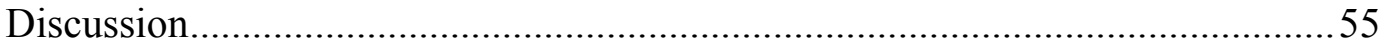

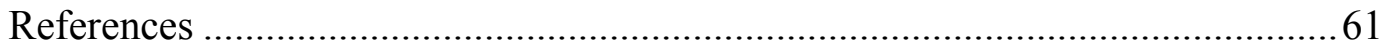

IV. THE INFLUENCE OF RISK FACTORS FOR CHILDHOOD OBESITY ON

BODY WEIGHT STATUS OF WIC PRESCHOOL CHILDREN …………………........... 64

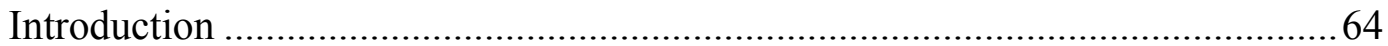

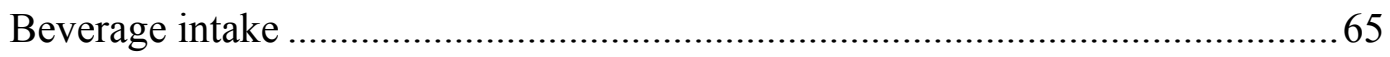

Fruits and vegetables intake ……………………….......................................67

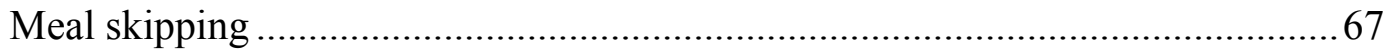

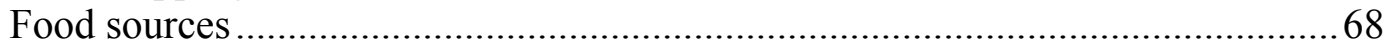

Snacking while watching television ...............................................................69

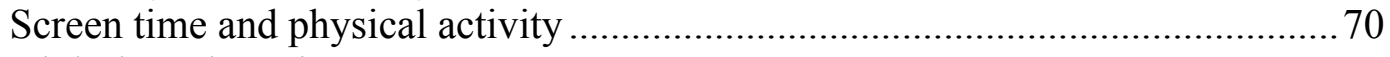

Nighttime sleep time ...................................................................................... 71

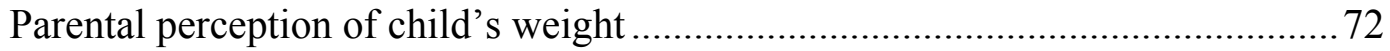

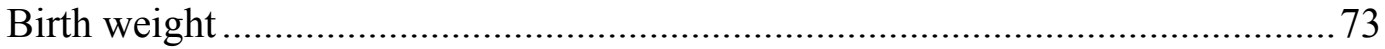




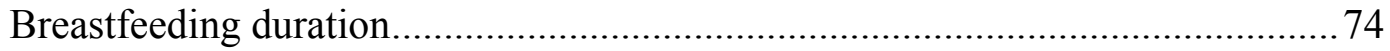

Race, ethnicity and socioeconomic status ........................................................74

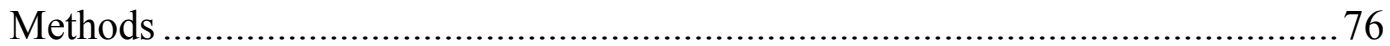

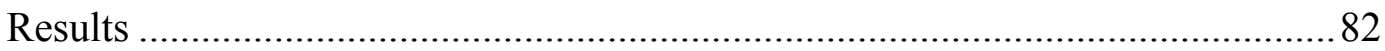

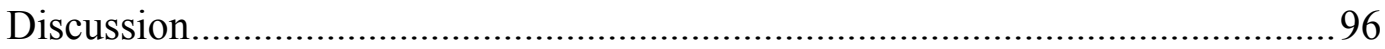

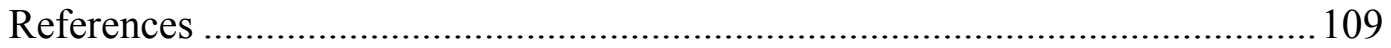

V. THE EFFECT OF CHILDCARE ARRANGEMENTS ON BODY WEIGHT

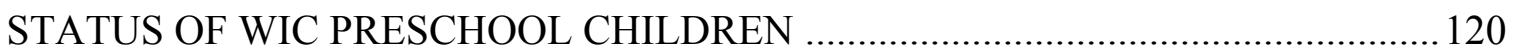

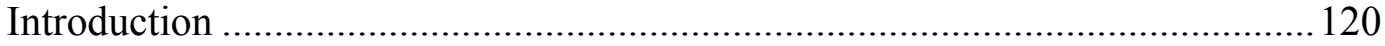

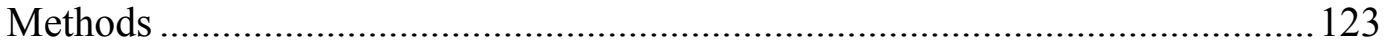

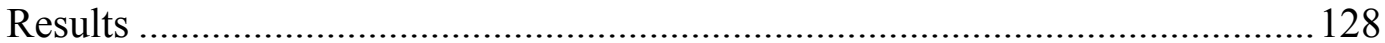

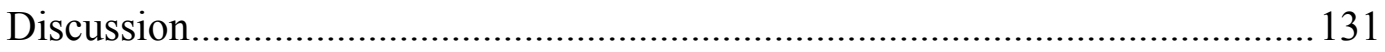

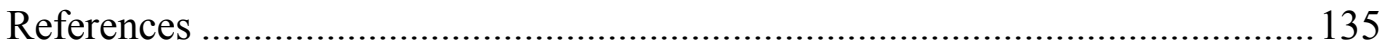

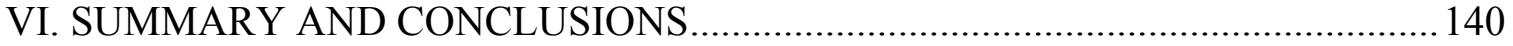

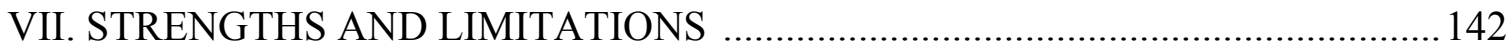

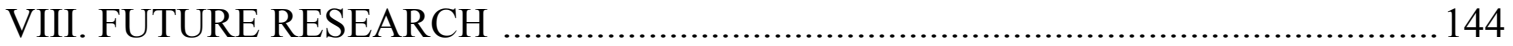

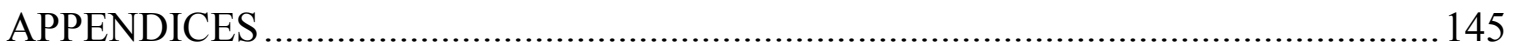

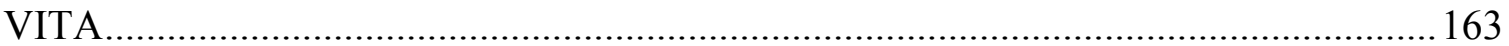




\section{LIST OF TABLES}

TABLE

PAGE

\section{CHAPTER II}

1. Characteristics of study population

2. Number of meals and snacks consumed on weekdays and on weekend

3. Comparison of mean number of meals and snacks consumed on weekdays and on the weekend

4. Number of daily eating episodes and prevalence (\%) of under/normal weight and overweight/obesity in WIC participating preschool children

\section{CHAPTER III}

1. Snack foods and beverages groups

2. Classification according to snack quality score assigned to snack foods and beverages groups

3. Characteristics of study population

4. Weekly average frequency of intake of individual food and beverage snack items, by weight category combined, sorted by overall mean.

5. Snack quality score and prevalence (\%) of under/normal weight and overweight/obesity in WIC participating preschool children

\section{CHAPTER IV}

1. Characteristics of study population

2. Proportion of overweight/obese and under/normal weight preschool children by ethnicity, race, gender, and hemoglobin status.

3. Daily average beverage intake in ounces, by weight status

4. Daily average beverage intake in ounces, by ethnicity and race

5. Proportion of type of milk most often consumed by weight category combined in WIC participating preschool children.

6. Ethnicity and race, and prevalence (\%) of WIC participating preschool children who snacked while watching TV frequently and infrequently 
7. Frequency of snacking while watching TV by snack quality score among WIC participating preschool children

8. Average minutes of physical activity or active play and hours of screen use per day by weight category combined, ethnicity, race, and gender for WIC participating preschool children

9. Authorized representatives' perception of their child's size according to weight category

10. Authorized representatives' perception of their child's size according to weight category combined, by ethnicity and race

11. Proportion of children who were ever breastfed by weight category combined in WIC participating preschool children

12. Predictors of the risk of overweight/obesity in WIC participating preschool children

13. Categorized predictors of the risk of overweight/obesity in WIC participating preschool children

\section{CHAPTER V}

1. Characteristics of study population

2. Distribution of preschool children by childcare arrangements during daytime on weekdays

3. Association between the type of center-based care setting and weight category combined by ethnicity 


\section{ABBREVIATIONS AND ACRONYMS}

BMI Body Mass Index

CACFP Child and Adult Care Food Program

CDC Centers for Disease Control and Prevention

EBT Electronic Benefit Transfer

FITS Feeding Infants and Toddlers Study

IRB Institutional Review Board

NHANES National Health and Nutrition Examination Surveys

REDCap Research Electronic Data Capture

SSB Sugar Sweetened Beverages

TV Television

UNC University of North Carolina

USDA United States Department of Agriculture

WIC Special Supplementation Nutrition Program for Women, Infants, and Children

WIC PC Special Supplementation Nutrition Program for Women, Infants, and Children Participants and Program Characteristics 


\section{CHAPTER I: INTRODUCTION}

The purpose of this research was to examine the relationship between eating frequency and snack quality on body weight status of preschool age children participating in the Broward County Special Supplementation Nutrition Program for Women, Infants, and Children (WIC). Additional objectives were to evaluate obesity risk factors and to examine the effect of childcare arrangements on body weight.

Figure 1 shows the conceptual framework of the study. Taking into account multiple risk factors that are related to childhood obesity, this study focused on eating frequency, snack quality, and childcare arrangements as potential contributing factors to the development of overweight and obesity in preschool children.

Figure1. Study conceptual framework.

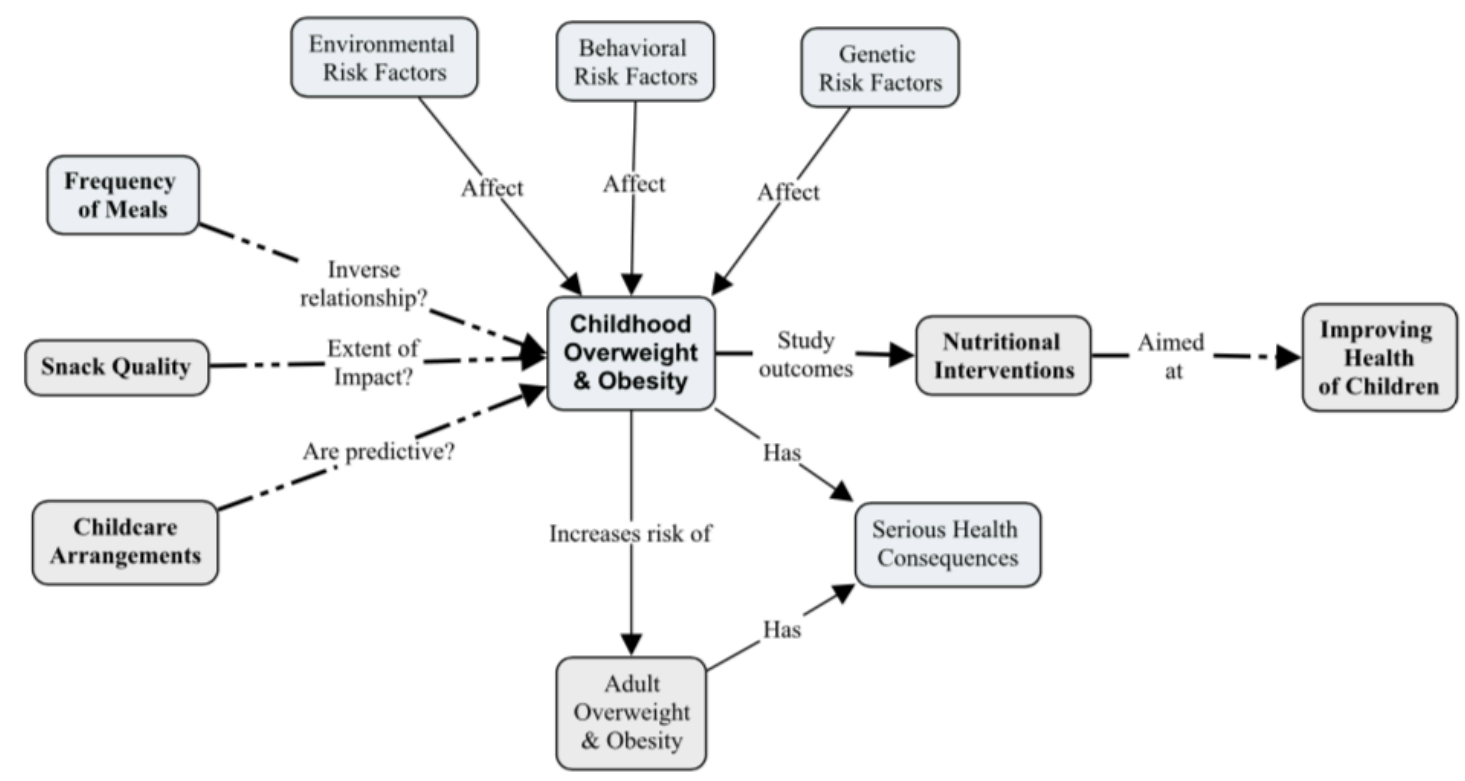




\section{Prevalence of childhood overweight and obesity}

In this work childhood overweight is defined as Body Mass Index (BMI)-for-age greater or equal to the $85^{\text {th }}$ percentile based on the Centers for Disease Control and Prevention (CDC, 2000) growth charts. Obesity is defined as BMI-for-age greater or equal to the $95^{\text {th }}$ percentile. The rate of U.S. children in these two weight ranges is a public health concern. Obesity prevalence trends among youth ages two to nineteen presented a significant increase from 1999-2000 through 2013-2014. ${ }^{1}$ Among US preschool-aged children obesity prevalence trends increased from $7.2 \%$ between the years of 1988 and 1994 to a high $13.9 \%$ in 2003-2004, after which it started to decline. ${ }^{2}$ The latest data on obesity prevalence in children 2 to 5 years from the National Health and Nutrition Examination Surveys (NHANES) 2011-2014 shows a rate of 8.9\%, compared to $17.0 \%$ in youth ages 2 to $19 .{ }^{1}$ In $2011-2012$, the prevalence of overweight and obesity combined was $22.8 \%$ in children 2 to 5 years, in contrast with $31.8 \%$ in youth 2 to 19 years. $^{3}$

Children from racial and ethnic minorities and those from low-income families are particularly affected. According to the 2011-2014 NHANES data, the prevalence of obesity in youth 2 to 19 years of age was greater in Hispanics (21.9\%) and non-Hispanic blacks (19.5\%) when compared to non-Hispanic whites (14.7\%) and non-Hispanic Asians $(8.6 \%)$. For children 2 to 5 years of age, the prevalence of obesity was $15.6 \%$ for Hispanics, $10.4 \%$ for non-Hispanic blacks, $5.2 \%$ for non-Hispanic whites, and $5.0 \%$ for non-Hispanic Asians. ${ }^{2}$

Obesity surveillance in young children from low-income families is being conducted through collaboration between the United States Department of Agriculture 
(USDA) and the CDC using data from WIC Participants and Program Characteristics (WIC PC). Overall obesity prevalence among WIC participants ages 2 to 4 years increased significantly from $14.0 \%$ in 2000 to $15.5 \%$ in 2004 and $15.9 \%$ in 2010 , decreasing significantly to $14.5 \%$ in $2014 .{ }^{4}$ This is substantially higher than NHANES data for the national prevalence of obesity in 2 to 5 year-olds of $8.9 \%$ between the years of 2011-2014. In Florida, obesity prevalence among WIC participants ages 2 to 4 years increased from $13.2 \%$ in 2000 to $14.5 \%$ in 2004 and $14.6 \%$ in 2010 , decreasing significantly to $12.7 \%$ in $2014 .{ }^{4}$ It has been speculated that this downward trend in obesity seen in most WIC state agencies since 2010 is related to the revisions in the WIC food packages that occurred in 2009 , combined with a number of federal and local obesity prevention initiatives. $^{4}$

During the past 3 years the state of Florida presented a slight decrease in the rates of overweight and obesity, while Broward County presented an increase in such rates from 2014 to the end of 2016. Nevertheless, overweight and obesity prevalence among WIC clients in Broward County is still lower than that for the State of Florida. Data on weight indicators provided by the Broward County Health Department WIC Program show that in 2014 on average $21.8 \%$ of Broward County WIC participating children ages 2 to 4 were overweight or obese while $10.6 \%$ were obese. As of December 2016, 24.2\% of Broward's WIC children were overweight or obese, while $11.4 \%$ were obese. ${ }^{5}$ The State of Florida total percentage of overweight or obese WIC participating children was $26.9 \%$ versus $12.9 \%$ obese in 2014 and $26.4 \%$ versus $12.3 \%$ obese in $2016^{5}$ 


\section{Incidence of childhood overweight and obesity}

While prevalence measures the proportion of a population who have a disease or condition in a given time period, incidence measures the rate of occurrence of new cases of a disease or condition. The prevalence of childhood overweight and obesity in the Unites States is well documented; however, data on its incidence are limited but consistent in showing a decline in obesity incidence as age increases.

A systematic review found that the mean obesity incidence was $4.0 \%$ at ages 0 1.9 years, $4.0 \%$ at $2.0-4.9$ years, $3.2 \%$ at $5.0-12.9$ years, and $1.8 \%$ at $13.0-18.0$ years. $^{6}$ Results from another recently published review showed that obese children and adolescents were more than five times likely of becoming obese adults than non-obese children. ${ }^{7}$ Both studies also reported that this association between childhood and adult obesity likely varies across populations, with Black and Hispanic children presenting a higher incidence rate than white children.

A longitudinal study by Cunningham and colleagues ${ }^{8}$ reported the cumulative incidence of obesity for 9 years, from the day a child entered kindergarten through the time that same child was in 8 th grade. Their findings showed that half of the obese children participating in the study had become overweight during the preschool years. For children entering kindergarten at normal weight the incidence of obesity was low and remained constant between the ages of 5 to 14 years. The results from this study add to those from other studies, suggesting that the early childhood period is critical to the

development of obesity. ${ }^{9-11}$ Early prevention of childhood obesity is among the most promising strategies to reduce obesity in children and adults, and prevent the serious health conditions associated with it. 


\section{Impact of obesity}

Obesity has serious health consequences such as increased risk for type II diabetes, cardiovascular disorders, some forms of cancer, ${ }^{10}$ asthma, joint and bone disorders, social rejection and low-self esteem, ${ }^{12-14}$ which negatively impact a person's quality of life and decrease longevity. Children who are obese have an increased risk of dying before the age of 55 when compared to children whose BMI is in the healthy range. ${ }^{15,16}$ It is estimated that life expectancy of an average American at birth could level off or even decline by mid-century if interventions are not implemented to slow down this epidemic. $^{17}$

Obesity also generates a large economic burden due to the high cost of treatment for the associated diseases. ${ }^{18}$ The medical costs of adult obesity are estimated to be from $\$ 147$ to nearly $\$ 210$ billion per year, while childhood obesity alone is responsible for $\$ 14.1$ billion in direct costs. ${ }^{19}$ A systematic review and meta-analysis by Kim and Basu explored the medical care costs attributable to obesity, and reported similar results, showing a cost of $\$ 149.4$ billion at the national level in the year of $2014 .{ }^{20}$ The authors also found that there was no significant difference in medical costs due to childhood obesity when compared to non-obese children when considering obesity-related comorbidities since they may take a long time to develop among children. On the other hand, when comparing expenses in outpatient visits, prescription drugs and emergency room, obese children had significantly increased utilization and costs than normal and underweight children. $^{21}$ 


\section{Risk factors for childhood overweight and obesity}

Understanding the risk factors that fuel the childhood obesity epidemic is crucial to address the problem. Research has shown that the development of childhood overweight and obesity involves a complex set of factors that interact with each other and place a child at risk. ${ }^{22}$ A child lives in an environment that includes the family, the school or day care, and the community. Improving dietary and lifestyle patterns requires measures that address not only individual behaviors but also the environment in which people live and make choices, such as home, child care, school, work site, retail store, and restaurant settings. ${ }^{23,24}$ The use of an ecological systems model has been suggested in the literature, in order to simultaneously analyze the effect of multiple potential risk factors on childhood obesity and possibly identify starting points for childhood obesity prevention interventions. $^{22,25}$

Several studies have identified individual risk factors for childhood overweight and obesity that go beyond eating habits. They include physical activity, ${ }^{26}$ television viewing, ${ }^{27}$ sleep duration, ${ }^{28}$ parental feeding styles, ${ }^{29,30}$ parental weight status, ${ }^{31}$ parental perception of child's weight, ${ }^{32,33}$ birth weight, ${ }^{34}$ breastfeeding duration, ${ }^{35}$ race, ethnicity and socioeconomic status ${ }^{36}$.

Substantial research clearly indicates that eating habits is a prominent risk factor for overweight and obesity, although its influence needs to be better understood. Changes in children's meal patterns over the past three decades may have had an important role. A study conducted by Nicklas et $\mathrm{al}^{37}$ with 10 -year-old children over a 21 -year period found that over time more children are skipping breakfast and eating foods prepared outside the home, and fewer children are consuming snacks between meals, even though the authors 
found no association between meal patterns and overweight status. Findings from other studies are in accordance with the reported increase in the intake of foods prepared outside the home, mainly fast food intake $\mathrm{e}^{38-40}$ but disagree in regards to the decreased consumption of snacks by children. Additional studies report an increase in the prevalence of snacking among children in the U.S. over the past three decades. ${ }^{41-43}$ Research shows that the majority of the children in the United States do not consume diets that meet the recommendations of the Dietary Guidelines for Americans in terms of macro and micronutrients, and also do not achieve adequate levels of physical activity. ${ }^{44}$ Food preferences and eating patterns are developed during early childhood and followed through adulthood, ${ }^{45-48}$ making children a potential target for nutrition interventions aimed at promoting healthy eating habits for life.

\section{Eating frequency and body weight status}

Even though many studies explore the relationship between eating habits and childhood obesity, the literature is limited in evaluating the influence of eating frequency on a child's weight. Previous studies in adults suggest that there is an inverse association between meal frequency and the prevalence of overweight and obesity. ${ }^{49-51}$ Fabry and colleagues $^{52}$ were the first to study the impact of meal frequency on the weight status of children and adolescents. Results showed that adolescents eating 3 meals per day had a higher body weight for height and a significantly greater skinfold thickness than those eating 5 or 7 smaller meals per day. However, they found no significant differences in body weight of younger children who ate 3, 5 or 7 meals per day. A recent review of the literature by Larson and Story ${ }^{53}$ showed that most studies exploring the association 
between snacking and weight status either found no relationship or found that children and adolescents who consume more snacks are less likely to become obese. A metaanalysis of 21 studies evaluated the extent to which eating frequency is associated with body weight status. Children and adolescents who ate more frequently were $22 \%$ less likely to be overweight or obese compared with those eating fewer times per day. ${ }^{54}$

Studies in adults have suggested that the time distribution of food intake may have metabolic effects such as changes in overall energy metabolism, more rapid absorption of glucose and fat from the intestine, increased glycogen synthesis, and an increased lipogenesis, as a way for the body to adapt and enhance its ability to form metabolic reserves. ${ }^{49,55}$ Different mechanisms exist that may explain the association between higher eating frequency and lower body weight in children. In addition to the thermogenic effect of food, the beneficial effect of increased eating frequency on insulin metabolism may be a potential biological mechanism to be considered. ${ }^{54}$ The observed protective effect of an increased daily meal frequency on obesity in children appears to be independent of other risk factors for childhood obesity. ${ }^{56}$

\section{Snack quality and body weight status}

The quality of snacks provided to children may be crucial in influencing body weight status. According to 2013-2014 NHANES data, snacks contribute approximately $30 \%$ of the total daily energy intake in children ages $2-5 .{ }^{57}$ In 2006 , the 3 main contributors to energy from snacking in U.S. children were reported to be dessert foods (such as cookies, cakes, ice cream) in first place, salty snacks in second place and

sweetened beverages in third place. ${ }^{43}$ But this was not the case thirty years ago, at a time 
when the obesity epidemic was not a concern. Diets of young children have changed in terms of food quality and also as to total daily energy intake. A nationwide study conducted by Ford et $\mathrm{al}^{45}$ found a marked increase in the intake of foods high in added sugars, solid fats and sodium in the diets of children ages 2 to 6 from 1989 to 2008 . Within the same period, total daily energy intake increased by $109 \mathrm{kcal} .{ }^{45}$

Maffeis et $\mathrm{al}^{58}$ assessed the relationship between the type and number of snacks consumed by 8 to 10 -year old children and body size, finding no significant difference between the number of snacks consumed and the child's body weight status, but also finding that overweight and obese children were consuming significantly more energy dense snacks than normal weight children. In a literature review on the implications of snacking for weight status in children and adolescents some studies presented evidence that a greater consumption of energy-dense snacks was associated with a higher BMI, however most studies either found no relationship or found evidence that children who consumed snacks between meals were less likely to be obese. ${ }^{53}$

Because snacks are a significant source of key nutrients in addition to energy, ${ }^{57}$ healthy snacking between the three main meals may potentially improve the quality of children's diets and help prevent childhood obesity. More research is needed to better understand the role of snacking on weight of preschool children.

\section{Childcare arrangements in early ages}

The home setting has an important role in forming eating habits, and several factors in the family food environment are associated with eating behaviors seen in children, such as parental food preferences, role modeling, media exposure, and child- 
parent interactions around food. ${ }^{59,60}$ Parents are particularly influential in the development of eating habits in very young children. ${ }^{30}$ It has been suggested that preschool experiences may also have a significant influence on eating habits, and consequently on weight status in childhood. ${ }^{9,61}$ In the United States, the number of 3 and 4 year old children enrolled in preschool increased from $48.7 \%$ in 1995 to $52.7 \%$ in $2015 .{ }^{62}$ In 2016, according to the National Center for Education Statistics, $73 \%$ of children ages 3-5 not yet in kindergarten had at least one weekly nonparental care arrangement, while $27 \%$ were only under parental care. ${ }^{63}$ From those participating in a nonparental childcare setting $82 \%$ were under center-based arrangements, $32 \%$ were cared for by a relative and, $16 \%$ were cared for by a non-relative in a home-based environment (children may have multiple arrangements). ${ }^{63}$

There is evidence for an association between childcare setting and childhood overweight and obesity, although the literature is limited and the results are not conclusive. A study examining the influence of the type of childcare the year before kindergarten on the risk of overweight or obesity when entering kindergarten using a nationally representative sample, found that non-Latino children in friend, family and neighbor care and in Head Start were significantly more likely to be obese at the start of kindergarten than children under parent care, while Latino children in parent care were more likely to be obese than those in Head Start or friend, family and neighbor care. ${ }^{64}$ Latino mothers usually perceive their children as being thinner than they actually are and share the cultural belief that "chubby" children are healthier than thinner ones, potentially influencing the risk for obesity. ${ }^{32}$ Another study conducted primarily with preschool children from low-income urban households in the U.S. found no significant relationship 
between race and ethnicity and weight category, but found that children who attended a public preschool for at least one year were at an increased risk for being overweight or obese when entering kindergarten compared to children under parental care. ${ }^{65}$ Even though some studies suggest a protective effect of parental care, other studies have found that preschool children who spend more time in center-based care were less likely to be obese than children under parental care. ${ }^{66,67} \mathrm{~A}$ recent literature review compiling findings from studies examining the association of childcare arrangement and weight outcome among preschool-aged children concluded there is no consistent evidence for a relationship between childcare and the risk for obesity except for Head Start; 3 out of 8 studies demonstrated a negative relationship between Head Start and the risk for obesity, while no study reported a positive relationship. ${ }^{68}$ Another systematic review reported that children ages 5 years and younger who are under informal care (family, friends and neighbors) have an increased risk of childhood overweight and obesity than preschool children who are on center-based care. ${ }^{69}$

Despite the unsatisfactory prognosis of preschool children who are obese to remain obese later in life, and the widespread use of childcare during early childhood, most states lack strong regulations for childcare settings related to healthy eating. ${ }^{23,61}$ Considerable variation exists among states in regulations related to obesity. Overall, childcare centers are the most regulated, followed by large family childcare homes, with the small ones tending to have the fewest regulations. ${ }^{61}$ The Child and Adult Care Food Program (CACFP), a federal program administered by the U.S. Department of Agriculture (USDA), provides free nutritious meals and snacks to infants and children from low-income families in a variety of public or private nonprofit childcare centers, 
Head Start programs, outside-school-hours care centers, and other institutions that are approved to participate in CACFP. ${ }^{70}$ To be able to participate in CACFP reimbursement the centers need to follow certain guidelines that require that meals and snacks include a minimum number of age-appropriate servings from 4 food groups. ${ }^{70}$ The drawback is that the CACFP guidelines do not require meals and snacks to meet any nutrient-based standards of the Dietary Guidelines for Americans, and they do not prohibit the centers from offering calorie dense foods and beverages, with low nutritional value. ${ }^{23} \mathrm{~A}$ multidisciplinary group of experts identified the assessment of the quality of children's meals and snacks as being the highest priority research area targeting obesity prevention in early care and education programs. ${ }^{71}$ In a position paper by the American Dietetic Association, Benjamin Neelon and Briley ${ }^{72}$ suggest that foods and beverages served in childcare programs should be consistent with the Dietary Guidelines for Americans, and should be provided in quantities and meal patterns appropriate to ensure optimal growth and development, including the fact that meals and snacks should be served to children every 2 to 3 hours. Currently, it is not known to what extent the foods and beverages offered to pre-school children meet the Dietary Guidelines for Americans, and more research in the area is needed.

\section{The Special Supplementation Nutrition Program for Women, Infants, and Children (WIC)}

In April 2014 there were 9.3 million women, infants and children enrolled in WIC, with just over $76 \%$ of those being infants and children under the age of $5 .{ }^{73}$ WIC

serves $50 \%$ of infants and $25 \%$ of preschool-aged children in the United States. ${ }^{74}$ It is 
administered by the USDA and has the mission to safeguard the health of low-income women, infants, and children through age 5 who are at nutritional risk. Race data from 2014 show that Whites are the largest group of WIC participants (58.7\%), followed by African Americans (20.3\%), American Indians or Alaska Natives (11.1\%), and Asian or Pacific Islanders (4.1\%). ${ }^{73}$ In 2014 Hispanics accounted for $41.6 \%$ of all participants. ${ }^{73}$

Pregnant women, when they meet the official requirements to receive WIC benefits, are certified to receive such benefits for the duration of pregnancy, postpartum women until the baby is six months of age, breastfeeding women up to the day the baby turns one year old. Infant and children are certified since birth up to his/her fifth birthday. ${ }^{74}$ To qualify for WIC, applicants must meet eligibility requirements, including residential, income, and nutritional risk. Nutritional risk is composed of five broad categories, each of them containing subgroups of indicators and specific criteria: anthropometric (such as low weight for height), biochemical (such as hemoglobin below state criteria), clinical/health/medical (nutrition-related conditions such as chronic, genetic or infectious diseases, failure-to-thrive, drug-nutrient interactions), dietary (inadequate or inappropriate nutrient intake), or other (such as homelessness). ${ }^{75}$ During the certification visit WIC requires the height and weight of each applicant to be updated and a blood test for anemia to be administered if due. Data on medical history and dietary patterns are collected using a standardized questionnaire. All data is recorded into the WIC data system. Re-certification varies by State. In Florida, clients are re-certified every year and height and weight is updated every 6 months. The most frequently recorded nutritional risks for children are inadequate or inappropriate nutrient intake (27\%), and high weight for height (23\%). ${ }^{74}$ WIC provides nutritious foods through a 
supplemental food package designed to address the nutritional needs of a specific population, given in form of vouchers or Electronic Benefit Transfer (EBT) cards to be used at participating food stores. Revisions of the provided food packages are periodically implemented, with study findings demonstrating positive changes in dietary

intake following WIC food package revisions. ${ }^{76,77}$ Nutrition education emphasizing the relationship between nutrition, physical activity and health, as well as improving the health status of individuals at nutritional risk, and referrals to health care and other social services are also part of the WIC program.

\section{Specific Aims and Hypotheses}

\section{Specific Aim 1}

To examine the relationship between the number of eating episodes per day and the child's body weight status as evidenced by BMI for age in a sample of children ages 3 to under 5 years participating in the WIC Program in Broward County, Florida.

\section{Hypothesis 1}

The number of eating episodes per day will be inversely associated with the prevalence of overweight or obesity.

\section{Specific Aim 2}

To examine the relationship between snack quality score, determined by healthfulness, nutrient density and energy density, and the child's body weight status as evidenced by BMI for age in a sample of children ages 3 to under 5 years participating in the WIC Program in Broward County, Florida. 


\section{Hypothesis 2}

The intake of nutrient-poor snacks, as evidenced by a low snack quality score, will be positively associated with the prevalence of overweight and obesity.

\section{Specific Aim 3}

To explore known risk factors for childhood obesity and their relationship with the child's body weight status in a sample of children ages 3 to under 5 years participating in the WIC Program in Broward County, Florida, including: beverages consumed, meal skipping, source of foods, fruits and vegetables intake, snacking while watching TV, nighttime sleep time, physical activity, screen time, parental perception of child's size, birth weight, breastfeeding duration, race and ethnicity.

\section{Hypothesis 3a}

The amount of sweetened beverages consumed will be positively associated with the prevalence of overweight and obesity.

\section{Hypothesis 3b}

The frequency of meal skipping will be positively associated with the prevalence of overweight and obesity.

\section{Hypothesis 3c}

The frequency of consumption of meals prepared away from home or daycare will be positively associated with the prevalence of overweight and obesity, while the frequency of consumption of meals prepared from scratch will be negatively associated with the prevalence of overweight and obesity. 


\section{Hypothesis 3d}

The average frequency of intake of fruits and vegetables will be negatively associated with the prevalence of overweight and obesity.

\section{Hypothesis 3e}

The amount of nighttime sleep and physical activity will be inversely associated with the prevalence of overweight and obesity, while the amount of screen time and snacking while watching TV will be positively associated with the prevalence of overweight and obesity.

\section{Hypothesis 3f}

A greater number of parents of children with a healthy body weight will perceive their children to be on the correct body weight category when compared to parents of children who are overweight or obese.

\section{Hypothesis 3g}

Birth weight will be positively associated with the prevalence of overweight and obesity.

\section{Hypothesis $3 h$}

Breastfeeding duration will be negatively associated with the prevalence of overweight and obesity.

\section{Hypothesis 3i}

Children from minority families such as Hispanics and non-Hispanic blacks will have a higher prevalence of overweight and obesity when compared to children from non-Hispanic white families. 


\section{Specific Aim 4}

To investigate if and to what extent participation in different childcare arrangements (parental care, nonparental care and mixed care) can predict a child's body weight status in a sample of children ages 3 to under 5 years participating in the WIC Program in Broward County, Florida.

\section{Hypothesis 4}

Children who are exclusively under parental care will have a lower prevalence of overweight and obesity when compared to children under nonparental or mixed care arrangements.

\section{References}

1. Ogden CL, Carroll MD, Fryar CD, Flegal KM. Prevalence of obesity among adults and youth: United States, 2011-2014. NCHS data brief. 2015(219):1-8.

2. Ogden CL, Carroll MD, Lawman HG, et al. Trends in obesity prevalence among children and adolescents in the United States, 1988-1994 through 2013-2014. JAMA. 2016;315(21):2292-2299.

3. Ogden CL, Carroll MD, Kit BK, Flegal KM. Prevalence of childhood and adult obesity in the United States, 2011-2012. JAMA. 2014;311(8):806-814.

4. Pan L, Freedman DS, Sharma AJ, et al. Trends in obesity among participants aged 2-4 years in the Special Supplemental Nutrition Program for Women, Infants, and Children United States, 2000-2014. MMWR Morb Mortal Wkly Rep. 2016;65(45):1256-1260.

5. Indicators. Florida WIC - Bureau of WIC Program Services Web site. https://floridahealth.sharepoint.com/sites/COMMUNITYHEALTH/WIC/Intranet/Docum ents/Indicators/indicators.html. Updated 2016. Accessed January 21, 2017.

6. Cheung PC, Cunningham SA, Naryan KMV, Kramer MR. Childhood obesity incidence in the United States: A systematic review. Child Obes. 2016;12(1):1-11.

7. Simmonds M, Llewellyn A, Owen CG, Woolacott N. Predicting adult obesity from childhood obesity: A systematic review and meta-analysis. Obes Rev. 2016;17(2):95-107. 
8. Cunningham SA, Kramer MR, Narayan KMV. Incidence of childhood obesity in the United States. N Engl J Med. 2014;370(5):403-411.

9. Birch LL, Ventura AK. Preventing childhood obesity: What works? Int J Obes. 2009;33(S1):S74-S81.

10. Serdula MK, Ivery D, Coates RJ, Freedman DS, Williamson DF, Byers T. Do obese children become obese adults? A review of the literature. Prev Med. 1993;22(2):167-177.

11. Manger WM, Manger LS, Minno AM, et al. Obesity prevention in young schoolchildren: Results of a pilot study. J Sch Health. 2012;82(10):462-468.

12. Adedze P, Chapman-Novakofski K, Witz K, Orr R, Donovan S. Knowledge, attitudes, and beliefs about nutrition and childhood overweight among WIC participants. Fam Community Health. 2011;34(4):301-310.

13. Lanigan JD. The substance and sources of young children's healthy eating and physical activity knowledge: Implications for obesity prevention efforts. Child Care, Hlth Dev. 2011;37(3):368-376.

14. Rodríguez G, Moreno LA. Is dietary intake able to explain differences in body fatness in children and adolescents? Nutr Metab Cardiovas. 2006;16(4):294-301.

15. Franks PW, Hanson RL, Knowler WC, Sievers ML, Bennett PH, Looker HC. Childhood obesity, other cardiovascular risk factors, and premature death. $N$ Engl J Med. 2010;362(6):485-493.

16. Baker JL, Olsen LW, Sørensen TIA. Childhood body-mass index and the risk of coronary heart disease in adulthood. N Engl J Med. 2007;357(23):2329-2337.

17. Olshansky SJ, Passaro DJ, Hershow RC, et al. A potential decline in life expectancy in the United States in the 21st century. N Engl J Med. 2005;352(11):1138-1145.

18. Swinburn BA, Sacks G, Hall KD, et al. The global obesity pandemic: Shaped by global drivers and local environments. Lancet. 2011;378(9793):804-814.

19. Levi J, Segal L, St. Laurent R, Lang A, Rayburn J. F as in fat: How obesity threatens America's future. Princeton, NJ: Trust for America's Health/Robert Wood Johnson Foundation. 2012. http://www.rwjf.org/content/dam/farm/reports/reports/2012/rwjf401318. Accessed March $27,2018$.

20. Kim DD, Basu A. Estimating the medical care costs of obesity in the United States: Systematic review, meta-analysis, and empirical analysis. Value Health. 2016;19(5):602613. 
21. Trasande L, Chatterjee S. The impact of obesity on health service utilization and costs in childhood. Obesity. 2009;17(9):1749-1754.

22. Davison KK, Birch LL. Childhood overweight: A contextual model and recommendations for future research. Obes Rev. 2001;2(3):159-171.

23. Story M, Kaphingst KM, Robinson-O'Brien R, Glanz K. Creating healthy food and eating environments: Policy and environmental approaches. Annu Rev Public Health. 2008;29:253-272.

24. Rahman T, Cushing RA, Jackson RJ. Contributions of built environment to childhood obesity. Mt Sinai J Med. 2011;78(1):49-57.

25. Dev DA, McBride BA, Fiese BH, Jones BL, Cho H, on behalf of The Strong Kids Research Team. Risk factors for overweight/obesity in preschool children: An ecological approach. Child Obes. 2013;9(5):399-408.

26. Steinbeck KS. The importance of physical activity in the prevention of overweight and obesity in childhood: A review and an opinion. Obes Rev. 2001;2(2):117-130.

27. Zhang G, Wu L, Zhou L, Lu W, Mao C. Television watching and risk of childhood obesity: A meta-analysis. Eur J Public Health. 2016;26(1):13-18.

28. Nielsen LS, Danielsen KV, Sørensen TIA. Short sleep duration as a possible cause of obesity: Critical analysis of the epidemiological evidence. Obes Rev. 2011;12(2):78-92.

29. Hughes SO, Power TG, Orlet Fisher J, Mueller S, Nicklas TA. Revisiting a neglected construct: Parenting styles in a child-feeding context. Appetite. 2005;44(1):83-92.

30. Stang J, Loth KA. Parenting style and child feeding practices: Potential mitigating factors in the etiology of childhood obesity. J Am Diet Assoc. 2011;111(9):1301-1305.

31. Whitaker RC, Wright JA, Pepe MS, Seidel KD, Dietz WH. Predicting obesity in young adulthood from childhood and parental obesity. N Engl J Med. 1997;337(13):869873.

32. Chaparro MP, Langellier BA, Kim LP, Whaley SE. Predictors of accurate maternal perception of their preschool child's weight status among hispanic WIC participants. Obesity. 2011;19(10):2026-2030.

33. Duncan DT, Hansen AR, Wang W, Yan F, Zhang J. Change in misperception of child's body weight among parents of american preschool children. Child Obes. 2015;11(4):384-393.

34. Binkin NJ, Yip R, Fleshood L, Trowbridge FL. Birth weight and childhood growth. Pediatrics. 1988;82(6):828-834. 
35. Harder T, Bergmann R, Kallischnigg G, Plagemann A. Duration of breastfeeding and risk of overweight: A meta-analysis. Am J Epidemiol. 2005;162(5):397-403.

36. Caprio S, Daniels SR, Drewnowski A, et al. Influence of race, ethnicity, and culture on childhood obesity: Implications for prevention and treatment. Obesity. 2008;16(12):2566-2577.

37. Nicklas TA, Morales M, Linares A, et al. Children's meal patterns have changed over a 21-year period: The Bogalusa heart study. J Am Diet Assoc. 2004;104(5):753-761.

38. Piernas C, Popkin BM. Food portion patterns and trends among U.S. children and the relationship to total eating occasion size, 1977-2006. J Nutr. 2011;141(6):1159-1164.

39. Nielsen SJ, Siega-Riz AM, Popkin BM. Trends in energy intake in U.S. between 1977 and 1996: Similar shifts seen across age groups. Obes Res. 2002;10(5):370-378.

40. Poti JM, Popkin BM. Trends in energy intake among US children by eating location and food source, 1977-2006. J Am Diet Assoc. 2011;111(8):1156-1164.

41. Jahns L, Siega-Riz AM, Popkin BM. The increasing prevalence of snacking among US children from 1977 to 1996. J Pediatr. 2001;138(4):493-498.

42. Popkin BM, Duffey KJ. Does hunger and satiety drive eating anymore? Increasing eating occasions and decreasing time between eating occasions in the United States. Am J Clin Nutr. 2010;91(5):1342-1347.

43. Piernas C, Popkin BM. Trends in snacking among U.S. children. Health Aff. 2010;29(3):398-404.

44. Story M, Nanney MS, Schwartz MB. Schools and obesity prevention: Creating school environments and policies to promote healthy eating and physical activity. Milbank $Q$. 2009;87(1):71-100.

45. Ford CN, Slining MM, Popkin BM. Trends in dietary intake among US 2- to 6-yearold children, 1989-2008. J Acad Nutr Diet. 2013;113(1):35-42.

46. Fox MK, Condon E, Briefel RR, Reidy KC, Deming DM. Food consumption patterns of young preschoolers: Are they starting off on the right path? J Am Diet Assoc. 2010;110(12 Suppl):S52-S59.

47. Cooke L. The importance of exposure for healthy eating in childhood: A review. $J$ Hum Nutr Diet. 2007;20(4):294-301.

48. Harris G. Development of taste and food preferences in children. Curr Opin Clin Nutr Metab Care. 2008;11(3):315-319. 
49. Fabry P, Hejl Z, Fodor J, Braun T, Zvolankova K. The frequency of meals, its relation to overweight, hypercholesterolaemia, and decreased glucose-tolerance. Lancet. 1964;2(7360):614-615.

50. Kant AK, Schatzkin A, Graubard BI, Ballard-Barbash R. Frequency of eating occasions and weight change in the NHANES I epidemiologic follow-up study. Int $J$ Obes Relat Metab Disord. 1995;19(7):468-474.

51. Metzner HL, Lamphiear DE, Wheeler NC, Larkin FA. The relationship between frequency of eating and adiposity in adult men and women in the Tecumseh community health study. Am J Clin Nutr. 1977;30(5):712-715.

52. Fábry P, Hejda S, Cerný K, Osancová K, Pechar J. Effect of meal frequency in schoolchildren. Changes in weight-height proportion and skinfold thickness. Am J Clin Nutr. 1966;18(5):358-361.

53. Larson N, Story M. A review of snacking patterns among children and adolescents: What are the implications of snacking for weight status? Child Obes. 2013;9(2):104-115.

54. Kaisari P, Yannakoulia M, Panagiotakos DB. Eating frequency and overweight and obesity in children and adolescents: A meta-analysis. Pediatrics. 2013;131(5):958-967.

55. Edelstein SL, Barrett-Connor EL, Wingard DL, Cohn BA. Increased meal frequency associated with decreased cholesterol concentrations; Rancho Bernardo, CA, 1984-1987. Am J Clin Nutr. 1992;55(3):664-669.

56. Toschke AM, Küchenhoff H, Koletzko B, von Kries R. Meal frequency and childhood obesity. Obes Res. 2005;13(11):1932-1938.

57. US Department of Agriculture, Agricultural Research Service. 2014. Snacks: Percentage of selected nutrients contributed by food and beverages consumed at snack occasions, by gender and age, What We Eat in America, NHANES 2011-2012. www.ars.usda.gov/ba/bhnrc/fsrg/. Accessed October 2, 2017.

58. Maffeis C, Grezzani A, Perrone L, Del Giudice EM, Saggese G, Tatò L. Could the savory taste of snacks be a further risk factor for overweight in children? J Pediatr Gastroenterol Nutr. 2008;46(4):429-437.

59. Birch LL, Davison KK. Family environmental factors influencing the developing behavioral controls of food intake and childhood overweight. Pediatr Clin North Am. 2001;48(4):893-907.

60. Campbell K, Crawford D. Family food environments as determinants of preschoolaged children's eating behaviors: Implications for obesity prevention policy. A review. Aust J Nutr Diet. 2001;58:19-25. 
61. Larson N, Ward DS, Neelon SB, Story M. What role can child-care settings play in obesity prevention? A review of the evidence and call for research efforts. $J$ Am Diet Assoc. 2011;111(9):1343-1362.

62. US Department of Education, National Center for Education Statistics. Percentage of the population 3 to 4 years old enrolled in school, by sex, race/ethnicity, and age group: Selected years, 1980 through 2015. Available at https://nces.ed.gov/programs/digest/d16/tables/dt16_103.10.asp?current=yes. Published July 2016. Accessed January 23, 2018.

63. Corcoran L, Steinley K. Early childhood program participation, from the National Household Education Surveys Program of 2016 (NCES 2017-101). Washington, DC: National Center for Education Statistics, Institute of Education Sciences, U.S. Department of Education. 2017;NCES 2017-101. http://nces.ed.gov/pubsearch. Accessed January 23, 2018.

64. Maher EJ, Li G, Carter L, Johnson DB. Preschool child care participation and obesity at the start of kindergarten. Pediatrics. 2008;122(2):322-330.

65. McGrady ME, Mitchell MJ, Theodore SN, Sersion B, Holtzapple E. Preschool participation and BMI at kindergarten entry: The case for early behavioral intervention. $J$ Obes. 2010:1;1-6. doi:10.1155/2010/360407.

66. Mandal B, Powell LM. Child care choices, food intake, and children's obesity status in the United States. Econ Hum Biol. 2014;14:50-61.

67. Lumeng JC, Gannon K, Appugliese D, Cabral HJ, Zuckerman B. Preschool child care and risk of overweight in 6- to 12-year-old children. Int J Obesity. 2005;29:60-66.

68. Swyden K, Sisson SB, Lora K, Castle S, Copeland KA. Association of childcare arrangement with overweight and obesity in preschool-aged children: A narrative review of literature. Int J Obesity. 2017;41(1):1-12.

69. Alberdi G, McNamara AE, Lindsay KL, et al. The association between childcare and risk of childhood overweight and obesity in children aged 5 years and under: A systematic review. Eur J Pediatr. 2016;175(10):1277-1294.

70. Child and adult care food program (CACFP) child day care centers. US Department of Agriculture, Food and Nutrition Service Web site.

http://www.fns.usda.gov/cacfp/child-day-care-centers. Updated 9/7/2017. Accessed January 31, 2018.

71. Ward DS, Vaughn A, Story M. Expert and stakeholder consensus on priorities for obesity prevention research in early care and education settings. Child Obes. 2013;9(2):116-124. 
72. Benjamin Neelon SE, Briley ME. Position of the American Dietetic Association: Benchmarks for nutrition in child care. J Am Diet Assoc. 2011;111(4):607-615.

73. Thorn B, Tadler C, Huret N, et al. WIC participant and program characteristics 2014. Alexandria, VA: U.S. Department of Agriculture, Food and Nutrition Service. November 2015. https://www.fns.usda.gov/sites/default/files/ops/WICPC2014Summary.pdf. Accessed March 28, 2017.

74. Oliveira V, Frazao E. The WIC program: Background, trends, and economic issues, 2009 edition. April 2009; Economic Research Report Number 73. U.S. Department of Agriculture, Economic Research Service. Available at: https://www.ers.usda.gov/webdocs/publications/46165/9502_err73.pdf?v=41056. Accessed May 17, 2018.

75. Committee on Dietary Risk Assessment in the WIC Program, Food and Nutrition Board, Institute of Medicine. Dietary risk assessment in the WIC program. Washington, DC: National Academy Press. 2002. Available at http://www.fns.usda.gov/sites/default/files/WICDietaryRisk.pdf. Accessed April 9, 2018.

76. Chiasson MA, Findley SE, Sekhobo JP, et al. Changing WIC changes what children eat. Obesity. 2013;21(7):1423-1429.

77. Odoms-Young AM, Kong A, Schiffer LA, et al. Evaluating the initial impact of the revised Special Supplemental Nutrition Program for Women, Infants, and Children (WIC) food packages on dietary intake and home food availability in African-American and Hispanic families. Public Health Nutr. 2014;17(1):83-93. 


\section{CHAPTER II: THE RELATIONSHIP OF EATING FREQUENCY AND BODY WEIGHT STATUS IN WIC PRESCHOOL CHILDREN}

\section{Introduction}

Overweight and obese children have a significantly higher risk of becoming overweight or obese adults when compared to normal weight children. ${ }^{1-3}$ Childhood obesity has serious health consequences, some psychosocial such as social discrimination and depression, and others medical such as early maturation, hyperlipidemia, glucose intolerance, type II diabetes, hypertension, orthopedic complications and sleep apnea. ${ }^{4}$ The medical costs of adult obesity are estimated from $\$ 147$ to nearly $\$ 210$ billion per year, while childhood obesity alone is responsible for $\$ 14.1$ billion in direct costs. ${ }^{5}$ Because of obesity's significant impact on an individual's health and quality of life, as well as its economic burden, it is important to address the problem early in life. Understanding potential risk factors facilitates the implementation of successful preventive measures.

Childhood obesity is a multifactorial disease that may begin early in life and particularly prevalent in racial and ethnic minorities. According to 2011-2014 NHANES data, obesity prevalence in children 2 to 5 years of age was $15.6 \%$ for Hispanics, $10.4 \%$ for non-Hispanic blacks, 5.2\% for non-Hispanic whites, and 5.0\% for non-Hispanic Asians. ${ }^{6}$ Evidence suggests that children from families of lower socioeconomic status present a higher risk for being overweight and obese. ${ }^{7,8}$ Still, the relationship of obesity with socioeconomic status is not well understood and might vary by race and ethnicity. ${ }^{9}$ Among the multiple risk factors for childhood obesity, some have been well explored in the literature while others still lack studies to explore their impact. Eating 
frequency may potentially influence body weight status. Studies conducted in adults have found an inverse relationship between meal frequency and BMI. ${ }^{10-12}$ In youth, data from recent studies point to a negative association between eating frequency and the prevalence of overweight and obesity, ${ }^{13-16}$ even though some studies found a positive association ${ }^{17}$ or found no relationship between eating frequency and body weight status. ${ }^{18}$ Fabry and colleagues ${ }^{19}$ were the first to study the impact of meal frequency on the weight status of children and adolescents. Results showed that adolescents eating 3 meals per day had a higher body weight for height and a significantly greater skinfold thickness than those eating 5 or 7 smaller meals per day. However, they found no significant differences in body weight of younger children who ate 3, 5 or 7 meals per day. The only study we found that assessed the relationship between childhood overweight and daily eating frequency including preschool age children as a group independent of older children and adolescents was conducted in another country. The study by Lioret at al ${ }^{20}$ included a nationally representative sample of people living in French households and found that overweight in children 3-6 years was inversely correlated to the number of eating episodes $(\mathrm{p}=0.009)$.

To our knowledge, this study is the first to explore eating frequency and body weight of children 3 to under 5 years from lower socioeconomic status including different racial and ethnic minority groups. The purpose of this study was to examine the relationship between the number of eating episodes per day and the child's body weight status as evidenced by BMI for age in a sample of children ages 3 to under 5 years participating in the Special Supplementation Nutrition Program for Women, Infants and Children (WIC) in Broward County, Florida. 


\section{Methods}

\section{Subject recruitment}

Data for this cross-sectional study was collected from a convenience sample recruited from all seven Broward County Health Department WIC clinics. Broward County WIC is the second largest agency in Florida, having served over 48 thousand clients during the 2017 fiscal year. ${ }^{21}$ WIC requires an authorized representative for the child, being a parent or guardian, to be present during the certification process. When a child is certified for WIC, his/her height and weight are updated on the system and a blood test for anemia is performed if needed. All data is recorded into the WIC data system. Anthropometric data for children is updated every 6 months at least, at the certification and the mid-certification visits.

Inclusion criteria consisted of being between the ages of 3 and under 5 years, currently enrolled in the WIC program in Broward County, being present at one of the WIC clinics for a certification or mid-certification visit and having height and weight data less than 30 days old updated on the WIC data system. Exclusion criteria included any medical health condition, as indicated by medical nutritional risks by WIC codes, children under foster care, legal guardians who do not know the biological mother's pregnancy history, children accompanied by an authorized representative who does not participate on the daily care of the child, children accompanied by an authorized representative who could not communicate in English or Spanish.

Recruitment flyers in both English and Spanish explaining the purpose of the study, inclusion and exclusion criteria, brief explanation of the procedures and compensation details, as well as the contact information for the researcher, were placed at 
participating Broward County clinics. Authorized representatives for children who would qualify for the study were approached by the research staff while waiting to receive their WIC services and invited to participate in the study. If interested, the authorized representative for the child met the researcher in an available location inside the WIC clinic to participate in the interview after they finished with their WIC appointment services. Informed consent was obtained from the authorized representative allowing the interview to be conducted and providing permission to access the child's data from the WIC data system. The consent form was available in English and Spanish. The authorized representative for each participant received a \$10 Publix gift card to compensate for the time they spent to participate in the study.

\section{Data Collection}

Approval to conduct the study was obtained from the Florida International University Institutional Review Board (IRB) (Protocol Approval \# IRB-15-0369) and the State of Florida Department of Health IRB (Protocol Title: Meal Frequency and the Role of Snacking on Weight of Minority Preschool Children). Study protocol included secondary analysis of data accessed through the WIC data system and the use of a questionnaire to collect additional data not available through the WIC data system. Research Electronic Data Capture (REDCap), a secure web application for building and managing surveys and databases, was used for data collection and data management.

Data fields collected from the WIC data system included: age, gender, anthropometric data (height, weight, BMI, BMI-for-age, weight-for-age, height-for-age, weight-for-length) - both current and retrospective, biochemical data (hemoglobin and/or 
hematocrit) - both current and retrospective, prematurity, completed weeks of gestation, birth weight, race and ethnicity, and breastfeeding (was the child ever breastfed and, if yes, for how long). The researcher had access to the WIC data system, and accessed all data fields to be collected from the WIC data system after the participant completed in person interview.

Definition of underweight, overweight and obesity was based on the CDC guidelines for BMI-for-age weight status categories and the corresponding percentiles: ${ }^{22}$

- Underweight: less than the $5^{\text {th }}$ percentile.

- Healthy weight: $5^{\text {th }}$ percentile to less than the $85^{\text {th }}$ percentile.

- Overweight: $85^{\text {th }}$ percentile to less than the $95^{\text {th }}$ percentile.

- Obese: equal to or greater than the $95^{\text {th }}$ percentile.

Crespi and colleagues ${ }^{23}$ conducted a study to assess the accuracy of anthropometric measurements collected by WIC staff. They compared the WIC data to the "gold standard" measurements collected by trained research personnel at seven clinics in California $(\mathrm{n}=287)$ and concluded that height and weight of children ages 2-5 years collected by trained WIC staff were sufficiently accurate to be used for monitoring and research purposes.

A previously validated questionnaire, adapted and tested in this population, was used to collect data during the interview with parents and guardians. The questionnaire used as reference was from a study conducted by Nelson et al. ${ }^{24}$ The authors used a selfadministered questionnaire to explore food and beverage consumption patterns and television-viewing as well as physical activity habits in WIC preschool children. They also explored the relationship of these life styles with one another and with overweight. 
Additional questions were added based on the Healthy Kids Checklist (University of California Department of Nutrition) ${ }^{25}$ and the NHANES questionnaire ${ }^{26}$ to explore the relationship between the source of food items and the child's body weight, as well as its relationship to other variables. Both research teams provided authorization to use and modify their questionnaires. The NHANES questionnaire is publicly available online. The study questionnaire was pilot tested with 10 subjects in one of the WIC clinics to ensure that the questions were relevant and appropriate for the population.

Data collected included child's food and beverage intake, including amounts of different drinks, frequency of meals, source of foods, intake of fruits and vegetables, intake of selected snack foods, and snacking while watching TV; knowledge and use of My Plate; physical activity; screen time; nighttime sleep time; parent's perception of child's size; childcare arrangements; and race and ethnicity.

Meals and snacks have been defined in different ways. ${ }^{27-29}$ For the purpose of this study, an eating episode is any distinct time a participant reported consuming at least one food or beverage item, excluding water, in a day. Meals refer to the 3 main meals, breakfast, lunch and dinner. Snacks are any other eating occasions outside the main meals. Eating frequency refers to the number of eating episodes, being meals or snacks.

\section{$\underline{\text { Data Analysis }}$}

Descriptive statistics were used for sample characteristics. Paired samples and independent samples t-tests were conducted to test for the relationship between meals and snacks intake and the child's body weight category combined into 2 groups, under/normal weight and overweight/obese. 
Cochran-Armitage test was used to test the trend between the number of eating episodes combined into 3 categories and the body weight category as a dichotomous variable (under/normal weight and overweight/obese). Cross tabulation presents the descriptive statistics for this trend.

All calculations were conducted using SPSS software version 24 (SPSS Inc.

Chicago, IL). A significance level of $\mathrm{p}<0.05$ was used for all statistical tests.

\section{Results}

From the 200 subjects who consented to participate in the study 3 extreme outliers, who reported over 10 eating episodes on one day, were excluded. Surveys have been answered mostly by mothers $(92.9 \%)$ with some fathers $(4.1 \%)$ and grandmothers (3\%). A total of 197 children were included in the data analysis. Children were between 3.0 to 4.9 years; mean age was 3.9 years $(\mathrm{SD}=0.6)$. Descriptive statistics are presented in Table 1. 
Table 1. Characteristics of study population $(\mathrm{N}=197)$

\begin{tabular}{ll|l}
\hline Characteristic & & $\begin{array}{l}\text { Frequency } \\
\%(\mathrm{~N})\end{array}$ \\
\hline Ethnicity & Hispanic or Latino & $47.2 \%(93)$ \\
& Not Hispanic or Latino & $52.8 \%(104)$ \\
\hline Race & Black or African American & $44.7 \%(88)$ \\
& White & $48.2 \%(95)$ \\
& Asian & $2.5 \%(5)$ \\
& American Indian or Alaska Native & 0 \\
& Native Hawaiian or Pacific Islander & 0 \\
& Mixed race & $4.6 \%(9)$ \\
\hline Gender & Male & $45.7 \%(90)$ \\
& Female & $54.3 \%(107)$ \\
\hline Weight category & Underweight & $3.6 \%(7)$ \\
& Normal weight & $64.4 \%(127)$ \\
& Overweight & $16.8 \%(33)$ \\
& Obese & $15.2 \%(30)$ \\
\hline Hemoglobin status & Low & $12.2 \%(24)$ \\
& Within normal limits & $87.7 \%(171)$ \\
\hline
\end{tabular}

${ }^{\mathrm{a}}$ Mixed race indicates more than one race has been selected.

Most children consumed 3 meals (97.5\%) and between $2(33.0 \%)$ to $3(37.1 \%)$ snacks on average per day. Eating frequency was not associated with ethnicity, race, gender or hemoglobin status. Number of meals and snacks on the weekend and on weekdays are reported on Table 2. Mean number of meals on weekdays did not differ from mean number of meals on the weekend $(2.97 \pm 0.16)$. Mean number of snacks on the weekend was significantly higher than mean number of snacks on weekdays $(2.78 \pm$ 1.20 vs. $2.67 \pm 1.08, \mathrm{p}=0.001)$ (Table 3$)$. 
Table 2. Number of meals and snacks consumed on weekdays and on weekend $(\mathrm{N}=197)$

\begin{tabular}{l|ll|ll}
\hline \multirow{2}{*}{ Eating episodes } & \multicolumn{2}{|c|}{ Weekdays } & \multicolumn{2}{c}{ Weekend } \\
& Frequency & Percent & Frequency & Percent \\
$(\mathrm{n})$ & $(\%)$ & $(\mathrm{n})$ & $(\%)$ \\
\hline Number of meals & 5 & 2.5 & 5 & 2.5 \\
2 & 192 & 97.5 & 192 & 97.5 \\
3 & & & & \\
\hline Number of snacks & 2 & 1.0 & 2 & 1.0 \\
0 & 19 & 9.6 & 21 & 10.7 \\
1 & 69 & 35.0 & 61 & 31.0 \\
2 & 75 & 38.1 & 71 & 36.0 \\
3 & 22 & 11.2 & 27 & 13.7 \\
4 & 5 & 2.5 & 7 & 3.6 \\
5 & 5 & 2.5 & 8 & 4.1 \\
6 & & & &
\end{tabular}

Table 3. Comparison of mean number of meals and snacks consumed on weekdays and on the weekend $(\mathrm{N}=197)$

\begin{tabular}{lll}
\hline Eating episodes & Mean \pm Std. Deviation & Significance \\
\hline Number of meals & & \\
Weekdays & $2.97 \pm 0.16$ & 0.999 \\
Weekend & $2.97 \pm 0.16$ & \\
\hline Number of snacks & & $0.001^{* *}$ \\
Weekdays & $2.67 \pm 1.08$ & \\
Weekend & $2.78 \pm 1.20$ & \\
\hline
\end{tabular}

** Paired samples t-test significant at a $99 \%$ confidence interval.

There was no correlation between the number of eating episodes or the number of snacks and the prevalence of overweight or obesity in our sample. A dose response effect was observed with respect to prevalence of overweight and obesity and eating frequency. The prevalence of overweight and obesity decreased as the number of eating episodes per day increased. The trend presented was not significant (Table 4). 
Table 4. Number of daily eating episodes and prevalence (\%) of under/normal weight and overweight/obesity in WIC participating preschool children.

\begin{tabular}{l|l|l}
\hline Daily eating episodes & \% Under/normal weight & $\%$ Overweight/Obese \\
\hline Less than 5 $(\mathrm{n}=25)$ & 56.0 & 44.0 \\
\hline 5 or 6 $(\mathrm{n}=133)$ & 68.4 & 31.6 \\
\hline More than 6 $(\mathrm{n}=39)$ & 74.4 & 25.6 \\
\hline Overall $(\mathrm{n}=197)$ & 68.0 & 32.0 \\
\hline
\end{tabular}

* Cochran-Armitage Trend Test, $\mathrm{p}=0.139$.

\section{Discussion}

The purpose of this study was to examine the relationship between the number of daily eating episodes and body weight status in preschool age children. Even though we found no correlation between the number of meals or snacks and body weight we did find a trend in which overweight/obesity prevalence decreased as the number of daily eating episodes increased. Because the trend was not statistically significant, further studies including preschool age children are needed to confirm our results. Studies including a larger sample size may help elucidate the relationship of eating frequency and body weight status in children younger than 5 years of age.

A similar trend in which the prevalence of obesity decreased by number of daily meals was reported in a study conducted with 4,370 German children ages 5 to 6 years. ${ }^{15}$ The authors found an adjusted odds ratio for obesity of 0.73 for four meals and 0.51 for five or more meals. The body of literature in its majority agrees with the presence of an inverse relationship between eating frequency and body weight in children, in addition to 
a similar relationship already found in adults. Possible advantages associated with frequent eating and a healthier body weight include a more even hunger profile throughout the day helping to prevent gorging at meals, an increase in the dietary carbohydrate-to-fat ratio, a shift in the temporal distribution of energy intake from the later to the earlier parts of the day, and an increased compatibility with a physically active lifestyle. ${ }^{30,31}$

The majority of U.S. children ages 2 to 5 years consume 3 meals a day and most often 2 or 3 snacks. ${ }^{32}$ Previous studies have found that eating 5 or more times per day is related to a lower body mass index in children. ${ }^{15,27}$ The fact that $97.5 \%$ of the children in our study consumed 3 meals/day and $66.5 \%$ consumed 2 to 3 snacks/day may have decreased the power for the analysis. It is possible that due to lack of power we could only observe a trend for a lower body mass index in children as the daily number of eating episodes increased. Our finding that children consumed the same number of meals but significantly more snacks on the weekends than on weekdays is mostly in agreement with the literature. Studies show that energy intake is consistently higher on the weekends compared to weekdays. ${ }^{33-35}$ NHANES data does not report eating patterns by weekday and weekend and very few studies look at them individually. A study by Larson et al ${ }^{36}$ including adolescents found that they were eating more snacks on vacation and weekend days compared to school days. On the other hand, a study including 156 children 5 to 17 years of age found that the number of snacks did not differ between weekends and weekdays. ${ }^{37}$ The first study was conducted in the U.S whereas the second was conducted in Scotland. 
Prevalence of overweight and obesity did not differ across race and ethnic groups. There is a complex set of interactions between genetics, physiological, environmental, cultural and socioeconomic factors that influence the prevalence of obesity ${ }^{38} \mathrm{We}$ speculate that including a sample from a low-income population might have led to this result. Socioeconomic status may be a determinant of diet quality, in which energy-dense and nutrient-poor diets are associated with lower socioeconomic status. ${ }^{39}$ In addition, it has been suggested in the literature that low socioeconomic status plays a more significant role in the childhood obesity epidemic than race and ethnicity. ${ }^{8}$ Our study was limited to low socioeconomic status families, which may have caused similarities in terms of access to healthy foods and environmental factors related to the prevalence of overweight and obesity.

Our study is unique in the fact that it includes low income, federal nutrition program participants. Minorities are more susceptible to being affected by overweight and obesity, while very few studies limit their sample selection to children 5 years old and younger. Some of the limitations of our study include relying only on food frequency dietary intake data instead of also using 24-hour recall data. On the other hand, the data used for this study is very reliable since anthropometric data was measured and not self reported and the questionnaire was researcher administered. This methodology permits probing answers that seem unusual as well as minimizes the appearance of missing data, a common problem with studies including WIC participants. ${ }^{24}$

Most studies exploring the relationship of eating frequency and body weight are cross sectional and there are several methodological deficiencies. The wide variety of age groups and populations included, combined with distinct methodologies, question the 
comparison of results from different studies. Controlled trials would be beneficial in establishing a causal relationship between eating frequency and body weight in children. Based on an established relationship, new recommendations can be put in practice with the goal of reducing the alarming rate of childhood overweight and obesity currently seen.

\section{References}

1. Cheung PC, Cunningham SA, Naryan KMV, Kramer MR. Childhood obesity incidence in the United States: A systematic review. Child Obes. 2016;12(1):1-11.

2. Simmonds M, Llewellyn A, Owen CG, Woolacott N. Predicting adult obesity from childhood obesity: A systematic review and meta-analysis. Obes Rev. 2016;17(2):95-107.

3. Cunningham SA, Kramer MR, Narayan KMV. Incidence of childhood obesity in the United States. $N$ Engl J Med. 2014;370(5):403-411.

4. Dietz WH. Health consequences of obesity in youth: Childhood predictors of adult disease. Pediatrics. 1998;101:518-525.

5. Levi J, Segal L, St. Laurent R, Lang A, Rayburn J. F as in fat: How obesity threatens America's future. Princeton, NJ: Trust for America's Health/Robert Wood Johnson Foundation. 2012.

http://www.rwjf.org/content/dam/farm/reports/reports/2012/rwjf401318. Accessed March 27, 2014.

6. Ogden CL, Carroll MD, Fryar CD, Flegal KM. Prevalence of obesity among adults and youth: United states, 2011-2014. NCHS data brief. 2015(219):1-8.

7. Shrewsbury V, Wardle J. Socioeconomic status and adiposity in childhood: A systematic review of cross-sectional studies 1990-2005. Obesity. 2008;16:275-284.

8. Rogers R. The relationship between childhood obesity, low socioeconomic status, and race/ethnicity: Lessons from Massachusetts. Child Obes. 2015;11(6):691-695.

9. Jones-Smith JC, Dieckmann MG, Gottlieb L, Chow J, Fernald LC. Socioeconomic status and trajectory of overweight from birth to mid-childhood: The early childhood longitudinal study-birth cohort. PLoS One. 2014;9(6):e100181.

doi:10.1371/journal.pone.0100181 
10. Fabry P, Hejl Z, Fodor J, Braun T, Zvolankova K. The frequency of meals, its relation to overweight, hypercholesterolaemia, and decreased glucose-tolerance. Lancet. 1964;2(7360):614-615.

11. Metzner HL, Lamphiear DE, Wheeler NC, Larkin FA. The relationship between frequency of eating and adiposity in adult men and women in the Tecumseh community health study. Am J Clin Nutr. 1977;30(5):712-715.

12. Kant AK, Schatzkin A, Graubard BI, Ballard-Barbash R. Frequency of eating occasions and weight change in the NHANES I epidemiologic follow-up study. Int $J$ Obes Relat Metab Disord. 1995;19(7):468-474.

13. Franko DL, Striegel-Moore RH, Thompson D, et al. The relationship between meal frequency and body mass index in black and white adolescent girls: More is less. Int $J$ Obes. 2008;32(1):23-29.

14. Kontogianni MD, Farmaki A, Vidra N, Sofrona S, Magkanari F, Yannakoulia M. Associations between lifestyle patterns and body mass index in a sample of Greek children and adolescents. J Am Diet Assoc. 2010;110(2):215-221.

15. Toschke AM, Küchenhoff H, Koletzko B, von Kries R. Meal frequency and childhood obesity. Obes Res. 2005;13(11):1932-1938.

16. Kaisari P, Yannakoulia M, Panagiotakos DB. Eating frequency and overweight and obesity in children and adolescents: A meta-analysis. Pediatrics. 2013;131(5):958-967.

17. Murakami K, Livingstone MBE. Associations between meal and snack frequency and overweight and abdominal obesity in US children and adolescents from National Health and Nutrition Examination Survey (NHANES) 2003-2012. Br J Nutr. 2016;115(10):1819-1829.

18. Coppinger T, Jeanes YM, Hardwick J, Reeves S. Body mass, frequency of eating and breakfast consumption in 9-13-year-olds. J Hum Nutr Diet. 2012;25(1):43-49.

19. Fábry P, Hejda S, Cerný K, Osancová K, Pechar J. Effect of meal frequency in schoolchildren. Changes in weight-height proportion and skinfold thickness. Am J Clin Nutr. 1966;18(5):358-361.

20. Lioret S, Touvier M, Lafay L, Volatier J, Maire B. Are eating occasions and their energy content related to child overweight and socioeconomic status? Obesity. 2008;16(11):2518-2523.

21. Indicators - FL-WISE participation. Florida WIC - Bureau of WIC Program Services Web site.

https:/floridahealth.sharepoint.com/sites/COMMUNITYHEALTH/WIC/Intranet/Indicat ors/Flwise/participation.html. Updated 2017. Accessed February 16, 2018. 
22. Centers for Disease Control and Prevention (CDC). About BMI for children and teens.

http://www.cdc.gov/healthyweight/assessing/bmi/childrens_BMI/about_childrens_BMI.h tml. Updated 2015. Accessed February 6, 2018.

23. Crespi CM, Alfonso VH, Whaley SE, Wang MC. Validity of child anthropometric measurements in the Special Supplemental Nutrition Program for Women, Infants, and Children. Pediatr Res. 2012;71(3):286-292.

24. Nelson JA, Carpenter K, Chiasson MA. Diet, activity, and overweight among preschool-age children enrolled in the Special Supplemental Nutrition Program for Women, Infants, and Children (WIC). Prev Chronic Dis. 2006;3(2). Available from: http://www.cdc.gov/pcd/issues/2006/apr/05_0135.htm.

25. University of California Department of Nutrition. Healthy kids checklist. Healthy Kids Web site. http://healthykids.ucdavis.edu. Accessed October 20, 2017.

26. Centers for Disease Control and Prevention (CDC). National Health and Nutrition Examination Survey. Diet, Behavior and Nutrition Questionnaire Web site. http://www.cdc.gov/nchs/data/nhanes/nhanes_13_14/DBQ_H.pdf. Published January 15, 2013. Updated 2013. Accessed October 20, 2017.

27. Evans EW, Jacques PF, Dallal GE, Sacheck J, Must A. The role of eating frequency on relative weight in urban school-age children. Pediatr Obes. 2015;1-6.

doi:10.1111/ijpo.12004.

28. Jahns L, Siega-Riz AM, Popkin BM. The increasing prevalence of snacking among US children from 1977 to 1996. J Pediatr. 2001;138(4):493-498.

29. Piernas C, Popkin BM. Trends in snacking among U.S. children. Health Aff. 2010;29(3):398-404.

30. Kirk T. Role of dietary carbohydrate and frequent eating in body-weight control. Proc Nutr Soc. 2000;59(3):349-358.

31. Palmer MA, Capra S, Baines SK. Association between eating frequency, weight, and health. Nutr Rev. 2009;67(7):379-390.

32. U.S. Department of Agriculture, Agricultural Research Service. 2016. Meals and snacks: Distribution of meal patterns and snack occasions, by gender and age, What we eat in America, NHANES 2013-2014.

https://www.ars.usda.gov/ARSUserFiles/80400530/pdf/1314/Table_33_DMP_GEN_13.p df. Updated 2017. Accessed February 16, 2018.

33. Rothausen BW, Matthiessen J, Hoppe C, Brockhoff PB, Andersen LF, Tetens I. Differences in Danish children's diet quality on weekdays v. weekend days. Public Health Nutr. 2012;15(9):1653-1660. 
34. Hart CN, Raynor HA, Osterholt KM, Jelalian E, Wing RR. Eating and activity habits of overweight children on weekdays and weekends. Int J Pediatr Obes. 2011;6(5-6):467472.

35. Haines PS, Hama MY, Guilkey DK, Popkin BM. Weekend eating in the United States is linked with greater energy, fat, and alcohol intake. Obes Res. 2003;11(8):945949.

36. Larson N, Story M, Eisenberg ME, Neumark-Sztainer D. Secular trends in meal and snack patterns among adolescents from 1999 to 2010. J Acad Nutr Diet. 2016;116(2):240-250.

37. Macdiarmid J, Loe J, Craig LCA, Masson LF, Holmes B, McNeill G. Meal and snacking patterns of school-aged children in Scotland. Eur J Clin Nutr. 2009;63(11):1297-1304.

38. Caprio S, Daniels SR, Drewnowski A, et al. Influence of race, ethnicity, and culture on childhood obesity: Implications for prevention and treatment. Obesity. 2008;16(12):2566-2577.

39. Darmon N, Drewnowski A. Does social class predict diet quality? Am J Clin Nutr. 2008;87(5):1107-1117. 


\section{CHAPTER III: THE ROLE OF SNACK QUALITY ON BODY WEIGHT STATUS IN WIC PRESCHOOL CHILDREN}

\section{Introduction}

Young children's diets have changed over the past thirty years, at the same time period childhood obesity reached epidemic proportions. A study conducted by Ford et al ${ }^{1}$ found a marked increase in the intake of foods high in added sugars, solid fats and sodium in the diets of children ages 2 to 6 from 1989 to 2008 , combined with a total daily energy intake increase of $109 \mathrm{kcal}$. NHANES data shows that obesity among children ages 2 to 5 increased from $5.0 \%$ to $10.4 \%$ between $1976-1980$ and $2007-2008 .^{2}$

Snacking is a common practice among the U.S. population. A study by Cross and colleagues, ${ }^{3}$ published in 1994, that included children and adults found that virtually all of the respondents snacked at least once per day. Recent studies have shown that snacking remains an important component of the American diet, ${ }^{4}$ with an increase in its prevalence among adults from $71 \%$ to $97 \%$ between 1977 and $2006 .{ }^{5}$ In children, snacking prevalence increased from $74 \%$ in $1977-78$ to $98 \%$ in $2003-06 .{ }^{6}$ The number of snacks consumed per day increased by 1.11 events in children 2 to 18 years old from 1977 to 2006, providing 168 more calories per day; children ages 2 to 6 years consumed 1.41 more daily snacks. ${ }^{6}$ Today, snacks contribute to approximately $30 \%$ of the total daily energy intake in boys and $32 \%$ in girls ages 2 to $5 .^{7}$

Not only the number of snacking occasions per day increased, but also the type of snack foods consumed during the past three decades has changed. There has been a shift

toward an increased intake of salty snacks, candies and sweetened beverages, ${ }^{1,6,8}$ combined with a smaller but present reduced intake of dairy products ${ }^{8}$ and fruits. ${ }^{6}$ 
Desserts remained the main source of snacking energy in children ages 2 to 18 from 1977 to 2006 , followed by salty snacks, which experienced the largest increase, and by sweetened beverages, which was the third-highest contributor to snacking energy in 2006. ${ }^{6}$ Snack occasions that consisted only of beverages, with no food being consumed, increased from $19 \%$ in $1977-1978$ to $28 \%$ in $2003-2006$ among children ages 2 to $18 .{ }^{9}$ Data from the Feeding Infants and Toddlers Study 2008 (FITS) showed that cow's milk and fruits were the most commonly consumed snacks for toddlers and preschool children 12 to 47 months of age, but cookies, crackers and $100 \%$ fruit juice were among the top five snacks for these ages. ${ }^{10}$ Overall, $86 \%$ of 2 - and 3-year-olds consumed some type of sweetened beverages, dessert, sweet or salty snack on a day, with the highest percentages being for the 3-year-olds. ${ }^{11}$ It is important to note that foods liked by children at age of 2 to 3 years remain the ones among the child's food preferences as they grow, confirming that meal and snack patterns are established as early as 24 months of age. ${ }^{10,12}$

A knowledge gap exists on how snacking patterns affect weight status in preschool children. Most studies investigating the relationship between snacking habits and obesity either found no association or found that children and adolescents who consumed snacks more often were less likely to be obese. ${ }^{13}$ When snack quality is considered, studies point to a positive association between adiposity and snacking habits consisting of energy-dense, nutrient-poor foods and beverages. A study conducted by Maffeis et al ${ }^{14}$ found that obese 8 - to 10 -year-old children did not consume more snacks than normal weight children, but they did consume more energy-dense snacks, especially salty snacks. Dietary patterns associated with childhood obesity include desserts and 
sweets, soft drinks and sugar sweetened beverages, salty pastry and chips, processed meats, and fat spreads (butter or margarine). ${ }^{15-17}$

Little is known about the snacking habits of preschool children participating in the Special Supplementation Nutrition Program for Women, Infants and Children (WIC). Snacking may be important in helping young children meet their nutritional needs, but the regular consumption of energy dense and nutrient poor snacks can contribute to the childhood obesity epidemic. This study aims to examine the relationship between snack quality and the prevalence of overweight and obesity in preschool children participating in the WIC program.

\section{Methods}

\section{$\underline{\text { Subject recruitment }}$}

Data for this cross-sectional study was collected from a convenience sample recruited from all seven Broward County Health Department WIC clinics. Broward County WIC is the second largest agency in Florida, having served over 48 thousand clients during the 2017 fiscal year. ${ }^{18}$ WIC requires an authorized representative for the child, being a parent or guardian, to be present during the certification process. When a child is certified for WIC, his/her height and weight are updated on the system and a blood test for anemia is performed if needed. All data is recorded into the WIC data system. Anthropometric data for children is updated every 6 months at least, at the certification and the mid-certification visits.

Inclusion criteria consisted of being between the ages of 3 and 5 years, currently enrolled in the WIC program in Broward County, being present at one of the WIC clinics 
for a certification or mid-certification visit and having height and weight data less than 30 days old updated on the WIC data system. Exclusion criteria included any medical health condition, as indicated by medical nutritional risks by WIC codes, children under foster care, legal guardians who do not know the biological mother's pregnancy history, children accompanied by an authorized representative who does not participate on the daily care of the child, children accompanied by an authorized representative who could not communicate in English or Spanish.

Recruitment flyers in both English and Spanish explaining the purpose of the study, inclusion and exclusion criteria, brief explanation of the procedures and compensation details, as well as the contact information for the researcher, were placed at participating Broward County clinics. Authorized representatives for children who would qualify for the study were approached by the research staff while waiting to receive their WIC services and invited to participate in the study. If interested, the authorized representative for the child met the researcher in an available location inside the WIC clinic to participate in the interview after they finished with their WIC appointment services. Informed consent was obtained from the authorized representative allowing the interview to be conducted and providing permission to access the child's data from the WIC data system. The consent form was available in English and Spanish. The authorized representative for each participant received a \$10 Publix gift card to compensate for the time they spent to participate in the study. 


\section{Data Collection}

Approval to conduct the study was obtained from the Florida International University Institutional Review Board (IRB) (Protocol Approval \# IRB-15-0369) and the State of Florida Department of Health IRB (Protocol Title: Meal Frequency and the Role of Snacking on Weight of Minority Preschool Children). Study protocol included secondary analysis of data accessed through the WIC data system and the use of a questionnaire to collect additional data not available through the WIC data system. Research Electronic Data Capture (REDCap), a secure web application for building and managing surveys and databases, was used for data collection and data management.

Data fields collected from the WIC data system included age, gender and anthropometric data (height, weight, BMI, BMI-for-age, weight-for-age, height-for-age, weight-for-length). The researcher had access to the WIC data system, and accessed all data fields to be collected from the WIC data system after the participant was dismissed.

Definition of underweight, overweight and obesity was based on the CDC

guidelines for BMI-for-age weight status categories and the corresponding percentiles: ${ }^{19}$

- Underweight: less than the $5^{\text {th }}$ percentile.

- Healthy weight: $5^{\text {th }}$ percentile to less than the $85^{\text {th }}$ percentile.

- Overweight: $85^{\text {th }}$ percentile to less than the $95^{\text {th }}$ percentile.

- Obese: equal to or greater than the $95^{\text {th }}$ percentile.

Crespi and colleagues ${ }^{20}$ conducted a study to assess the accuracy of anthropometric measurements collected by WIC staff. They compared the WIC data to the "gold standard" measurements collected by trained research personnel at seven clinics in California $(\mathrm{n}=287)$ and concluded that height and weight of children ages 2-5 years 
collected by trained WIC staff were sufficiently accurate to be used for monitoring and research purposes.

A previously validated questionnaire, adapted and tested in this population, was used to collect data during the interview with parents and guardians. The questionnaire used as reference is from a study conducted by Nelson et al. ${ }^{21}$ The authors used a selfadministered questionnaire to explore food and beverage consumption patterns, television viewing, and physical activity habits in WIC preschool children, as well as the relationship of such patterns with one another and with overweight. Additional questions were added based on the Healthy Kids Checklist, University of California Department of Nutrition, ${ }^{22}$ and the NHANES questionnaire ${ }^{23}$ to explore the relationship between the source of food items and the child's body weight, as well as its relationship to other variables. Both research teams provided authorization to use and modify their questionnaires, while the NHANES questionnaire is publicly available online. A small pilot test with 10 subjects was conducted in one of the WIC clinics to ensure the questionnaire was relevant and appropriate for the population.

Data collected included child's food and beverage intake, including amounts of different drinks, frequency of meals, source of foods, intake of fruits and vegetables and intake of selected snack items. Data on snacking while watching TV, knowledge and use of My Plate, physical activity, screen time, nighttime sleep time, parent's perception of child's size, childcare arrangements, and race and ethnicity was also collected.

A question exploring frequency of consumption of selected snack foods was added to the questionnaire. After a through literature review we found that the literature is not consistent in ways to categorize snack foods and beverages. The research team in 
University of North Carolina at Chapel Hill (UNC Chapel Hill) has conducted extensive research on snack foods and beverages and created a food grouping system that could be adapted for use in our study. ${ }^{24,25}$ Researchers at UNC Chapel Hill have a detailed systematic approach that allows categorizing snack intake into nutrient-based food groups, which facilitates a meaningful categorization of snack quality. After receiving appropriate authorization, we categorized the snack foods and beverages used in this study into groups using the UNC Chapel Hill approach (Table 1). We collected frequency of snack food and beverage consumption per week for 32 items, divided into 12 main groups. Data for ready to eat cereals, breads and bars was collected as WIC approved \& non-WIC approved products. WIC provides only $100 \%$ whole wheat/whole grain breads without added sugars; breakfast cereals should contain no more than 21.2 grams of sugar per 100 grams of dry cereal and at least half of the total number of breakfast cereals on a State agency's authorized food list must have whole grain as the primary ingredient. ${ }^{26}$ This can be very different than most breads and breakfast cereals available in the market. Results are reported based on these 13 total groups, as well as on each snack food and beverage item individually.

In order to increase the comparability of our study with other studies that categorize snack foods as sweet and savory, ${ }^{1,4,14}$ we divided the pertinent snack foods into two groups as follows. Sweet snacks included candy, dairy desserts, grain desserts, and ready to eat non-WIC approved cereals and bars; savory snacks included salty and savory snacks, and fast food. 
Table 1. Snack foods and beverages groups. ${ }^{\text {a }}$

\begin{tabular}{|c|c|}
\hline $\begin{array}{l}\text { Food or Beverage } \\
\text { Group Name }\end{array}$ & Food or Beverage Group Description \\
\hline Fruit juice & $\begin{array}{l}\text { Includes } 100 \% \text { fruit juice. Examples: apple, orange, or grape } \\
\text { juice; fruit blends; fruit nectars. }\end{array}$ \\
\hline Sweetened beverages & $\begin{array}{l}\text { Includes sodas, fruit drinks, commercially prepared teas and } \\
\text { sports drinks (regular, sugar-free, and diet). Examples: soft } \\
\text { drinks, fruit juice drinks, lemonade, Arizona iced-tea, Gatorade } \\
\text { and Powerade. }\end{array}$ \\
\hline Milk & $\begin{array}{l}\text { Includes whole, } 2 \%, 1 \% \text {, and nonfat milk (plain, chocolate, or } \\
\text { flavored), or any milk substitute. Examples: soy and almond } \\
\text { milk. }\end{array}$ \\
\hline Cheese and yogurt & $\begin{array}{l}\text { Includes all cheeses, and plain and flavored yogurts made from } \\
\text { nonfat, low fat, or whole milk. }\end{array}$ \\
\hline Fruits and vegetables & $\begin{array}{l}\text { Includes fresh, frozen, canned, or dried fruit; and fresh, frozen, or } \\
\text { canned non-starchy vegetables. }\end{array}$ \\
\hline Dairy desserts & $\begin{array}{l}\text { Includes dairy-based desserts. Examples: ice cream; sundaes; ice } \\
\text { cream sandwiches, cones, or bars; sherbet; ice cream sodas; } \\
\text { frozen yogurt; puddings; mousse; cheesecake; and flan. }\end{array}$ \\
\hline Grain desserts & $\begin{array}{l}\text { Includes all grain-based desserts. Examples: cookies, graham } \\
\text { crackers, sweet rolls, doughnuts, Danish, muffins, cakes, } \\
\text { cupcakes, pies, animal crackers, and breakfast tarts. }\end{array}$ \\
\hline $\begin{array}{l}\text { Salty and savory } \\
\text { snacks }\end{array}$ & $\begin{array}{l}\text { Includes savory salty snacks. Examples: potato chips; } \\
\text { corn/cornmeal chips; snack, cheese, saltine, wheat, or rice } \\
\text { crackers; pretzels; popcorn; snack mixes; and rice cakes. }\end{array}$ \\
\hline $\begin{array}{l}\text { Ready to eat cereals, } \\
\text { breads and bars } \\
\text { (WIC cereals \& } \\
\text { breads \& non-WIC }\end{array}$ & $\begin{array}{l}\text { Includes ready to eat cereals, breads and rolls, and cereal, protein, } \\
\text { granola, meal replacement, and other bars. Examples: Cheerios, } \\
\text { Mini-Wheats, Rice Krispies, loose granola, white bread, wheat } \\
\text { bread, white rolls, bagels, pita bread, pancakes, waffles, and }\end{array}$ \\
\hline
\end{tabular}




\begin{tabular}{|l|l|}
\hline $\begin{array}{l}\text { cereals, breads \& } \\
\text { bars })\end{array}$ & $\begin{array}{l}\text { cornbread. Collected as WIC approved and non-WIC approved } \\
\text { products. }\end{array}$ \\
\hline Nuts and seeds & $\begin{array}{l}\text { Includes nuts, nut butters, and seeds. Examples: peanut butter, } \\
\text { almonds, peanuts, sunflower seeds, and nut/seed mixtures with } \\
\text { dried fruit. }\end{array}$ \\
\hline Candy & $\begin{array}{l}\text { Includes candy, chocolate, and sweet snacks. Examples: } \\
\text { chocolate; non-chocolate candy such as hard candy or caramels; } \\
\text { chocolate candy such as M\&M's; chewing gum; popsicles; } \\
\text { gelatin; marshmallows; chocolate-covered pretzels, nuts, or } \\
\text { raisins; and fruit rollups/snacks. }\end{array}$ \\
\hline Fast-food & $\begin{array}{l}\text { Includes hamburgers, cheeseburgers, hot-dog; French fries; and } \\
\text { all types of pizzas and pizza rolls such as Hot-Pockets. }\end{array}$ \\
\hline
\end{tabular}

${ }^{a}$ Adapted from the University of North Carolina at Chapel Hill food grouping system. ${ }^{24}$

Although calorie and nutrient content was not calculated for the purpose of this study, snack food intake was reported based on healthfulness, energy density and nutrient density using a snack quality score. Snack foods and beverages groups were given 3 different snack quality scores, from one to three. The score of one was given to nutrientpoor snacks, while the score of 3 was given to more nutritious snack items, as shown in Table 2. The concept of nutrient density defines that nutrient-dense foods are those that provide substantial amounts of micronutrients and relatively few calories. ${ }^{27}$ This definition involves several issues and the concept of nutrient density was not used in full for this paper. Most preschool children are physically active and have high energy needs, making nutrient quality more important than calorie content. Therefore some foods that are nutrient dense but also energy dense were still given a high snack quality score. 
Table 2. Classification according to snack quality score assigned to snack foods and beverages groups.

\begin{tabular}{|l|l|}
\hline Snack quality score & Food or Beverage Group \\
\hline 1 & $\begin{array}{l}\text { Sweetened beverages } \\
\text { Candy }\end{array}$ \\
\hline 2 & $\begin{array}{l}\text { Dairy desserts } \\
\text { Grain desserts } \\
\text { Salty and savory snacks } \\
\text { Fast-food } \\
\text { Ready to eat cereals, breads and bars - Non-WIC approved }\end{array}$ \\
\hline 3 & $\begin{array}{l}\text { Fruits and vegetables } \\
\text { Nuts and seeds } \\
\text { Cheese and yogurt } \\
\text { Ready to eat cereals and breads - WIC approved } \\
\text { Milk } \\
\text { Fruit juice }\end{array}$ \\
\hline
\end{tabular}

\section{Data Analysis}

Descriptive statistics were used for sample characteristics. When classifying snack foods and beverages into the 13 main groups, the highest frequency of intake for any of the items included on a certain group was considered. For example, if a child consumed cheese daily and yogurt twice per week, the frequency considered for the intake of the cheese and yogurt group was daily. The same procedure was followed when looking at the frequency of intake of sweet and savory snack items. This allowed us to account for how often children were consuming any snack item in a certain group and consider the highest frequency per group. When assigning the three snack quality scores, 
we averaged the frequency of intake for all the snack items included in score 1, score 2 and score 3 and assigned each child to the score with the highest average. By averaging the intake of all items, including items never consumed, we were able to make a distinction between the children who ate from all of the items in a group and those who ate only a few items in a group. The same procedure was followed when assigning a child to the sweet or savory snack groups.

For data analysis purposes the child's body weight category was combined into 2 groups, under/normal weight and overweight/obese. Descriptive statistics were used to look at the mean intake of the individual snack foods and beverages, as well as the snack groups. Independent samples $t$ tests were used to compare mean intake of different snacks and snack groups by weight status. Cochran-Armitage test of trend was conducted to test for the relationship between the snack quality score and the child's body weight category combined. Chi-square test of homogeneity was performed to test for the difference in the proportion of overweigh/obese children who consumed sweet or savory snacks more often compared to the under/normal weight children.

All calculations were conducted using SPSS software version 24 (SPSS Inc. Chicago, IL). A significance level of $\mathrm{p}<0.05$ was used for all statistical tests.

\section{Results}

From the 200 subjects who consented to participate in the study 3 extreme outliers, who reported over 10 eating episodes in one day, were excluded. Surveys have been answered mostly by mothers $(92.9 \%)$ with some fathers $(4.1 \%)$ and grandmothers (3\%) also participating. A total of 197 children were included in the data analysis. 
Children were between 3.0 to 4.9 years of age; mean age was 3.9 years $(\mathrm{SD}=7.11)$.

Descriptive statistics are presented in Table 3.

Table 3. Characteristics of study population $(\mathrm{N}=197)$

\begin{tabular}{ll|l}
\hline Characteristic & & $\begin{array}{l}\text { Frequency } \\
\%(\mathrm{~N})\end{array}$ \\
\hline Ethnicity & Hispanic or Latino & $47.2 \%(93)$ \\
& Non-Hispanic or Latino & $52.8 \%(104)$ \\
\hline Race & Black or African American & $44.7 \%(88)$ \\
& White & $48.2 \%(95)$ \\
& Asian & $2.5 \%(5)$ \\
& American Indian or Alaska Native & 0 \\
& Native Hawaiian or Pacific Islander & 0 \\
& Mixed race & $4.6 \%(9)$ \\
\hline Gender & Male & $45.7 \%(90)$ \\
& Female & $54.3 \%(107)$ \\
\hline Weight category & Underweight & $3.6 \%(7)$ \\
& Normal weight & $64.4 \%(127)$ \\
& Overweight & $16.8 \%(33)$ \\
& Obese & $15.2 \%(30)$ \\
\hline Hemoglobin status & Low & $12.2 \%(24)$ \\
& Within normal limits & $87.7 \%(171)$ \\
\hline
\end{tabular}

${ }^{\mathrm{a}}$ Mixed race indicates more than one race has been selected.

Most children consumed 3 meals (97.5\%) and between $2(33.0 \%)$ to $3(37.1 \%)$ snacks on average per day. There was no significant correlation between the number of eating episodes or the number of snacks and the prevalence of overweight or obesity in our sample (data reported elsewhere). 
When looking at the intake of individual snack foods and beverages, the most frequently consumed snack items were milk, 100\% fruit juice and fresh fruits, consumed daily by $89.3 \%, 73.6 \%$ and $68.0 \%$ of the children respectively. From all the snack items included in our frequency questionnaire, the only ones that presented a significantly different frequency of intake by weight category combined were nuts and seeds, pastries and sweet rolls, and hamburgers and cheeseburgers; hot dogs presented a marginal significance (Table 4).

Table 4. Weekly average frequency of intake of individual food and beverage snack items, by weight category combined, sorted by overall mean (mean $\pm \mathrm{SD}){ }^{\mathrm{a}}$

\begin{tabular}{l|l|l|l}
\hline Snack foods and beverages & Under/Normal Weight & Overweight/Obese & p-value \\
\hline Milk & $5.87 \pm 0.46$ & $5.75 \pm 0.72$ & 0.228 \\
\hline Fresh fruit & $5.34 \pm 1.10$ & $5.43 \pm 1.03$ & 0.575 \\
\hline $100 \%$ Fruit juice & $5.26 \pm 1.41$ & $5.44 \pm 1.12$ & 0.366 \\
\hline Vegetables & $4.46 \pm 1.39$ & $4.29 \pm 1.53$ & 0.441 \\
\hline Breakfast cereal - WIC & $4.27 \pm 1.37$ & $4.03 \pm 1.48$ & 0.271 \\
\hline Cheese & $4.23 \pm 1.48$ & $3.92 \pm 1.44$ & 0.167 \\
\hline Yogurt & $4.09 \pm 1.55$ & $4.11 \pm 1.56$ & 0.928 \\
\hline Chips & $3.43 \pm 1.19$ & $3.40 \pm 1.19$ & 0.875 \\
\hline Sweetened beverages & $3.18 \pm 2.00$ & $3.54 \pm 2.05$ & 0.243 \\
\hline Bread - WIC & $3.31 \pm 1.59$ & $3.16 \pm 1.18$ & 0.468 \\
\hline Cookies & $3.19 \pm 1.23$ & $3.29 \pm 1.17$ & 0.593 \\
\hline Crackers & $3.16 \pm 1.51$ & $2.90 \pm 1.38$ & 0.250 \\
\hline Chocolate/Candy & $2.84 \pm 1.29$ & $2.84 \pm 1.31$ & 0.992 \\
\hline Animal/Graham crackers & $2.84 \pm 1.48$ & $2.62 \pm 1.26$ & 0.300 \\
\hline Breakfast cereal - non-WIC & $2.68 \pm 1.56$ & $2.79 \pm 1.72$ & 0.643 \\
\hline Bread - Non-WIC & $2.65 \pm 1.45$ & $2.75 \pm 1.26$ & 0.633 \\
\hline Pizza/Hot Pockets & $2.54 \pm 0.76$ & $2.63 \pm 0.75$ & 0.400 \\
\hline Hot dog & $2.45 \pm 1.07$ & $2.75 \pm 1.15$ & 0.076 \\
\hline
\end{tabular}




\begin{tabular}{l|l|l|l}
\hline French fries & $2.55 \pm 0.92$ & $2.52 \pm 0.88$ & 0.796 \\
\hline Ice cream & $2.52 \pm 1.15$ & $2.48 \pm 0.98$ & 0.783 \\
\hline Canned fruit & $2.44 \pm 1.51$ & $2.30 \pm 1.53$ & 0.550 \\
\hline Peanut butter & $2.31 \pm 1.35$ & $2.44 \pm 1.33$ & 0.523 \\
\hline Muffin/Cake/Cupcake & $2.18 \pm 0.87$ & $2.35 \pm 0.97$ & 0.220 \\
\hline Popcorn & $2.13 \pm 0.96$ & $2.37 \pm 1.14$ & 0.154 \\
\hline Hamburger/Cheeseburger & $1.86 \pm 0.92$ & $2.21 \pm 1.00$ & $0.017^{*}$ \\
\hline Dried fruit & $1.94 \pm 1.23$ & $2.02 \pm 1.23$ & 0.688 \\
\hline Nuts and seeds & $1.96 \pm 1.22$ & $1.59 \pm 0.99$ & $0.035^{*}$ \\
\hline Pretzels & $1.71 \pm 0.98$ & $1.70 \pm 1.16$ & 0.947 \\
\hline Cereal bars & $1.62 \pm 1.10$ & $1.60 \pm 1.14$ & 0.924 \\
\hline Donuts & $1.56 \pm 0.86$ & $1.60 \pm 0.83$ & 0.739 \\
\hline Pudding/Flan & $1.48 \pm 0.93$ & $1.54 \pm 1.06$ & 0.679 \\
\hline Pastries/Sweet rolls & $1.24 \pm 0.60$ & $1.10 \pm 0.35$ & $0.036^{*}$ \\
\hline
\end{tabular}

${ }^{\text {a }}$ Frequency of intake is coded as: $1=$ never, $2=$ less than once/week, $3=1-2$ times/week, $4=3-4$ times/week, 5=5-6 times/week, $6=$ daily.

* Independent samples $t$ test significant at $95 \%$ confidence interval.

${ }^{\#}$ Independent samples $\mathrm{t}$ test marginally significant at $95 \%$ confidence interval.

The milk, fruit juice and fruits and vegetables groups are being consumed daily by most of the children, irrespective of being overweight or obese or not. When vegetables and fresh, canned and dry fruits are considered as a group, $71 \%$ of the children consume at least one of them on a daily basis. A snack from the fast-food group is consumed 1 to 2 times per week by $53.8 \%$ of the children. Normal/under weight children consumed WIC approved breakfast cereals and breads more often than overweight/obese children (4.59 \pm 1.23 vs $4.25 \pm 1.36, \mathrm{p}=0.085)$. None of the other snack groups showed a marginal or a significant difference in frequency of intake by weight category combined. The weekly average frequency of intake of each snack group by weight category combined is presented in Figure 1. 
Figure 1. Weekly average frequency of intake of snack groups, by weight category combined. ${ }^{\mathrm{a}}$

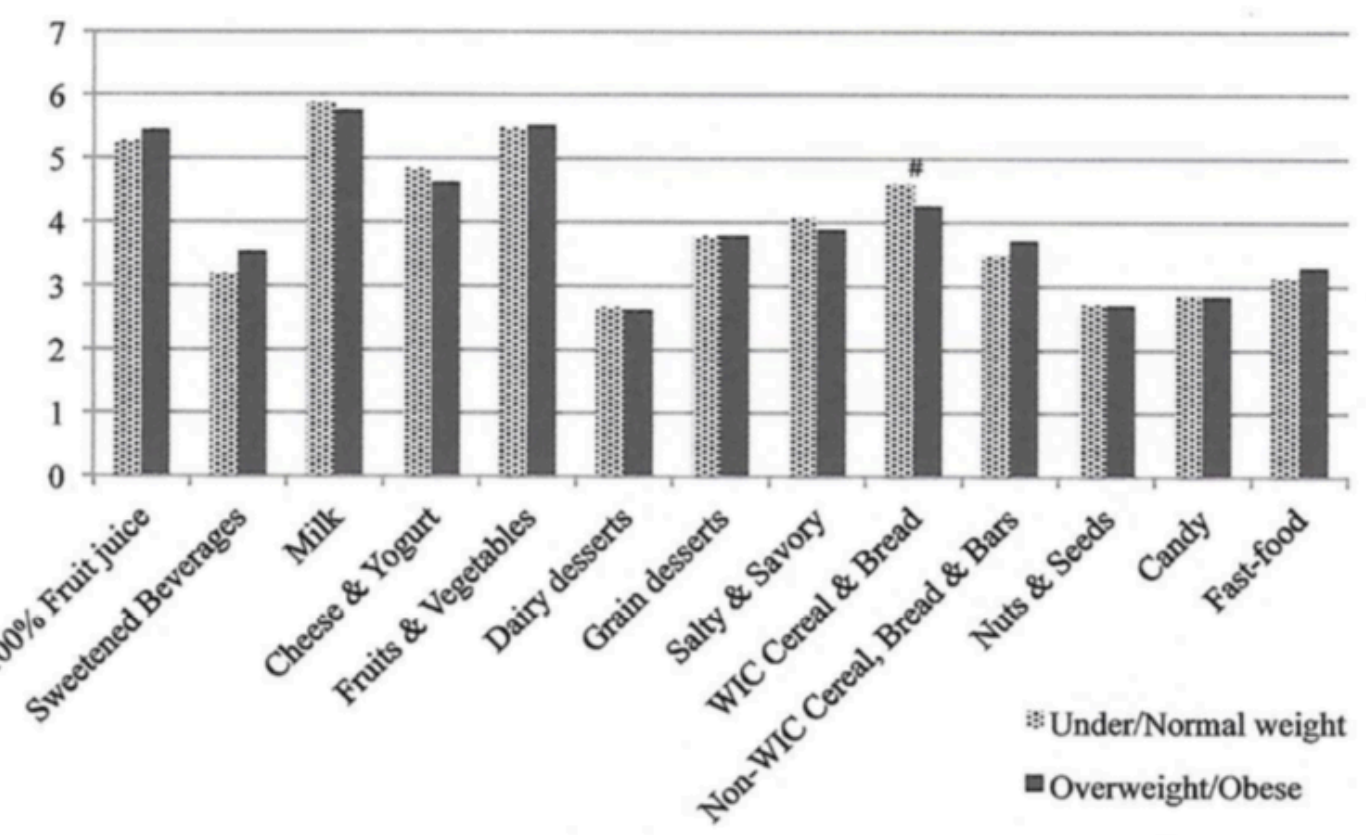

${ }^{\text {a }}$ Frequency of intake is coded as: $1=$ never, $2=$ less than once/week, $3=1-2$ times/week, 4=3-4 times/week, 5=5-6 times/week, $6=$ daily.

\# Independent samples t test marginally significant $(\mathrm{p}=0.085)$.

Sweet and savory snacks were consumed on average 3 to 4 times per week by the WIC preschool children included in this study. Considering averages of frequency of all sweet and all savory snack intake, $69 \%$ of the children had a higher frequency of savory snacks intake when compared to $31 \%$ of the children consuming sweet snacks more often than savory snacks. There was no significant difference in the frequency of intake of sweet or savory snacks when comparing under/normal weight versus overweight/obese children (results not shown). Sweet snacks included candy, dairy desserts, grain desserts, 
and ready to eat non-WIC approved cereals and bars groups; savory snacks included salty and savory snacks, and fast food groups.

Snack items that received a score of 3, more nutritious, were the ones most often consumed by $66 \%$ of the preschool children included, while snack items with a score of 1, nutrient-poor, were the ones most often consumed by $33.5 \%$ of the children. Only one child in the study consumed snack items with a score of 2 more often than the other snacks. We found a marginally significant trend in which the under/normal weight children had a higher frequency of intake of the more nutritious snack items when compared to the overweight/obese children (Table 5).

Table 5. Snack quality score and prevalence (\%) of under/normal weight and overweight/obesity in WIC participating preschool children.

\begin{tabular}{l|l|l|l}
\hline Snack quality score & \% Under/normal weight & \% Overweight/Obese & Overall \% \\
\hline Score $1^{\mathrm{a}}(\mathrm{n}=66)$ & 29.9 & 41.3 & 33.5 \\
\hline Score $2^{\mathrm{b}}(\mathrm{n}=1)$ & 0.0 & 1.6 & 0.5 \\
\hline Score $3^{\mathrm{c}}(\mathrm{n}=130)$ & 70.1 & 57.1 & 66.0 \\
\hline Overall $(\mathrm{n}=197)$ & 68.0 & 32.0 & 100 \\
\hline
\end{tabular}

${ }^{a}$ Score 1: Sweetened beverages and candy groups.

${ }^{\mathrm{b}}$ Score 2: Dairy desserts, grain desserts, salty \& savory, fast-food, and non-WIC cereal, breads and bars groups.

${ }^{\mathrm{c}}$ Score 3: Fruits \& vegetables, nuts \& seeds, cheese \& yogurt, milk, 100\% fruit juice, WIC cereal and breads groups. Cochran-Armitage Trend Test, $\mathrm{p}=0.090$.

\section{Discussion}

To our knowledge, this is the first study to explore the snack consumption patterns of WIC preschool children and its relationship to prevalence of overweight and 
obesity. Snacks that received the lowest snack quality score, nutrient-poor snacks comprised of the sweetened beverages and candy groups, were the most frequently consumed by $33.5 \%$ of the children. Snacks that received the highest snack quality score, more nutritious snacks, were the most frequently consumed by $66 \%$ of the children. We observed a marginally significant trend in which the WIC preschool children that more frequently consumed nutrient-poor snacks had a higher prevalence of overweight/obesity.

Our findings are consistent with other studies on snack consumption in children. Results from the Feeding Infants and Toddlers Study $2008{ }^{10}$ showed that the most commonly consumed snack foods and beverages among young children ages 2 to 4 years were cow's milk and fruits. The intake of sweets, specifically sweetened beverages, and low-quality foods was positively associated with overweight status in 10-year-olds included in the Bogalusa Study. ${ }^{17}$ Other studies have shown a positive association between the intake of sweetened beverages and excess weight among children and adolescents. ${ }^{16,28}$

Milk, fresh fruits, and $100 \%$ fruit juice were the snack items with the highest frequency of intake. These items were consumed daily by most of the preschool children included in this study. Vegetables, WIC breakfast cereal, and cheese and yogurt, were consumed 3 to 4 times per week on average. When considering any type of fruit, fresh fruit was the most frequently consumed, followed closely by $100 \%$ fruit juice. Canned fruit and dried fruit were consumed less often, around once per week. Our findings are in agreement with a study by Fox et al, ${ }^{11}$ that reports milk to be among the most commonly consumed beverages by young children. The authors also report that $73 \%$ of preschool 
children consumed fresh fruit, 59\% consumed 100\% fruit juice, $20 \%$ canned fruit and $8 \%$ dried fruit.

The first seven most consumed snack items in our study were foods and beverages that are included in the WIC benefits. Supplemental foods provided in the food package for children 1 through 4 years of age include milk, 100\% unsweetened fruit and/or vegetable juice, fruits and vegetables, breakfast cereal, whole wheat or whole grain bread, cheese, yogurt, eggs, legumes, and peanut butter. ${ }^{26}$ Fruits and vegetables include any fresh variety, whole or cut, without added sugars; canned, frozen or dried fruits and vegetables are offered at the State agency's option. All forms of fruits and vegetables must be without added sugars. Breakfast cereals should contain no more than 21.2 grams of sugar per 100 grams of dry cereal and at least half of the total number of breakfast cereals on a State agency's authorized food list must have whole grain as the primary ingredient. WIC provides only $100 \%$ whole wheat/whole grain breads without added sugars. We have seen a higher frequency of intake of WIC approved breakfast cereal and bread when compared to breakfast cereal and bread not approved by WIC. This pattern was not found in other studies. In fact, Fox et al ${ }^{11}$ reported that 3-year-olds consume as much breakfast cereal containing more than $21.2 \mathrm{~g}$ of sugar per $100 \mathrm{~g}$ than cereal that is not sweetened, even though around twice as many consume cereal having whole grains as the first ingredient listed on the label versus those that do not. The same study found that $10.3 \%$ of 3 -year-olds consume whole grain bread versus $29.5 \%$ consume not whole grain bread. ${ }^{11}$ Our study found a weak negative relationship between the intake of WIC approved breakfast cereal and bread group and the risk of overweight/obesity. 
Our results showed a preference for savory snacks over sweet snacks, independent of weight status. The savory taste of snacks has been shown to be predictive of obesity in children 8 to 10 years old. ${ }^{14}$ According to nationally representative studies, the main sources of energy from snacks do not differ much between children and adults. In children ages 2 to 18 , desserts are the main contributors to snacking calories, followed by salty snacks, sweetened beverages, candy, milk and dairy, and juice and fruit. ${ }^{6}$ In adults, the top five sources of energy from snacks were desserts, salty snacks, sweetened beverages, juice and fruit, and candies. ${ }^{5}$ The largest increase in consumption for both age groups between 1977 and 2006 was in salty snacks. ${ }^{5,6}$ A more recent study including nationally representative samples found an increase in the intake of savory snacks, pizza, sweet snacks and candy, together with fruit, cheese and fruit juice, among children 2 to 6 years of age between 1989 and 2008. ${ }^{1}$ Because this is a cross-sectional study we are unable to evaluate any trends in dietary intake. The finding that $69 \%$ of the preschool children in our study consumed savory snacks more often than sweet snacks, even though both are consumed often, is consistent with the trend of an increasing consumption of salty and savory snacks found in these studies.

Snacking is common and contributes to the intake of key nutrients. Studies have shown that between $25 \%$ to more than $27 \%$ of total daily energy intake in preschool children is coming from snacks. ${ }^{6,10}$ Not only snacks are an important source of energy; they are also an important source of micronutrients. ${ }^{7}$ Deming and colleagues ${ }^{10}$ reported that foods and beverages consumed as snacks made important contributions to the intake of micronutrients such as vitamin $\mathrm{C}$, iron and calcium, as well as dietary fiber in toddlers and preschool children. In adults, most snacking patterns were associated with a higher 
energy intake, but several snacking patterns were associated with a higher intake of vitamins and minerals, and with a better diet quality than those consuming no snacks. ${ }^{29}$ Young children have high nutrient needs compared to their energy needs so all efforts should be made in providing them with nutritious foods.

The strengths of this study include the use of a researcher-administered questionnaire, providing virtually no unanswered questions and allowing the researcher to probe as necessary. In addition, the inclusion of a sample consisted of WIC participants granted control for socioeconomic-status. Potential biases due to underreporting or over reporting of food and beverage intake may be present. Despite the efforts made during the interviews to communicate that frequency of intake data should be reported for foods and beverages consumed as snacks only there is a possibility that some responders considered foods and beverages consumed with meals as well. This likely happened with the considerably high frequency of intake of vegetables we found. It is unlikely that the preschool children included in our study are consuming vegetables as snacks three to four times per week, when excluding potatoes. Other studies report a low intake of vegetables even when considering all meals. Durao et al ${ }^{15}$ found that the average consumption of vegetables on a plate for children 4 years of age is around $26 \%$. Data from the Feeding Infants and Toddlers Study $2008{ }^{11}$ reports that approximately $68 \%$ of 3 -year-olds consume some vegetable on a day, but white potatoes is the vegetable most consumed by $31 \%$ of them.

Possibly the greatest limitation of this study is the small sample size for the amount of snack foods and beverages taken into account. When analyzing data we mostly found a marginal significance for the tests applied. For many of the individual snack 
items we observed an expected higher frequency of intake for the under/normal weight group or for the overweight/obese group depending on the snack type, but most of the time no significance was found. Despite its many limitations, this study adds to the body of literature on snacking habits of young children and provides valuable data that can aid in better understanding the role of snacking in childhood obesity.

The use of a more uniform snack foods and beverages classification system is necessary to increase comparability of the studies and allow researchers to better evaluate the findings. This would also facilitate the design for new studies. Healthy snacking between the three main meals may potentially improve the quality of food intake, but more research is needed to understand the role of snacking on weight of preschool children. Longitudinal studies including preschool children examining snacking patterns and their relationship to body weight status are necessary. In specific, a longitudinal study following WIC preschool children to evaluate the changes that happen in their dietary intake after they turn 5 years of age and become ineligible to continue receiving WIC benefits would provide extremely valuable data.

This study highlights a higher frequency of intake of more nutritious snack items among WIC preschool children when compared to the intake of nutrient-poor snacks. It also shows an association between the intake of nutrient-poor snacks and an increased risk for overweight/obesity. Lower quality snack items such as sweetened beverages, chips, cookies and crackers are being consumed more than twice per week. The snack patterns found among this group are likely to follow as they age, affecting the future diets of these preschoolers. Efforts should be put on the education of caregivers about the importance of continuing to offer nutritious snack options to children. 


\section{References}

1. Ford CN, Slining MM, Popkin BM. Trends in dietary intake among US 2- to 6-yearold children, 1989-2008. J Acad Nutr Diet. 2013;113(1):35-42.

2. Ogden C, Carroll M. Prevalence of obesity among children and adolescents: United States, trends 1963-1965 through 2007-2008.

https://www.cdc.gov/nchs/data/hestat/obesity_child_07_08/obesity_child_07_08.pdf. Updated 2010. Accessed June 22, 2017.

3. Cross AT, Babicz D, Cushman LF. Snacking patterns among 1,800 adults and children. J Am Diet Assoc. 1994;94(12):1398-1403.

4. Dunford EK, Popkin BM. Disparities in snacking trends in US adults over a 35 year period from 1977 to 2012. Nutrients. 2017;9:809. doi:10.3390/nu9080809.

5. Piernas C, Popkin BM. Snacking increased among U.S. adults between 1977 and 2006. J Nutr. 2010;140(2):325-332.

6. Piernas C, Popkin BM. Trends in snacking among U.S. children. Health Aff. 2010;29(3):398-404.

7. U.S. Department of Agriculture, Agricultural Research Service. 2016. Snacks: Percentage of selected nutrients contributed by food and beverages consumed at snack occasions, by gender and age, What We Eat in America, NHANES 2013-2014. https://www.ars.usda.gov/ARSUserFiles/80400530/pdf/1314/Table_25_SNK_GEN_13.p df. Updated 2017. Accessed February 16, 2018.

8. Nielsen SJ, Siega-Riz AM, Popkin BM. Trends in energy intake in U.S. between 1977 and 1996: Similar shifts seen across age groups. Obes Res. 2002;10(5):370-378.

9. Popkin BM, Duffey KJ. Does hunger and satiety drive eating anymore? Increasing eating occasions and decreasing time between eating occasions in the united states. Am J Clin Nutr. 2010;91(5):1342-1347.

10. Deming DM, Reidy KC, Fox MK, Briefel RR, Jacquier E, Eldridge AL. Crosssectional analysis of eating patterns and snacking in the US feeding infants and toddlers study 2008. Public Health Nutr. 2017;20(9):1584-1592.

doi:10.1017/S136898001700043X.

11. Fox MK, Condon E, Briefel RR, Reidy KC, Deming DM. Food consumption patterns of young preschoolers: Are they starting off on the right path? $J$ Am Diet Assoc.

2010;110(12 Suppl):S52-S59. 
12. Skinner JD, Carruth BR, Wendy B, Ziegler PJ. Children's food preferences: A longitudinal analysis. J Am Diet Assoc. 2002;102(11):1638-1647.

13. Larson N, Story M. A review of snacking patterns among children and adolescents: What are the implications of snacking for weight status? Child Obes. 2013;9(2):104-115.

14. Maffeis C, Grezzani A, Perrone L, Del Giudice EM, Saggese G, Tatò L. Could the savory taste of snacks be a further risk factor for overweight in children? J Pediatr Gastroenterol Nutr. 2008;46(4):429-437.

15. Durão C, Severo M, Oliveira A, et al. Association between dietary patterns and adiposity from 4 to 7 years of age. Public Health Nutr. 2017;20(11):1973-1982.

16. Dong D, Bilger M, van Dam RM, Finkelstein EA. Consumption of specific foods and beverages and excess weight gain among children and adolescents. Health Aff. 2015;34(11):1940-1948.

17. Nicklas TA, Yang S, Baranowski T, Zakeri I, Berenson G. Eating patterns and obesity in children. The Bogalusa heart study. Am J Prev Med. 2003;25(1):9-16.

18. Indicators - FL-WISE participation. Florida WIC - Bureau of WIC Program Services Web site. https://floridahealth.sharepoint.com/sites/COMMUNITYHEALTH/WIC/Intranet/Indicat ors/Flwise/participation.html. Updated 2017. Accessed February 16, 2018.

19. Centers for Disease Control and Prevention (CDC). About BMI for children and teens.

http://www.cdc.gov/healthyweight/assessing/bmi/childrens_BMI/about_childrens_BMI.h tml. Updated 2015. Accessed February 6, 2018.

20. Crespi CM, Alfonso VH, Whaley SE, Wang MC. Validity of child anthropometric measurements in the Special Supplemental Nutrition Program for Women, Infants, and Children. Pediatr Res. 2012;71(3):286-292.

21. Nelson JA, Carpenter K, Chiasson MA. Diet, activity, and overweight among preschool-age children enrolled in the special supplemental nutrition program for women, infants, and children (WIC). Prev Chronic Dis. 2006;3(2). Available from: http://www.cdc.gov/pcd/issues/2006/apr/05_0135.htm.

22. University of California Department of Nutrition. Healthy kids checklist. Healthy Kids Web site. http://healthykids.ucdavis.edu. Accessed October 20, 2017.

23. Centers for Disease Control and Prevention (CDC). National Health and Nutrition Examination Survey. Diet, Behavior and Nutrition Questionnaire Web site. 
http://www.cdc.gov/nchs/data/nhanes/nhanes_13_14/DBQ_H.pdf. Published January 15, 2013. Updated 2013. Accessed October 20, 2017.

24. Johnston R, Poti JM, Popkin BM. Eating and aging: Trends in dietary intake among older Americans from 1977-2010. J Nutr Health Aging. 2014;18(3):234-242.

25. Popkin BM, Haines PS, Siega-riz AM. Dietary patterns and trends in the United States: The UNC-CH approach. Appetite. 1999;32(1):8-14.

26. U.S. Department of Agriculture, Food and Nutrition Service. WIC food packages regulatory requirements for WIC-eligible foods. https://www.fns.usda.gov/wic/wic-foodpackages-regulatory-requirements-wic-eligible-foods. Updated 2018. Accessed March 14, 2018.

27. Pennington J, Kandiah J, Nicklas T, Pitman S, Stitzel K. Practice paper of the American Dietetic Association: Nutrient density: Meeting nutrient goals within calorie needs. J Am Diet Assoc. 2007;107(5):860-869.

28. Zheng M, Rangan A, Olsen NJ, et al. Substituting sugar-sweetened beverages with water or milk is inversely associated with body fatness development from childhood to adolescence. Nutrition. 2015;31(1):38-44.

29. Nicklas TA, O'Neil CE, Fulgoni III VL. Snacking patterns, diet quality, and cardiovascular risk factors in adults. BMC Public Health. 2014;14:388. doi:10.1186/1471-2458-14-388. 


\section{CHAPTER IV: THE INFLUENCE OF RISK FACTORS FOR CHILDHOOD OBESITY ON BODY WEIGHT STATUS OF WIC PRESCHOOL CHILDREN}

\section{Introduction}

The serious health consequences attributable to childhood obesity make it an important public health concern. Overweight or obese children are at significantly higher risk of becoming overweight or obese adults when compared to normal weight children. ${ }^{1-}$

${ }^{4}$ The impact of obesity in health includes an increased risk for type II diabetes, cardiovascular disorders, some forms of cancer, asthma, sleep apnea, joint and bone disorders, social rejection and low-self esteem, which negatively impact a person's quality of life and decrease longevity. ${ }^{5-7}$ In fact, a study by Olshansky and colleagues ${ }^{8}$ found that due to the negative effect of obesity, life expectancy could be shortened by two to five years or more in the coming decades if increasing prevalence is not controlled. Obesity also generates a large economic burden due to the high cost of treatment for the associated diseases. ${ }^{9}$ The medical costs of adult obesity are estimated to be from $\$ 147$ to nearly $\$ 210$ billion per year, while childhood obesity alone is responsible for $\$ 14.1$ billion in direct costs. ${ }^{10}$

Childhood obesity is not simply caused by an energy imbalance. It is a complex multifactorial condition and needs to be addressed as such. The need for a broader approach when studying the process leading to the development of excess weight gain in children has been suggested by previous research. ${ }^{11-13}$ Factors associated with preventing excess adiposity in children described in the 2010 Dietary Guidelines Advisory Committee Report ${ }^{14}$ include: greatly reduced intake of sugar sweetened beverages, smaller amounts of fruit juice, increased intake of fruits and vegetables, smaller portions 
of foods and beverages, infrequent consumption of meals from quick service (i.e., fast food) restaurants, habitual consumption of breakfast, fewer hours of screen time, more hours of active play. Nevertheless, little is known about the potential risk factors for childhood overweight and obesity among the Special Supplementation Nutrition Program for Women, Infants, and Children (WIC) preschool-aged participants.

\section{Beverage intake}

Current research on the relationship between beverage intake and body weight in children has been focusing mainly on sugar sweetened beverages (SSB) intake, and to a lesser extent in juice and milk intake. SSB include sodas, fruit drinks (including lemonade, flavored water and fruit nectars with added sugars), commercially prepared teas and coffees, sports and energy drinks. SSB intake has been positively associated with the risk for overweight and obesity. ${ }^{15-18}$ Because SSB can contribute excess calories while providing few or no key nutrients, the 2015-2020 Dietary Guidelines for Americans recommends the intake to be within the overall calorie limit for added sugars, which is less than 10 percent of total daily calories. ${ }^{19}$ According to NHANES 2011-2014 data, U.S. youth ages 2 to 19 years consumed on average $143 \mathrm{kcal} /$ day from SSB, corresponding to $7.3 \%$ of their daily energy intake. ${ }^{20}$ There seems to be enough evidence to support that reducing the intake of SSB will help reduce obesity prevalence in both children and adults. Nevertheless, data from WIC participants is insufficient and limited

to Hispanic toddlers. ${ }^{21,22}$ WIC has been pointed out as being potentially playing a role in the decline of SSB consumption among young children, and also as having the potential to reduce fruit juice consumption through the revisions of WIC food packages. ${ }^{23}$ 
There has been a shift from a higher intake of fresh fruit in 1977 to more frequent consumption of fruit juice in 2006 in U.S. children ages 2 to $18 .{ }^{24}$ The Dietary Guidelines for Americans recommends majority of fruit intake to come from whole fruits due to their antioxidant and fiber content. ${ }^{19}$ Overall, a serving of fruit contains less than 90 calories and between $35 \%$ and $61 \%$ less sugar than a juice serving. ${ }^{25}$ There are also significant differences in antioxidant density between fruit and fruit juices, with fresh fruit having up to $54 \%$ higher antioxidant density compared to $100 \%$ juice. ${ }^{25}$ Despite this, one hundred percent fruit juice intake is associated with an increased nutrient adequacy in children's diets and may play a beneficial role when combined with a healthy dietary pattern. ${ }^{26,27}$ A recent evidence-based review found no association between $100 \%$ fruit juice intake and weight status or adiposity in children after controlling for total energy intake. ${ }^{27}$ Studies that did not adjust for energy intake found significant differences between higher and lower juice intake in terms of weight status.

The findings on the association between milk intake and the risk for overweight or obesity are inconclusive. Barba et al ${ }^{28}$ demonstrated a significant inverse association between frequency of milk intake and body mass in a large sample of elementary school children in Italy. Other studies have found higher milk consumption by children to be associated with higher body mass, ${ }^{29}$ or have found no relationship between milk intake and body weight status. ${ }^{30}$ It has been suggested that replacing SSB with milk may reduce weight gain in children. ${ }^{31,32}$ 


\section{Fruits and vegetables intake}

Across all ages and gender groups, the vast majority of the U.S. population consume less than the recommended amounts of fruits and vegetables. Most young children meet the recommended intake for fruits but less than $15 \%$ consume the recommended 1-cup of vegetables per day. ${ }^{33}$ Exposure to a greater number of fruits and vegetables at an early age has been associated with a greater intake of fruits and vegetables later in childhood. ${ }^{34,35}$ The consumption of all forms of fruits and vegetables whether they are fresh, frozen, canned, or dried - should be encouraged as part of a healthful diet. ${ }^{36}$ Consumption of fruits and vegetables helps provide an adequate intake of key nutrients and is associated with health benefits, having a possible protective effect against obesity. ${ }^{19}$ A study including a nationally representative sample found that overweight and obese adults consumed significantly less fruits and vegetables than normal-weight adults after controlling for potential confounding factors. ${ }^{37}$ Studies in children are limited and have found an inverse association between the consumption of fruits and vegetables and adiposity, ${ }^{35}$ or found no relationship. ${ }^{36}$

\section{Meal skipping}

Meal skipping rates may be the highest among young adults, with $14-88 \%$ skipping breakfast, $8-57 \%$ skipping lunch, and $4-57 \%$ skipping dinner. ${ }^{38}$ Breakfast is the most commonly skipped meal; consequently most studies focus on breakfast skipping. In preschool children, it has been reported that $10 \%$ skip breakfast at least once a week, with these numbers increasing, as children get older. ${ }^{39}$ Research has associated breakfast consumption with several key outcomes, including an improved overall nutrient intake 
and diet quality, a possible protective effect against obesity, and improvement in cognitive function and academic performance. ${ }^{40,41}$ In cross-sectional studies including children and adolescents, daily breakfast consumption has been associated with a decreased risk for overweight and obesity. ${ }^{39,42-44}$ From these, only one study was conducted in U.S. children; using NHANES data for children ages 9 to 18 years. Authors reported that breakfast consumers had a lower BMI z-score for age and a better nutrient intake than breakfast skippers. ${ }^{42}$ One longitudinal study conducted in the Netherlands found that breakfast skipping at age of 4 years was associated with a higher percent fat mass at age 6 years, but no associations were found with BMI or weight status. ${ }^{45}$ The authors did not find any association between lunch and dinner skipping at 4 years of age and body fat at age 6 .

\section{Food sources}

Individuals obtain foods in a diverse array of locations, including stores, fullservice restaurants, quick-serve restaurants, school, and childcare centers. Studies have examined food sources on different ways, varying from location of purchase, location of consumption, location of preparation, or even a combination of the above. There was a major shift between 1977 and 2006 toward increased energy consumed away from home by children, with only a slight decline in energy consumed at home. ${ }^{46}$ It is important to note though that the proportion of energy intake from foods eaten at home but prepared away from home increased, while the proportion of energy intake from foods eaten away from home but prepared at home also increased. ${ }^{46}$ Food group and nutrient quality vary by where food is obtained. ${ }^{33}$ Food prepared away from home accounts for $41 \%$ of food 
expenditures and $32 \%$ of caloric intake in U.S. individuals 2 years of age and older, and is higher in total fat, saturated fat, sodium and cholesterol, and lower in calcium and dietary fiber than foods prepared at home. ${ }^{47}$ The 2015 Dietary Guidelines Advisory Committee concluded that, in adults, moderate evidence indicates higher frequency of fast-food consumption is associated with a higher risk for obesity, while among children 8 to 16 years of age there is limited evidence that higher frequency of fast-food consumption is associated with a higher risk for obesity during childhood, adolescence, and during the transition from adolescence into adulthood. ${ }^{48}$ The Committee also concluded that the evidence for the association between other types of away from home meals and body weight outcomes in children and adults is insufficient.

\section{Snacking while watching television}

Increased caloric intake via snacking while watching TV, possibly combined with the advertising of energy-dense foods affecting the intake of "junk food", have a potential role on the risk for childhood obesity. ${ }^{49}$ Lobstein and Dibb ${ }^{50}$ reported an association between TV advertisements of sweet and fatty foods and excess body weight, while advertisements of healthier foods appear to be mildly protective against excess body weight. The contribution of the exposure of children to TV food advertising to the prevalence of childhood obesity is estimated to be between 16 and $40 \%$ in the U.S. ${ }^{51} \mathrm{~A}$ study by Hingle et al ${ }^{49}$ found that nearly all food and beverage advertisements targeting children exceeded recommended federal guidelines for saturated fat, trans fat, sugar or sodium. Eating while watching TV was associated with poorer diet quality among children, including more frequent consumption of SSB and high-fat, high-sugar foods, 
and fewer fruits and vegetables. ${ }^{52}$ Viewing TV may also be associated with an excessive intake and consequently pose an increased risk for obesity by promoting mindless eating. ${ }^{53}$ Francis and Birch ${ }^{54}$ found that preschool children who reportedly watched more hours of TV and more frequently ate meals in front of the TV had a higher food intake at lunch during TV viewing versus without the TV.

\section{Screen time and physical activity}

Screen time refers to the time in front of a computer, television, video or computer game system, or smartphone or tablet or related device. The new guidelines from the American Academy of Pediatrics recommend limiting screen use to one hour per day of high-quality programs for children 2 to 5 years of age. ${ }^{55}$ A positive relationship between TV viewing and adiposity in preschool children has been reported in most studies, although the mechanisms by which this happens remain unclear. ${ }^{56}$ Spontaneous energy intake in male children was greater while watching TV when compared to recreational computer use and sedentary video game play. ${ }^{57}$ A recent metaanalysis found that the risk for childhood obesity increased by $13 \%$ for each one hour per day increment in TV watching. ${ }^{58} \mathrm{TV}$ viewing among children, from preschool to adolescence, predicted an increased risk for obesity over time. ${ }^{59-61}$ The 2015 Dietary Guidelines Advisory Committee concluded that there is moderate and consistent evidence from prospective studies supporting that adults have a higher incidence of overweight and obesity when the amount of TV viewing is higher in children and adolescents. ${ }^{33}$

The CDC recommends children and adolescents to do 60 minutes or more of physical activity each day. ${ }^{62}$ Data from a nationally representative sample of the U.S. 
population including children 6 to 11 years reported that, overall, 54\% of the children met screen time viewing recommendations, while $70 \%$ met physical activity

recommendations. ${ }^{63}$ Physical activity habits seem to track from childhood into

adulthood, with active youth presenting a lower risk of becoming obese adults. ${ }^{64}$ A study including WIC preschool children found that, on average, children spent more than twice as much time in front of a screen as they did engaging in physical activity; a low level of physical activity combined with a large amount of screen time were strong predictors of overweight. ${ }^{65}$

\section{Nighttime sleep time}

Children's sleep duration decreased 0.75 minutes per year over the last century, accounting for more than 1 hour of sleep reduction worldwide; in the U.S. the decline reached almost 2 hours of sleep from 1905 to $2008 .{ }^{66}$ Preschoolers typically sleep between 11 and 13 hours each night and may nap during daytime until 5 years of age. ${ }^{67}$ Although daytime sleep is very common in preschool children, previous studies did not find an association between daytime sleep and obesity, but found that reduced nighttime sleep is an independent risk factor for childhood obesity. ${ }^{68}$ Evidence from a recent systematic review found a strong relationship between short sleep duration and obesity in children. ${ }^{69}$ Data in preschool aged children suggest a similar relationship, although there are only a few studies including this age group and results are non-conclusive. ${ }^{68,70-72}$ The mechanisms through which nighttime sleep duration influences a child's weight are still not clear, but it has been hypothesized that it may be due to a decrease in physical activity as a result of being tired, increased energy intake from nighttime feedings, or an 
imbalance in the hormones that regulate body weight, glucose homeostasis, and appetite. ${ }^{73,74}$ Children who sleep less present less favorable eating behaviors, including a poorer diet quality. ${ }^{69,72,75}$ Shorter sleep duration during childhood has been associated with higher BMI values at 32 years of age. ${ }^{76}$ This suggests a long-term effect of shorter sleep duration on the risk for obesity.

Parental perception of child's weight

The misperception that children are at normal weight is common among parents of overweight and obese children. Data from the 2007 to 2012 NHANES showed that $94.9 \%$ of parents of overweight 2 - to 5 -years-old perceived their children as just about the right weight, while $78.4 \%$ of parents perceived their obese child as just about the right weight. ${ }^{77}$ There are not many studies focused on WIC children, but they have reported a high prevalence of parental misperception of their child's weight among WIC clients despite the feedback received from WIC nutrition staff. ${ }^{78-81}$ Chaparro et al ${ }^{80}$ found that $93.6 \%$ of mothers of overweight children, and $77.5 \%$ of mothers of obese, children failed to identify them as such. Asian American WIC mothers were more than twice as likely as Hispanic mothers to accurately perceive their child's weight. ${ }^{81}$ However, this relationship disappeared after adjusting for mother's BMI, suggesting lower prevalence of obesity among Asian Americans may partially explain the more accurate perception seen in this population. It is possible that the high prevalence of overweight and obesity among adults contribute to parents being unsuccessful in perceiving the excess body weight in their children. While obesity rates are the highest among African Americans, parents of black children had the lowest rates of accurately perceiving their child as overweight or 
obese. $^{77}$ A nationally representative study found that many parents cannot understand the data in a growth chart, and do not comprehend the term percentile. ${ }^{82}$ The parent's health literacy level was found to be a significant predictor of the accuracy of their child's body weight perceptions. ${ }^{83}$ Parents have demonstrated a limited understanding of how childhood overweight is actually defined, and instead of relying on clinical and scientific measures they preferred to compare their children with others in order to identify childhood overweight. ${ }^{84}$

\section{Birth weight}

Higher birth weight and rapid weight gain during early infancy have been positively associated with obesity. ${ }^{85-87}$ Some studies found that a low birth weight with rapid catch-up growth also increases the risk for obesity, suggesting a "U-shaped" or "Jshaped" relationship between birth weight and obesity. ${ }^{88,89}$ The mechanisms through which birth weight and rapid infant growth influence subsequent adiposity remains unclear. It is possible that the relationship between birth weight and the development of obesity may be partially explained by the associations between birth weight and later fat mass, fat-free mass, and fat distribution. ${ }^{90}$ Adipogenesis occurs primarily during prenatal and postnatal development; consequently, its programming may be affected by departures from optimal growth in utero. ${ }^{88}$ Maternal diabetes, obesity, or weight gain during pregnancy alters the transfer of metabolic substrates between mother and fetus, which in consequence could influence insulin secretion and sensitivity, fat cell number, size and function, or the regulation of appetite by the central nervous system. ${ }^{91}$ The most recent systematic review and meta-analysis on infant rapid weight gain reports the odds of 
children experiencing rapid weight gain during the first 2 years of life becoming overweight or obese later in life to be 3.66 times greater than those who did not experience it. ${ }^{92}$ A recent literature review found that children and adolescents who were born heavier and experienced rapid postnatal growth had the highest odds of obesity, highest BMIs, and indicators of adiposity. ${ }^{89}$

\section{Breastfeeding duration}

Breast milk is the ideal food for infants until the age of 6 months. Breastfeeding can greatly affect health outcomes in both the child and the mother. It is estimated that, if every child in the world could be exclusively breastfed for the first 6 months and breastfed until 2 years of age, 823,000 annual deaths in children younger than 5 years could be prevented, and 20,000 annual deaths from breast cancer could be prevented in mothers. ${ }^{93}$ Most studies agree that breastfeeding has a protective effect against obesity, with a dose-response effect between breastfeeding duration and reduced risk of childhood

obesity. ${ }^{93,94}$ A recent study by Wang et al ${ }^{95}$ reported a decreased risk for childhood obesity by $42 \%$ when breastfed for more than 6 months compared to those children never breastfed. Even though the evidence linking breastfeeding with protection from later overweight or diabetes is growing, there is still no consensus, largely because of potential residual confounding factors.

Race, ethnicity and socioeconomic status

Minorities and low socioeconomic status groups are disproportionally affected by childhood overweight and obesity. According to the 2011-2014 NHANES data, the 
prevalence of obesity in children 2 to 5 years of age was greater in Hispanics (15.6\%) and non-Hispanic blacks (10.4\%) when compared to non-Hispanic whites $(5.2 \%)$ and nonHispanic Asians (5.0\%). ${ }^{96}$ Research has shown that the relationship between obesity and socioeconomic status is predominantly inverse ${ }^{97}$ and varies significantly by race and ethnicity. ${ }^{98,99}$

WIC clients are part of low socioeconomic status families and the majority belongs to racial and ethnic minorities, a population known to be at an increased risk for overweight and obesity. National obesity prevalence among WIC participants ages 2 to 4 years increased significantly from $14.0 \%$ in 2000 to $15.5 \%$ in 2004 and $15.9 \%$ in 2010 , decreasing significantly to $14.5 \%$ in $2014 .{ }^{100}$ In Florida, obesity prevalence among WIC participants ages 2 to 4 years increased from $13.2 \%$ in 2000 to $14.5 \%$ in 2004 and $14.6 \%$ in 2010 , decreasing significantly to $12.7 \%$ in $2014 .{ }^{100}$ It has been speculated that this downward trend in obesity seen in most WIC state agencies since 2010 is related to the revisions in the WIC food packages that occurred in 2009, combined with a number of federal and local obesity prevention initiatives. ${ }^{100}$

Understanding risk factors that are predictive of obesity in WIC preschool children may allow new guidelines to be proposed for both the home setting and the preschool setting with the goals of preventing childhood obesity and improving the health of children. The aim of this study was to investigate the relationship of known risk factors for childhood obesity with the child's body weight status in a sample of children ages 3 to under 5 years participating in the WIC Program in Broward County, Florida. 


\section{Methods}

\section{Subject recruitment}

This cross-sectional study included a convenience sample collected from all seven Broward County Health Department WIC clinics. Broward County WIC is the second largest agency in Florida, having served over 48 thousand clients during the 2017 fiscal year. ${ }^{101}$ WIC requires an authorized representative for the child, being a parent or guardian, to be present during the certification process. When a child is certified for WIC, his/her height and weight are updated on the system and a blood test for anemia is performed if needed. All data is recorded into the WIC data system. Anthropometric data for children is updated at least every 6 months, at the certification and the midcertification visits.

Inclusion criteria consisted of being between the ages of 3 and under 5 years, currently enrolled in the WIC program in Broward County, being present at one of the WIC clinics for a certification or mid-certification visit and having height and weight data less than 30 days old updated on the WIC data system. Exclusion criteria were any medical health condition, as indicated by medical nutritional risks by WIC codes, children under foster care, legal guardians who do not know the biological mother's pregnancy history, children accompanied by an authorized representative who does not participate on the daily care of the child, children accompanied by an authorized representative who could not communicate in English or Spanish.

Recruitment flyers both in English and Spanish explaining the purpose of the study, inclusion and exclusion criteria, brief explanation of the procedures and compensation details, as well as the contact information for the researcher, were placed at 
participating Broward County clinics. Authorized representatives for children who would qualify for the study were approached by the research staff while waiting to receive their WIC services and invited to participate in the study. If interested, the authorized representative for the child met the researcher in an available location inside the WIC clinic to participate in the interview after they finished with their WIC appointment services. Informed consent was obtained from the authorized representative allowing the interview to be conducted and providing permission to access the child's data from the WIC data system. The consent form was available in English and Spanish. The authorized representative for each participant received a \$10 Publix gift card to compensate for the time they spent to participate in the study.

\section{Data Collection}

Approval to conduct the study was obtained from the Florida International University Institutional Review Board (IRB) (Protocol Approval \# IRB-15-0369) and the State of Florida Department of Health IRB (Protocol Title: Meal Frequency and the Role of Snacking on Weight of Minority Preschool Children). Study protocol included secondary analysis of data accessed through the WIC data system and the use of a questionnaire to collect additional data not available through the WIC data system. Research Electronic Data Capture (REDCap), a secure web application for building and managing surveys and databases, was used for data collection and data management.

Data collected from the WIC data system:

Data fields collected from the WIC data system included: age, gender, anthropometric data (height, weight, BMI, BMI-for-age, weight-for-age, height-for-age, 
weight-for-length) - both current and retrospective, biochemical data (hemoglobin and/or hematocrit) - both current and retrospective, prematurity, completed weeks of gestation, birth weight, race and ethnicity, and breastfeeding (was the child ever breastfed - yes or no - and, if yes, for how many months). The researcher had access to the WIC data system, and accessed all data fields to be collected from the WIC data system after the participant completed in person interview.

Definition of underweight, overweight and obesity was based on the CDC guidelines for BMI-for-age weight status categories and the corresponding percentiles: ${ }^{102}$

- Underweight: less than the $5^{\text {th }}$ percentile.

- Healthy weight: $5^{\text {th }}$ percentile to less than the $85^{\text {th }}$ percentile.

- Overweight: $85^{\text {th }}$ percentile to less than the $95^{\text {th }}$ percentile.

- Obese: equal to or greater than the $95^{\text {th }}$ percentile.

Crespi and colleagues ${ }^{103}$ conducted a study to assess the accuracy of anthropometric measurements collected by WIC staff. They compared the WIC data to the "gold standard" measurements collected by trained research personnel at seven clinics in California $(\mathrm{n}=287)$ and concluded that height and weight of children ages 2-5 years collected by trained WIC staff were sufficiently accurate to be used for monitoring and research purposes.

\section{Data collected through a researcher-administered questionnaire:}

A previously validated questionnaire, adapted and tested in this population, was used to collect data during the interview with parents and guardians. The questionnaire used as reference is from a study conducted by Nelson et al. ${ }^{65}$ The authors used a selfadministered questionnaire to explore food and beverage consumption patterns, television 
viewing, and physical activity habits in WIC preschool children, as well as the relationship of these life styles with one another and with overweight. Additional questions were added based on the Healthy Kids Checklist, University of California Department of Nutrition ${ }^{104}$ and the NHANES questionnaire ${ }^{105}$ to explore the relationship between the source of food items and the child's body weight, as well as its relationship to other variables. Both research teams provided authorization to use and modify their questionnaires. The NHANES questionnaire is publicly available online. The study questionnaire was pilot tested with 10 subjects in one of the WIC clinics to ensure that the questions were relevant and appropriate for the population.

Data collected included frequency of snacks and meals, amounts of different beverages consumed per day and how many times per week, daily and weekly intake of fruits (not including fruit juice) and vegetables (not including French fries) and selected snack foods, food sources on a daily and weekly basis, frequency of snacking while watching TV, knowledge and use of My Plate, physical activity time, screen time, bedtimes and rising times, parent's perception of child's size, childcare arrangements, and race and ethnicity. For the purpose of this study, we examined where the food consumed was prepared, if at daycare or preschool, at home, or away from home. We also asked how often the foods prepared at home were cooked from scratch or not, such as from a frozen pre-packaged meal.

Knowledge and use of My Plate questions were added to the questionnaire based on the fact that WIC uses My Plate as a nutrition education tool to help WIC clients adopt healthy eating habits consistent with the Dietary Guidelines for Americans. These questions were extracted from the NHANES questionnaire. This data can provide a better 
understanding of the correlation of My Plate knowledge and use by WIC clients to the data collected on child's snack food and beverage intake.]

\section{Data Analysis}

Sample characteristics are presented using descriptive statistics. For data analysis purposes the child's body weight category was combined into 2 groups, under/normal weight and overweight/obese. Average daily intake of beverages was calculated by multiplying the number of days a child drank that beverage per week by how many ounces per day and dividing by 7 days on a week. Sugar sweetened beverage intake is an average of the daily intake of fruit drink, sweet tea, sports drink and soda. The kind of milk the child consumes most often was grouped into whole and $2 \%$ milk, $1 \%$ and fat free milk, and soy or other type. Average number of times a child ate fruits and vegetables per day was calculated by multiplying the number of days per week by the number of times per day a child ate fruits or vegetables and dividing by 7 days on a week. When reporting food sources we calculated the total number of meals (breakfast, lunch and dinner) cooked from scratch per week by multiplying the number of days per week by the number of times per day a child ate foods cooked from scratch. The same rationale was used to compute total meals per week prepared at home but not from scratch, prepared at daycare or preschool, and prepared away from home or daycare/preschool. Frequency of snacking while watching TV was categorized into 2 groups to facilitate data analysis; most days, almost every day, and every day were grouped into "frequently", and rarely and some days were grouped into "infrequently". Nighttime sleep time was 
calculated from bedtimes and rising times. Because we had too many missing cases we could not use the data collected for prematurity and completed weeks of gestation.

Independent samples t-tests were conducted to test for the relationship between continuous variables and the child's body weight category combined. Categorical variables were tested using Chi-square test of homogeneity. Race, ethnicity and gender were added as layers when conducting the analysis. Because over $92 \%$ of our sample was composed of either Whites or Blacks/African Americans, for dichotomization purposes, in some analyses only these two races were included. Cochran-Armitage test of trend was conducted to test for the relationship between the frequency of snacking while watching TV dichotomized into frequently and infrequently, and the snack quality score. The strength and direction of the relationship within the continuous confounders, screen time, physical activity time, and nighttime sleep time, was determined using Pearson's correlation.

A binomial logistic regression analysis was performed including all variables showing significance or marginal significance in the association with the child's weight. Exploratory tests were conducted with variables that did not show a significant correlation with weight in our study but have repeatedly found to be associated with overweight and obesity in other populations. Body weight was categorized into 2 groups, under/normal weight and overweight/obese, and used as the dichotomous dependent variable. All continuous variables included in the model were tested for linearity applying the Box-Tidwell procedure and using Bonferroni correction to test for significance, and found to be linearly correlated to the logit of the dependent variable. There was one residual with a value of 2.866 standard deviations, which was kept in the analysis. In 
order to increase relevance for public health practice, the potential confounders were divided into categories and then placed into a second logistic regression model.

All calculations were carried out with SPSS software version 24 (SPSS In. Chicago, IL). A significance level of $\mathrm{p}<0.05$ was used for all statistical tests. A confidence interval between 90 to $95 \%$ was considered marginally significant.

\section{Results}

From the 200 subjects who consented to participate in the study 3 extreme outliers, who reported over 10 eating episodes in one day, were excluded. Surveys have been answered mostly by mothers $(92.9 \%)$ with some fathers $(4.1 \%)$ and grandmothers (3\%). A total of 197 children were included in the data analysis. Children were between 3.0 to 4.9 years of age; mean age was 3.9 years $(\mathrm{SD}=0.6)$. Descriptive statistics are presented in Table 1. It is important to note that in our sample Hispanic or Latino were composed of $6.7 \%$ Black or African American, 86.5\% White, and 6.7\% mixed race, while non-Hispanic or Latino were composed of 87.1\% Black or African American, 5.4\% White, 5.4\% Asian, and 2.2\% mixed race. From Black or African Americans, 92\% were non-Hispanic or Latinos and 8\% were Hispanic or Latinos, while from Whites, $5.3 \%$ were non-Hispanic or Latinos and 94.7\% were Hispanic or Latinos.

Mean hemoglobin value for under/normal weight children was $11.88 \mathrm{~g} / \mathrm{dL} \pm 0.95$ and for overweight/obese children was $12.15 \mathrm{~g} / \mathrm{dL} \pm 0.91$ (independent samples $\mathrm{t}$ test $\mathrm{p}=$ 0.062). There was no significant difference in the prevalence of overweight/obesity by ethnicity, race, gender, or hemoglobin status (Table 2). 
Table 1. Characteristics of study population $(\mathrm{N}=197)$

\begin{tabular}{ll|l}
\hline Characteristic & & $\begin{array}{l}\text { Frequency } \\
\%(\mathrm{~N})\end{array}$ \\
\hline Ethnicity & Hispanic or Latino & $47.2 \%(93)$ \\
& Non-Hispanic or Latino & $52.8 \%(104)$ \\
\hline Race & Black or African American & $44.7 \%(88)$ \\
& White & $48.2 \%(95)$ \\
& Asian & $2.5 \%(5)$ \\
& American Indian or Alaska Native & $0(0)$ \\
& Native Hawaiian or Pacific Islander & $0(0)$ \\
& Mixed race & $4.6 \%(9)$ \\
\hline Gender & Male & $45.7 \%(90)$ \\
& Female & $54.3 \%(107)$ \\
\hline Weight category & Underweight & $3.6 \%(7)$ \\
& Normal weight & $64.4 \%(127)$ \\
& Overweight & $16.8 \%(33)$ \\
& Obese & $15.2 \%(30)$ \\
\hline Hemoglobin status & Low & $12.2 \%(24)$ \\
& Within normal limits & $87.7 \%(171)$ \\
\hline
\end{tabular}

${ }^{\mathrm{a}}$ Mixed race indicates more than one race has been selected.

Most children consumed 3 meals (97.5\%) and between $2(33.0 \%)$ to $3(37.1 \%)$ snacks on average per day. There was no significant correlation between the number of eating episodes or the number of snacks and the prevalence of overweight or obesity in our sample, but a trend in which the prevalence of overweight and obesity decreased as the number of eating episodes per day increased (data reported elsewhere). 
Table 2. Proportion of overweight/obese and under/normal weight preschool children by ethnicity, race, gender, and hemoglobin status.

\begin{tabular}{ll|l|l|l}
\hline Characteristic & $\begin{array}{l}\text { Under/normal } \\
\text { weight }(\mathrm{n}=134) \\
\%(\mathrm{~N})\end{array}$ & $\begin{array}{l}\text { Overweight/ } \\
\text { Obese }(\mathrm{n}=63) \\
\%(\mathrm{~N})\end{array}$ & p-value \\
\hline Ethnicity & Hispanic or Latino & $66.3(69)$ & $33.7(35)$ & 0.594 \\
& Non-Hispanic or Latino & $69.9(65)$ & $30.1(28)$ & \\
\hline Race & Black or African American & $68.2(60)$ & $31.8(28)$ & 0.380 \\
& White & $65.3(62)$ & $34.7(33)$ & \\
& Asian & $100.0(5)$ & $0(0)$ & \\
& Mixed race & $77.8(7)$ & $22.2(2)$ & \\
\hline Gender & Male & $66.7(60)$ & $33.3(30)$ & 0.709 \\
& Female & $69.2(74)$ & $30.8(33)$ & \\
\hline Hemoglobin & Low & $79.2(19)$ & $20.8(5)$ & 0.199 \\
status & Within normal limits & $66.1(113)$ & $33.9(58)$ & \\
\hline
\end{tabular}

${ }^{a}$ Mixed race indicates more than one race has been selected.

Children consumed on average 17.8 oz. of milk, 11.6 oz. of $100 \%$ fruit juice, 5.5 oz. of SSB, and $18.2 \mathrm{oz}$. of water per day. Beverage intake by weight status is reported on Table 3. The intake of SSB including fruit drinks was significantly higher in overweight/obese children when compared to normal/underweight. The intake of SSB was more than 2 times greater in Non-Hispanics or Latinos and Blacks or African Americans than in Hispanic or Latinos and Whites. The same ethic and race groups consumed significantly more $100 \%$ fruit juice. Beverage intake by ethnicity and race is reported on Table 4. 
Table 3. Daily average beverage intake in ounces, by weight status (mean $\pm \mathrm{SD}$ ).

\begin{tabular}{|c|c|c|c|}
\hline \multirow[t]{2}{*}{ Beverage (oz.) } & \multicolumn{2}{|c|}{ Weight status } & \multirow[t]{2}{*}{ p-value } \\
\hline & Under/Normal Weight & Overweight/Obese & \\
\hline Plain milk & $11.8 \pm 9.1$ & $11.9 \pm 9.5$ & 0.956 \\
\hline Flavored milk & $5.7 \pm 7.4$ & $6.5 \pm 8.7$ & 0.506 \\
\hline Milk (any) & $17.5 \pm 8.4$ & $18.4 \pm 10.1$ & 0.526 \\
\hline Fruit juice & $11.2 \pm 8.2$ & $12.5 \pm 8.7$ & 0.312 \\
\hline Fruit drink & $3.6 \pm 5.7$ & $6.2 \pm 8.2$ & $0.025 *$ \\
\hline Sweet tea & $0.3 \pm 1.1$ & $0.2 \pm 0.6$ & 0.408 \\
\hline Sports drink & $0.3 \pm 0.9$ & $0.6 \pm 1.9$ & 0.362 \\
\hline Soda & $0.4 \pm 1.5$ & $0.6 \pm 1.0$ & 0.471 \\
\hline $\mathrm{SSB}^{\mathrm{a}}$ & $4.6 \pm 6.6$ & $7.5 \pm 8.7$ & $0.024 *$ \\
\hline Water & $18.6 \pm 9.2$ & $17.6 \pm 6.2$ & 0.360 \\
\hline
\end{tabular}

${ }^{a}$ SSB includes fruit drink, sweet tea, sports drink, and soda.

* Independent samples t test significant at 95\% confidence interval.

There was no significant difference in beverage intake by gender. Children with hemoglobin levels within normal limits drank significantly more fruit drinks than children with low hemoglobin (4.73 oz/day vs. $2.56 \mathrm{oz} /$ day, $\mathrm{p}=0.049)$. There was no significant difference on hemoglobin levels by any other beverage intake, including total milk intake (data not reported).

Overall $65.5 \%$ of the participating preschool children consumed $1 \%$ or fat free milk most often than any other type of milk, being the first choice mostly for overweight/obese children (Table 5). 
Table 4. Daily average beverage intake in ounces, by ethnicity and race (mean $\pm \mathrm{SD}$ ).

\begin{tabular}{l|ll|l|ll|l}
\hline \multirow{2}{*}{ Beverage } & \multicolumn{3}{|c|}{ Ethnicity } & \multicolumn{3}{c}{ Race } \\
\cline { 2 - 7 } & $\begin{array}{l}\text { Non-Hispanic/ } \\
\text { Latino }\end{array}$ & $\begin{array}{l}\text { Hispanic/ } \\
\text { Latino }\end{array}$ & p-value & $\begin{array}{l}\text { Black/ } \\
\text { African American }\end{array}$ & White \\
\hline Plain milk & $12.9 \pm 9.9$ & $10.9 \pm 8.4$ & 0.125 & $12.8 \pm 10.2$ & $10.9 \pm 8.2$ & 0.182 \\
\hline Flavored milk & $5.1 \pm 7.0$ & $6.7 \pm 8.4$ & 0.157 & $4.7 \pm 7.1$ & $7.1 \pm 8.5$ & 0.067 \\
\hline Milk (any) & $18.0 \pm 9.8$ & $17.6 \pm 8.3$ & 0.727 & $17.7 \pm 10.4$ & $18.0 \pm 7.8$ & 0.837 \\
\hline Fruit juice & $13.1 \pm 8.4$ & $10.4 \pm 8.3$ & $0.025^{*}$ & $13.7 \pm 8.7$ & $9.9 \pm 8.0$ & $0.003^{*}$ \\
\hline Fruit drink & $6.5 \pm 7.9$ & $2.5 \pm 4.6$ & $0.000^{*}$ & $6.6 \pm 8.0$ & $2.7 \pm 4.7$ & $0.000^{*}$ \\
\hline Sweet tea & $0.4 \pm 1.3$ & $0.1 \pm 0.5$ & $0.045^{*}$ & $0.3 \pm 1.0$ & $0.1 \pm 0.2$ & $0.030^{*}$ \\
\hline Sports drink & $0.6 \pm 1.8$ & $0.3 \pm 0.7$ & 0.135 & $0.6 \pm 1.8$ & $0.3 \pm 0.7$ & 0.158 \\
\hline Soda & $0.5 \pm 1.6$ & $0.4 \pm 1.1$ & 0.632 & $0.5 \pm 1.6$ & $0.4 \pm 1.1$ & 0.611 \\
\hline SSB ${ }^{\text {a }}$ & $8.0 \pm 8.8$ & $3.3 \pm 5.1$ & $0.000^{*}$ & $8.0 \pm 9.0$ & $3.5 \pm 5.2$ & $0.000^{*}$ \\
\hline Water & $18.0 \pm 8.3$ & $18.5 \pm 8.4$ & 0.675 & $17.6 \pm 7.8$ & $18.2 \pm 8.7$ & 0.615 \\
\hline
\end{tabular}

${ }^{a}$ SSB includes fruit drink, sweet tea, sports drink, and soda.

* Independent samples t test significant at 95\% confidence interval.

Table 5. Proportion of type of milk most often consumed by weight category combined in WIC participating preschool children.

\begin{tabular}{|c|c|c|c|}
\hline Type of milk & $\begin{array}{l}\text { Under/normal weight }{ }^{*}(\mathrm{n}=134) \\
\%(\mathrm{~N})\end{array}$ & $\begin{array}{l}\text { Overweight/Obese }{ }^{*}(n=63) \\
\%(N)\end{array}$ & $\begin{array}{l}\text { Overall }(\mathrm{n}=197) \\
\%(\mathrm{~N})\end{array}$ \\
\hline Whole or $2 \%$ & $35.8(48)$ & $15.9(10)$ & $29.4(58)$ \\
\hline $1 \%$ or fat free & $59.0(79)$ & $79.4(50)$ & 65.5 (129) \\
\hline Soy or other & $5.2(7)$ & $4.8(3)$ & $5.1(10)$ \\
\hline
\end{tabular}

* Chi-Square test of homogeneity, $\mathrm{p}=0.014$.

Fruits were consumed daily by $67 \%$ of the children, mostly once or twice per day, while vegetables were consumed daily by $35 \%$ of the children, most often only once per day. On average, vegetables were consumed 4 days a week, with $4.6 \%$ of the parents reporting their preschool children never consumed vegetables. Fruit and vegetable average intake per day (1.41 and 0.76 times per day respectively) were not significantly different by weight category and by hemoglobin status. Hispanics or Latinos consumed 
fruits more days per week than non-Hispanics or Latinos $(6.23 \pm 1.62$ vs. $5.55 \pm 1.95, \mathrm{p}=$ 0.009 ) and consumed fruits more often, on average $1.53 \pm 0.77$ times per day versus 1.28 \pm 0.81 times per day $(\mathrm{p}=0.026)$. Whites consumed fruits more days per week than Blacks or African Americans (6.32 \pm 1.50 vs. $5.49 \pm 2.00, \mathrm{p}=0.002)$. Whites also consumed fruits more often, on average $1.55 \pm 0.78$ times per day versus $1.25 \pm 0.81$ times per day $(\mathrm{p}=0.010)$, and vegetables more often than Blacks or African Americans $(0.86 \pm 0.72$ vs. $0.67 \pm 0.54, \mathrm{p}=0.036)$.

Thirty percent of the children skip at least one meal per week. Breakfast meal was the most often skipped, with $16.5 \%$ of the children eating breakfast on fewer than 7 days a week. There was no significant difference in the frequency of meal skipping, which was on average 0.65 times per week, by weight category, hemoglobin status, ethnicity, race, or gender (data not shown).

Non-Hispanic or Latino and Black or African American children ate significantly less meals prepared from scratch, ate more foods prepared at home but not from scratch (i.e. from a frozen meal), and ate more meals at daycare or preschool on a weekly basis than Hispanic or Latino and White children (Figure 1). There was no significant difference by weight category, hemoglobin status, or gender. We found a marginally significant difference with overweight/obese children consuming meals prepared away from home or daycare or preschool more often than under/normal weight children (1.33 \pm 0.93 vs. $1.28 \pm 1.02$ times per week, $\mathrm{p}=0.050$ ). Non-Hispanic or Latino and Black or African American children consumed fast food or pizza 25\% more often than Hispanic or Latino and White children $(1.26 \pm 0.97$ vs. $0.95 \pm 0.61$ times per week, $\mathrm{p}=0.010$ and $1.26 \pm 1.00$ vs. $0.96 \pm 0.56$ times per week, $p=0.014$ respectively) 
Figure 1. Average times per week meals consumed by the participating preschool children are prepared according to food source, by weight category, ethnicity, and race.

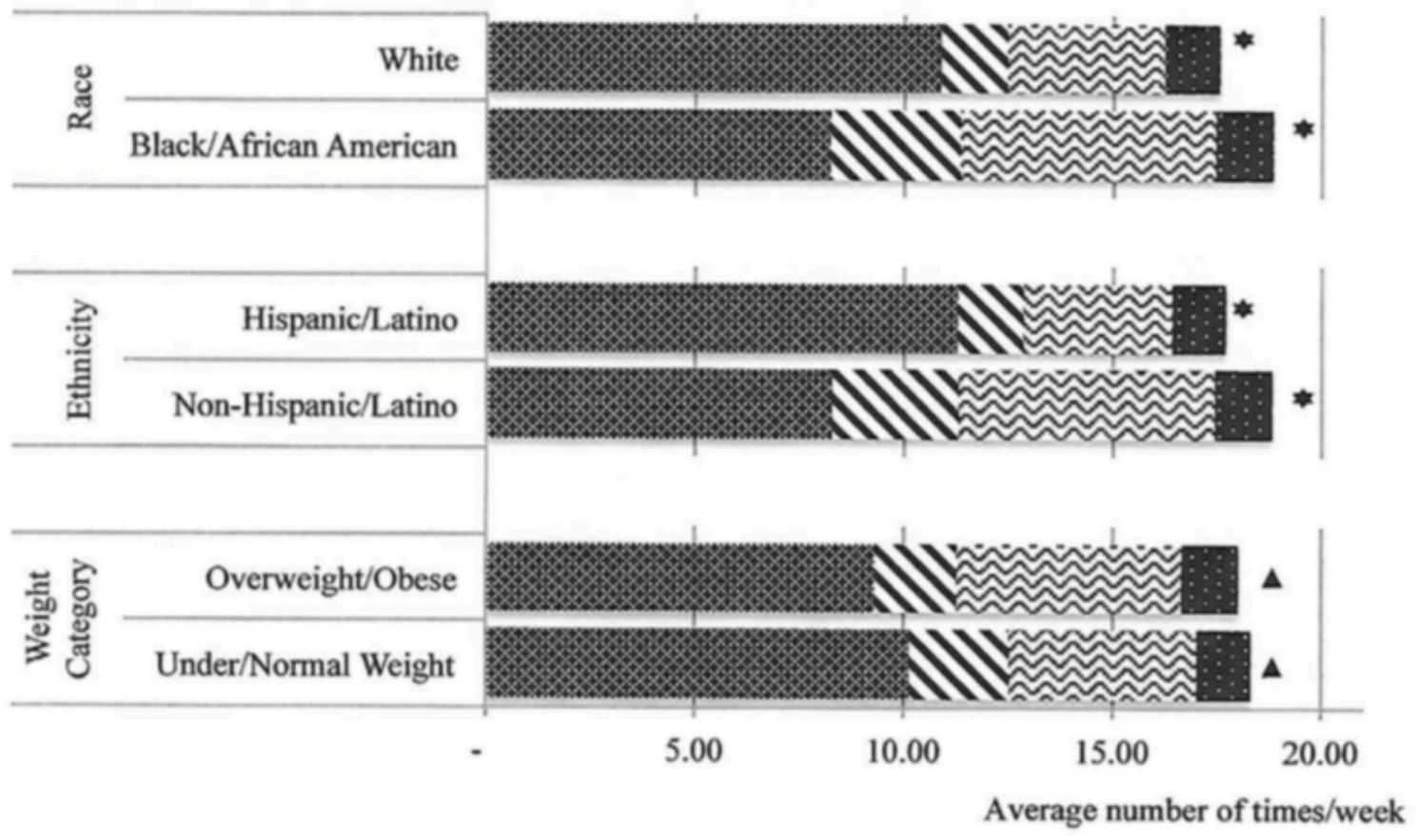

\footnotetext{
Meals prepared at home from scratch

$\checkmark$ Meals prepared at home but not from scratch (i.e. pre-packaged frozen meals)

Meals prepared at daycare or preschool

2. Meals prepared away from home or daycare/preschool
}

* Independent samples $t$ test significant for meals prepared at home from scratch $(p<0.001)$, meals prepared at home but not from scratch $(\mathrm{p}<0.001)$, and meals prepared at daycare/preschool $(\mathrm{p}=0.007$ for ethnicity and $p=0.017$ for race)

$\Delta$ Independent samples $\mathrm{t}$ test marginally significant for meals prepared away from home or daycare/preschool $(\mathrm{p}=0.050)$

Only around $20 \%$ of the authorized representatives who participated in this study reported they had heard of "My Plate", while 58.4\% do read the nutrition or health information for products they purchase.

Forty five percent of the participating children consumed snacks while watching TV most days to every day of the week, while $55 \%$ rarely or only some days a week consumed snacks while watching TV. This was independent of being overweight/obese 
or not and it did not differ by gender, but it varied significantly according to ethnicity and race. From the children who snacked while watching TV frequently, $60.2 \%$ were nonLatinos or Hispanics and 59.1\% Blacks or African Americans (Table 6).

Table 6. Ethnicity and race, and prevalence (\%) of WIC participating preschool children who snacked while watching TV frequently and infrequently.

\begin{tabular}{|c|c|c|c|c|}
\hline \multicolumn{2}{|c|}{ Snacking while watching TV } & $\begin{array}{l}\text { Infrequently }^{a^{*}} \\
\%(\mathrm{~N})\end{array}$ & $\begin{array}{l}\text { Frequently }{ }^{b^{*}} \\
\%(N)\end{array}$ & $\begin{array}{l}\text { Overall } \\
\%(\mathrm{~N})\end{array}$ \\
\hline \multirow[t]{2}{*}{ Ethnicity } & $\begin{array}{l}\text { Non-Hispanic or } \\
\text { Latino }\end{array}$ & $36.7(40)$ & $60.2(53)$ & $47.2(93)$ \\
\hline & Hispanic or Latino & $63.3(69)$ & $39.8(35)$ & $52.8(104)$ \\
\hline \multirow{4}{*}{ Race } & $\begin{array}{l}\text { Black or African } \\
\text { American }\end{array}$ & $33.0(36)$ & $59.1(52)$ & $44.7(88)$ \\
\hline & White & $56.9(62)$ & $37.5(33)$ & $48.2(95)$ \\
\hline & Asian & $3.7(4)$ & $1.1(1)$ & $2.5(5)$ \\
\hline & Mixed & $6.4(7)$ & $2.3(2)$ & $4.6(9)$ \\
\hline \multicolumn{2}{|c|}{$\%$ Overall $(n=197)$} & $55.3(109)$ & $44.7(88)$ & 100 \\
\hline
\end{tabular}

${ }^{a}$ Children who consumed snacks while watching TV rarely or some days of the week.

${ }^{\mathrm{b}}$ Children who consumed snacks while watching TV most days to every day of the week.

* Chi-Square test of homogeneity significant at a 95\% confidence level, $p=0.001$ for ethnicity and $\mathrm{p}=0.003$ for race.

Consumption of snack foods and beverages were scored based on snack quality. Scores ranged from one to three. The score of one was given to nutrient-poor snacks, while the score of 3 was given to more nutritious snack items (methodology described on chapter III). We found a marginally significant trend in which the children who consumed snacks while watching TV more often had a higher frequency of intake of the nutrient-poor snack items when compared to the children who consumed snacks while watching TV 
infrequently (Table 7). When excluding the one case that received a score of 2 from the analysis the trend became significant (results not shown, $p=0.041$ ). Average SSB intake per day was significantly higher in children who consumed snacks while watching TV frequently versus those who consumed snacks while watching TV infrequently (7.32 vs. $4.05, p=0.003)$. The average number of times a child ate vegetables per day was significantly higher in children who consumed snacks while watching TV infrequently versus those who consumed snacks while watching TV frequently $(0.86$ vs. $0.64, p=$ 0.018). The average number of times a child ate fruit per day was not significantly different $(1.49$ vs. $1.31, \mathrm{p}=0.117)$. Children who frequently snacked while watching TV spent significantly more hours per day in front of a screen $(3.0 \pm 1.5$ vs. $1.9 \pm 1.3, \mathrm{p}<$ $0.001)$.

Table 7. Frequency of snacking while watching TV by snack quality score among WIC participating preschool children.

\begin{tabular}{l|l|l|l}
\hline Snack quality score & $\begin{array}{l}\text { Infrequently }^{*} \\
\%(\mathrm{~N})\end{array}$ & $\begin{array}{l}\text { Frequently } \\
\%(\mathrm{~N})\end{array}$ & $\begin{array}{l}\text { Overall } \\
\%(\mathrm{~N})\end{array}$ \\
\hline${\text { Score } 1^{\mathrm{a}}}^{*}$ & $27.5(30)$ & $40.9(36)$ & $33.5(66)$ \\
\hline${\text { Score } 2^{\mathrm{b}}}$ & $0.0(0)$ & $1.1(1)$ & $0.5(1)$ \\
\hline Score $3^{\mathrm{c}}$ & $72.5(79)$ & $58.0(51)$ & $66.0(130)$ \\
\hline Overall & $55.3(109)$ & $44.7(88)$ & $100(197)$ \\
\hline
\end{tabular}

${ }^{a}$ Score 1: Sweetened beverages and candy groups.

${ }^{\mathrm{b}}$ Score 2: Dairy desserts, grain desserts, salty \& savory, fast-food, and non-WIC cereal, breads and bars groups.

${ }^{\mathrm{c}}$ Score 3: Fruits \& vegetables, nuts \& seeds, cheese \& yogurt, milk, $100 \%$ fruit juice, WIC cereal and breads groups.

* Cochran-Armitage Trend Test, $\mathrm{p}=0.067$. 
Children played actively or exercised enough to make them breathe hard on average 4.7 days per week for 53.2 minutes each of these days. The average amount of time being physically active per day was 37.9 minutes, while the average time of screen use was 2.3 hours. The time spent exercising per day was significantly greater in under/normal weight children when compared to overweight/obese children. There was no significant difference in screen use time by body weight category. Non-Hispanic or Latino and Black or African American children spent more hours in front of a screen than Hispanic or Latino and White children. Results for the independent samples t-test for screen time and physical activity are shown in Table 8.

Table 8 . Average minutes of physical activity or active play and hours of screen use per day by weight category combined, ethnicity, race, and gender for WIC participating preschool children (mean $\pm \mathrm{SD})$.

\begin{tabular}{|c|c|c|c|c|c|}
\hline Variables & & $\begin{array}{l}\text { Physical } \\
\text { activity (min) }\end{array}$ & p-value & $\begin{array}{l}\text { Screen use } \\
\text { (hours) }\end{array}$ & p-value \\
\hline $\begin{array}{l}\text { Weight } \\
\text { category }\end{array}$ & $\begin{array}{l}\text { Under/Normal wt. } \\
\text { Overweight/Obese }\end{array}$ & $\begin{array}{l}41.9 \pm 29.3 \\
29.3 \pm 27.0\end{array}$ & $0.004^{*}$ & $\begin{array}{l}2.3 \pm 1.5 \\
2.4 \pm 1.6\end{array}$ & 0.723 \\
\hline Ethnicity & $\begin{array}{l}\text { Non-Hispanic or } \\
\text { Latino } \\
\text { Hispanic or Latino }\end{array}$ & $\begin{array}{l}38.8 \pm 28.8 \\
37.1 \pm 29.6\end{array}$ & 0.693 & $\begin{array}{l}2.9 \pm 1.6 \\
1.9 \pm 1.2\end{array}$ & $<0.001^{*}$ \\
\hline Race & $\begin{array}{l}\text { Black or African } \\
\text { American } \\
\text { White }\end{array}$ & $\begin{array}{l}37.1 \pm 26.6 \\
38.4 \pm 30.2\end{array}$ & 0.756 & $\begin{array}{l}2.9 \pm 1.7 \\
1.9 \pm 1.2\end{array}$ & $<0.001^{*}$ \\
\hline Gender & $\begin{array}{l}\text { Male } \\
\text { Female }\end{array}$ & $\begin{array}{l}38.5 \pm 27.6 \\
37.4 \pm 30.5\end{array}$ & 0.802 & $\begin{array}{l}2.4 \pm 1.5 \\
2.3 \pm 1.6\end{array}$ & 0.862 \\
\hline
\end{tabular}

\footnotetext{
* Independent samples t test significant at 95\% confidence interval.
} 
Children slept on average ten and a half hours per night. Average nighttime sleep time was not significantly different by weight category, race or gender. Hispanics or Latinos slept on average more hours than non-Hispanic or Latinos (10.7 \pm 1.0 vs. $10.3 \pm$ $1.1, \mathrm{p}=0.023)$. There was no relationship between mean nighttime sleep time and snack quality score. There was no significant correlation between mean nighttime sleep time, mean screen time use, and mean physical activity time.

The misperception that children were at normal weight was common among authorized representatives of overweight and obese children (Table 9). Hispanics or Latinos and Whites had a more accurate perception of their child's size than nonHispanics or Latinos and Blacks or African Americans, even though the misperception that their child was just the right size when the child was actually overweight or obese was highly prevalent in both ethnicities and both races $(60 \%$ vs. $75 \%$ respectively for ethnicity and $63.6 \%$ vs. $71.4 \%$ respectively for race). The distribution of the authorized representatives' perception of their child's size by ethnicity and race can be found in Table 10.

Table 9. Authorized representatives' perception of their child's size according to weight category.

\begin{tabular}{l|l|l|l|l}
\hline $\begin{array}{l}\text { Actual weight } \\
\text { category }\end{array}$ & $\begin{array}{l}\text { Just the right } \\
\text { size } \%(\mathrm{~N})\end{array}$ & $\begin{array}{l}\text { Too big } \\
\%(\mathrm{~N})\end{array}$ & $\begin{array}{l}\text { Too little } \\
\%(\mathrm{~N})\end{array}$ & $\begin{array}{l}\text { Overall } \\
\%(\mathrm{~N})\end{array}$ \\
\hline Underweight & $28.6(2)$ & $0(0)$ & $71.4(5)$ & $3.6(7)$ \\
\hline Normal weight & $79.5(101)$ & $7.1(9)$ & $13.4(17)$ & $64.4(127)$ \\
\hline Overweight & $75.8(25)$ & $15.2(5)$ & $9.1(3)$ & $16.8(33)$ \\
\hline Obese & $56.7(17)$ & $43.3(13)$ & $0(0)$ & $15.2(30)$ \\
\hline \% Overall & $73.6(145)$ & $13.7(27)$ & $12.7(25)$ & $100(197)$ \\
\hline
\end{tabular}


Table 10. Authorized representatives' perception of their child's size according to weight category combined, by ethnicity and race.

\begin{tabular}{|c|c|c|c|c|}
\hline Ethnicity & $\begin{array}{l}\text { Weight category } \\
\text { combined }\end{array}$ & $\begin{array}{l}\text { Just the right } \\
\text { size } \%(\mathrm{~N})\end{array}$ & $\begin{array}{l}\text { Too big } \\
\%(\mathrm{~N})\end{array}$ & $\begin{array}{l}\text { Too little } \\
\%(\mathrm{~N})\end{array}$ \\
\hline $\begin{array}{l}\text { Non-Hispanic or } \\
\text { Latino }\end{array}$ & $\begin{array}{l}\text { Overweight/Obese } \\
\text { Under/Normal wt. }\end{array}$ & $\begin{array}{l}75.0(21) \\
75.4(49)\end{array}$ & $\begin{array}{l}25.0(7) \\
3.1(2)\end{array}$ & $\begin{array}{l}0(0) \\
21.5(14)\end{array}$ \\
\hline Hispanic or Latino & $\begin{array}{l}\text { Overweight/Obese } \\
\text { Under/Normal wt. }\end{array}$ & $\begin{array}{l}60.0(21) \\
78.3(54)\end{array}$ & $\begin{array}{l}31.4(11) \\
10.1(7)\end{array}$ & $\begin{array}{l}8.6(3) \\
11.6(8)\end{array}$ \\
\hline \multicolumn{5}{|l|}{ Race } \\
\hline $\begin{array}{l}\text { Black or African } \\
\text { American }\end{array}$ & $\begin{array}{l}\text { Overweight/Obese } \\
\text { Under/Normal wt. }\end{array}$ & $\begin{array}{l}71.4(20) \\
78.3(47)\end{array}$ & $\begin{array}{l}28.6(8) \\
3.3(2)\end{array}$ & $\begin{array}{l}0(0) \\
18.3(11)\end{array}$ \\
\hline White & $\begin{array}{l}\text { Overweight/Obese } \\
\text { Under/Normal wt. }\end{array}$ & $\begin{array}{l}63.6(21) \\
79.0(49)\end{array}$ & $\begin{array}{l}27.3(9) \\
9.7(6)\end{array}$ & $\begin{array}{l}9.1(3) \\
11.3(7)\end{array}$ \\
\hline
\end{tabular}

Data for prematurity and completed weeks of gestation was available from the WIC data system only for 25 and 28 participants respectively and was not analyzed. Birth weight data was available for 190 participants. Mean birth weight for overweight/obese children was significantly higher than for under/normal weight children $(7.41 \mathrm{lbs} \pm 1.12$ vs. $7.04 \mathrm{lbs} \pm 1.17, \mathrm{p}=0.038)$. There was no significant difference by ethnicity or race. Information if the child was ever breastfed was available from the WIC data system for 184 participants, while breastfeeding duration data was available for 166 participants. Cases with missing data were excluded from this analysis. Independent of the duration, $85.9 \%$ of the participating children had been breastfed, while $14.1 \%$ were never breastfed. Most of the children were breastfed for 2 or less months, with average breastfeeding duration of 5.75 months. Breastfeeding duration mean was not significantly different by weight category, race or ethnicity. Chi-square test results showed a trend in 
which a higher percentage of the overweight/obese children had never been breastfed when compared to the under/normal weight children. This trend was not significant (Table 11). There was no significant relationship between having ever been breastfed and ethnicity or race.

Table 11. Proportion of children who were ever breastfed by weight category combined in WIC participating preschool children.

\begin{tabular}{l|l|l}
\hline Was this child ever breastfed? & $\begin{array}{l}\text { No } \\
\%(\mathrm{~N})\end{array}$ & $\begin{array}{l}\text { Yes } \\
\%(\mathrm{~N})\end{array}$ \\
\hline Overweight/Obese $(\mathrm{n}=59)$ & $18.6(11)$ & $81.4(48)$ \\
\hline Under/Normal weight $(\mathrm{n}=125)$ & $12.0(15)$ & $88.0(110)$ \\
\hline$\%$ Overall $(\mathrm{n}=184)$ & $14.1(26)$ & $85.9(158)$ \\
\hline
\end{tabular}

* Chi-Square test of homogeneity not significant, $\mathrm{p}=0.227$.

Logistic regression was conducted to ascertain the effects of SSB intake, frequency of consuming meals prepared away from home or daycare/preschool, physical activity, and birth weight on the risk of overweight or obesity. The logistic regression model was statistically significant, Chi-square $=15.975, \mathrm{p}=0.003$. The model explained $11.3 \%$ (Nagelkerke $\mathrm{R}^{2}$ ) of the variance in overweight/obesity and correctly classified $71.6 \%$ of cases. Sensitivity was $21.7 \%$, specificity was $94.6 \%$, positive predictive value was $65 \%$ and negative predictive value was $72.4 \%$. Of the four predictor variables three were statistically significant. Mean SSB intake per day and total birth weight were positively associated with the risk of overweight and obesity, while average minutes of physical activity per day was negatively associated with the risk of overweight and obesity (Table 12). 
Table 12. Predictors of the risk of overweight/obesity in WIC participating preschool children.

\begin{tabular}{l|l|l}
\hline Predictor variable & Odds ratio (95\% C.I.) & $p$ \\
\hline SSB average intake (oz./day) & $1.046(1.003,1.091)$ & $0.035^{*}$ \\
\hline $\begin{array}{l}\text { Meals prepared away from home or } \\
\text { daycare/preschool (times /week) }\end{array}$ & $0.928(0.672,1.280)$ & 0.647 \\
\hline Exercise average (minutes/day) & $0.986(0.973,0.999)$ & $0.042^{*}$ \\
\hline Birth weight (lbs) & $1.337(1.001,1.784)$ & $0.049^{*}$ \\
\hline
\end{tabular}

* Significant at $95 \%$ confidence interval.

A second logistic regression was performed after categorizing the predictor variables to provide results with greater relevance for public health practice. SSB intake was classified as $4 \mathrm{oz}$ or less per day or more than $4 \mathrm{oz}$ per day. Consuming meals prepared away from home or daycare/preschool was used as one time or less per week and more than once per week. Physical activity was entered as 60 or more minutes per day or less than 60 minutes per day. Birth weight was categorized as low ( $\leq 5.5 \mathrm{lbs})$, normal (5.6 lbs $-8.9 \mathrm{lbs}$ ), or high ( $\geq 9.0 \mathrm{lbs}$ ). All assumptions of a logistic regression were respected. The logistic regression model was statistically significant, Chi-square $=12.677, \mathrm{p}=$ 0.027. Of the four predictor variables two were statistically significant while one was marginally significant. Consuming meals prepared away from home or daycare/preschool was not significant for both models. Drinking over 4 oz. of SSB per day significantly increased the risk of overweight and obesity by 1.97 times while being born at a low birth weight significantly decreased the risk of overweight and obesity by 10.64 times at age 3 to 4.9 years. Exercising less than 60 minutes per day marginally significantly increased the odds of being overweight and obese by 1.91 times (Table 13). 
Table 13. Categorized predictors of the risk of overweight/obesity in WIC participating preschool children.

\begin{tabular}{|c|c|c|}
\hline Categorized predictor variable & Odds ratio $(95 \%$ C.I. $)$ & $p$ \\
\hline SSB ( $>4$ oz/day) & $1.972(1.028,3.780)$ & $0.041 *$ \\
\hline Consuming meals prepared away from & & \\
\hline home or daycare/preschool > once/week & $0.981(0.496,1.940)$ & 0.955 \\
\hline Exercising $<60$ minutes per day & $1.908(0.866,4.111)$ & $0.099^{\#}$ \\
\hline Low birth weight ${ }^{\mathrm{a}}(\leq 5.5 \mathrm{lbs})$ & $0.094(0.009,0.984)$ & $0.048^{*}$ \\
\hline Normal birth weight $^{\mathrm{a}}(5.6 \mathrm{lbs}-8.9 \mathrm{lbs})$ & $0.496(0.153,1.608)$ & 0.243 \\
\hline
\end{tabular}

${ }^{\mathrm{a}}$ High birth weight as reference group ( $\left.\geq 9.0 \mathrm{lbs}\right)$.

* Significant at $95 \%$ confidence interval.

\# Marginally significant at $95 \%$ confidence interval.

\section{Discussion}

This study looked at potential confounding factors for childhood overweight and obesity. Their interaction is complex; while we found for some of the confounders a significant association with the risk of overweight or obesity, for others no significance was found. It is important to note that these factors may not work as risk or protective when considered in isolation of each other, but when considered in combination or within the context they may work together to determine the risk for childhood obesity.

Ethnicity and race were not predictive of weight status, even though nationally the prevalence of obesity in children 2 to 5 years of age was greater in Hispanics and nonHispanic Blacks when compared to non-Hispanic Whites and non-Hispanic Asians. ${ }^{96}$ This may be due to the fact that all study participants belong to low socioeconomic status families. It has been suggested that a low socioeconomic status is a more important predictor of overweight and obesity than race and ethnicity. ${ }^{106}$ Non-Hispanic or Latino children and Black or African American children included in this study presented 
behaviors that may place them at an increased risk of obesity. In our sample, Whites were predominately Hispanics or Latinos, while Blacks or African Americans were predominately non-Hispanics or Latinos. Thus, overall, our sample was composed of Hispanics or Latinos Whites and non-Hispanics or Latinos Blacks, the two populations at most risk for overweight/obesity. This may partially explain the obesity prevalence rate found in our study of $15.2 \%$, which is much greater than the latest data on obesity prevalence in children 2 to 5 years from the National Health and Nutrition Examination Surveys (NHANES) $2011-2014$ of $8.9 \%$ overall. ${ }^{96}$ In addition, NHANES is a nationally representative sample, while our sample was much smaller and not randomly selected. When compared to each other in our study, non-Hispanic or Latino Black children were at a greater risk of overweight or obesity than Hispanic or Latino White children, although the prevalence of overweight/obesity did not differ between them.

There was no significant difference in $100 \%$ fruit juice intake by weight category, but the intake of SSB was significantly greater in overweight/obese children when compared to under/normal weight. A recent study including a nationally representative sample of 2- to 5-year-old children found no difference in the prevalence of overweight/obesity between consistent $100 \%$ fruit juice drinkers and inconsistent or nondrinkers using cross-sectional analysis. ${ }^{107}$ The same study, which did not adjust for energy intake, did find that children who drank $100 \%$ fruit juice regularly at age 2 years had greater increases in BMI z-score by age 4 years than those who did not drink juice frequently or did not drink it at all. ${ }^{107}$ Studies controlling for energy intake found no relationship between $100 \%$ fruit juice consumption and the prevalence of overweight or obesity in children. ${ }^{27}$ We did not measure energy intake in this study. Despite the 
beneficial nutrient intake associated with $100 \%$ fruit juice, ${ }^{26}$ the excessive intake of any food may lead to weight gain. National efforts have been made to support a limited exposure of high obesity risk preschool children to quickly ingested, energy-dense beverages, including fruit juice. ${ }^{108}$ On the other hand, SSB can contribute excess calories while providing few or no key nutrients. There is consistent evidence that SSB increase the risk for overweight/obesity. ${ }^{18}$ The preschool children in our study consumed more $100 \%$ fruit juice than SSB. Research has shown that SSB consumption is the lowest among 2-5-year-old children, increasing with age ${ }^{20}$ On average, we found that children were consuming $11.6 \mathrm{oz}$. of fruit juice per day, which is twice as much as the American Academy of Pediatrics recommendation of, at most, 4 oz. for toddlers ages 1 to 3 and 4 to $6 \mathrm{oz}$. for children ages 4 to $6 .{ }^{109}$ Some children were consuming as much as $40 \mathrm{oz}$. of $100 \%$ fruit juice per day. Average intake of SSB was 5.5 oz., although some children consumed as much as $33 \mathrm{oz}$. per day. Children ages 1 to under 5 receive a total of $128 \mathrm{oz}$. of $100 \%$ fruit juice per month in the WIC food package, which may be encouraging the intake of fruit juice. Recommended amounts for juice intake should be considered when providing it to children. Non-Hispanic or Latino and Black or African American children consumed a significantly greater amount of $100 \%$ fruit juice and SSB than Hispanic or Latino and White children, placing them at a greater risk for overweight and obesity. Daily average intake of milk was not significantly different by weight category. Studies including children found mostly an inverse association between milk consumption and adiposity, possibly due to the protective role of dietary calcium. ${ }^{110,111} \mathrm{~A}$ significantly lower prevalence of overweight was found in children consuming whole milk daily when compared to those who consumed milk less frequently. ${ }^{28}$ Since the 
revisions in WIC food packages implemented in all states by 2009 there has been an improvement in the healthfulness of foods and mostly beverages purchased by WIC participants. ${ }^{112}$ Since then WIC provides $1 \%$ milk to all participants 2 years of age and older who are not underweight or at risk of being underweight, in an attempt to reduce saturated fat and cholesterol intake. A study conducted in the New York State WIC program found an increased consumption of low fat or fat-free milk by $4.5 \%$ among children 2-4 years after the implementation of the revised food package. ${ }^{113}$ Nevertheless, $29.4 \%$ of the WIC participating preschool children in our study consumed $2 \%$ or whole milk, suggesting the importance of nutrition education focusing on the risks of providing high-fat milk to children over the age of 2 years. Contrary to what we expected, high-fat milk intake was more prevalent in under/normal weight preschoolers. This difference remained significant if we considered the underweight children, who may choose to receive $2 \%$ milk in their WIC benefits package, independently of the normal weight children. This suggests a success of the nutrition education provided to authorized representatives of overweight or obese WIC preschool children approaching whole milk versus low fat or fat free milk.

With the addition of fruits and vegetables to the WIC food packages after the 2009 revision, there has been an increase in daily consumption of fruits by $5.3 \%$ and vegetables by $3.5 \%$ in 2-4-year-olds. ${ }^{113}$ This study did not include portion size of fruits and vegetables consumed in the analysis, only frequency of intake. The preschool children in our study consumed fruits on average 1.41 times per day and vegetables on average 0.77 times per day. Average daily frequency of intake of fruits and vegetables was not significantly different by weight category. A study using 1999-2002 NHANES 
data found that children ages 2 to 5 years consumed 1.29 cups of fruit per day and 0.76 cups of vegetables. ${ }^{114}$ Mean intake of vegetables was also found to have no difference by weight status in children 2 to 18 years of age, but mean total fruit intake was significantly higher in at-risk-for-overweight, but not in overweight children, when compared to normal weight children. ${ }^{114}$ The authors included $100 \%$ fruit juice intake for total fruit intake and French fries for total vegetable intake, while our study excluded fruit juice and French fries from fruits and vegetables intake. Hispanics or Latinos consumed fruits on average more times per day than non-Hispanics or Latinos, and Whites consumed both fruits and vegetables on average more times per day than Blacks or African Americans. We found that fruits, not including juice, were consumed daily by $67 \%$ of the children, and vegetables, not including French fries, by $35 \%$ of the children. There was no significant difference by weight category status. A study including a nationally representative sample reported that fruits were consumed daily by $72.7 \%$ of children 2 and 3 years of age, and vegetables were consumed daily by $69.7 \%$ of children 2 and 3 years of age, including white potatoes used for French fries, which by far was the most commonly consumed vegetable (31\%). ${ }^{115}$ Hispanics or Latinos and Whites consumed fruits more days per week than non-Hispanics or Latinos and Blacks or African Americans. The difference was not significant for vegetables. It is important to consistently offer fruits and vegetables to preschool age children. Offering a variety of fruits and vegetables to children ages 3 to 5 years as a snack has been reported to significantly increase their intake. ${ }^{116}$ Food preferences are developed early in life, making it important to expose young children to a wide variety of fruits and vegetables to foster the development of lifelong healthy eating habits. 
Skipping breakfast becomes more prevalent as children get older, and has been associated with an increased risk for overweight and obesity, mostly in older children and adults. NHANES data showed that $20 \%$ of children 9 to 13 years and $31.5 \%$ of adolescents 14 to 18 years skipped breakfast. ${ }^{42}$ There are few studies examining the association between skipping meals and the risk for obesity in younger children. A crosssectional study in Canada including preschoolers found that $10 \%$ of the children skipped breakfast at least one day per week and this behavior was associated with an increased mean BMI and an uneven distribution of meals throughout the day. ${ }^{39}$ Thirty percent of the preschool children included in our study skipped at least one meal per week, with breakfast being skipped by $16.2 \%$ of the children. We did not find any association between how frequently children skipped meals and if the meal skipped was breakfast, lunch, or dinner with the risk for overweight or obesity, regardless of ethnicity, race, or gender. It may be because the cross-sectional design used in this study could not detect the effect of skipping meals on adiposity at an early age. One longitudinal study conducted in the Netherlands found that breakfast skipping at age 4 years was associated with a higher percent fat mass at age 6 years. ${ }^{45}$

Eating away from home has been associated with a lower diet quality and consequently weight gain, ${ }^{117,118}$ although the evidence for an association between food source and body weight outcomes in children is insufficient. In this study food sources were not significantly associated with overweight or obesity, however we found a marginally significant higher frequency of overweight/obese children consuming meals prepared away from home or daycare/preschool when compared to under/normal weight children $(\mathrm{p}=0.050)$. A study including 10 -year-old children found an increase in the 
consumption of dinner prepared outside the home, but no association between consuming meals away from home or school and overweight status. ${ }^{119}$ Non-Hispanic or Latino and Black or African American children ate significantly fewer meals prepared from scratch and more meals prepared at home but not from scratch and at daycare or preschool than Hispanic or Latino and White children. They also consumed fast food or pizza over $25 \%$ more often. Longitudinal studies looking at the effect of this pattern on adiposity over time could better explain any existing association.

Over one quarter of the preschool children included in our study snacked while watching TV daily. Children from less educated, lower income families and younger mothers were found to be more likely to have the TV on while eating. ${ }^{120} \mathrm{We}$ found that consuming snacks while watching TV was more prevalent among non-Latino or Hispanic and Black or African American children, being they all belong to low socio-economic status families. Eating while watching television may potentially influence food intake due to the distraction factor and the amount of advertising of unhealthy food options. A study by Hingle at el ${ }^{49}$ found that child-targeted food advertising was strongly biased towards less healthy options. The relationship with overweight and obesity in young children remains unclear. In this study, we did not observe a relationship between eating while watching TV and prevalence of overweight and obesity, but we noted a significantly higher intake of SSB and a marginally significant increased intake of "empty calories" snacks in preschool children who consumed snacks while watching TV frequently compared to those who infrequently snacked in front of a TV. We also observed that children who frequently snacked while watching TV had a lower average intake of vegetables, but not fruits, per day than those who infrequently snacked while 
watching TV. Other studies have shown an association between eating while watching TV and a poorer diet quality in children, including higher SSB intake and high-fat, highsugar foods and fewer fruits and vegetables. ${ }^{52}$ Considering the unhealthier dietary patterns we found on preschool children who frequently snacked while watching TV, the finding that those same kids also spent significantly more hours in front of a screen per day may have a potential impact in the future.

Limited screen time and increased physical activity are part of a healthier lifestyle in both children and adults. The relationship between screen time, physical activity, and overweight/obesity is not fully understood. In our study, children spent on average greater than 3 times in front of a screen than playing actively or exercising. Mean screen use time per day was 2.3 hours, with only $30 \%$ of the preschool children meeting the recommendation of the American Academy of Pediatrics of one hour per day or less of high-quality programs. ${ }^{55} \mathrm{~A}$ study including a nationally representative sample reported that $60.6 \%$ of children ages 2 to 5 watch TV for 2 hours or more per day. ${ }^{121}$ The same study did not find an association between TV viewing and energy intake in the preschool age group. This is consistent with our findings that $58.9 \%$ of the preschool children spent 2 hours or more a day in front of a screen. We found no association between screen use time and the prevalence of overweight/obesity. Our results differ from those of Chiasson et al, ${ }^{122}$ who reported that WIC children with less than 2 hours of screen time per day were significantly less likely to be obese. The preschool children included in our study played actively or exercised on average 38 minutes per day, more than $30 \%$ below the minimum of 60 minutes recommended by the CDC. ${ }^{62}$ Physical activity was inversely associated with the risk for overweight/obesity. Similar results were found by Nelson et 
al ${ }^{65}$ in a study including New York City WIC children, which reported a mean of 42 minutes of physical activity per day and a significant relationship with overweight. Data on the relationship between physical activity and adiposity in preschool children is limited. Longitudinal studies found that preschool children who watched the most TV had the greatest increase in body fat by the time they reached early adolescence. ${ }^{59,123}$ Non-Hispanic or Latino and Black or African American children spent more hours in front of a screen than Hispanic or Latino and White children. Parents play a central role in determining screen time in young children, while socio-demographic variables, decreased physical activity, and snacking while watching TV do not fully explain the relationship between screen time and overweight. ${ }^{124}$ WIC programs provide education focused on increasing physical activity and reducing screen time for children in addition to the core nutrition education. Interventions should target caregiver's education about the risks associated with prolonged screen time and limited physical activity and the prevalence of overweight and obesity in children.

There was no significant correlation between physical activity, screen use and nighttime sleep times in our study. Contrary to the results from Jiang et al, ${ }^{68}$ in our study, average nighttime sleep time was not associated with obesity in preschool children. Results from longitudinal studies including young children are conflicting. Klingenberg and colleagues ${ }^{71}$ found no associations between sleep time at 9 and 18 months and adiposity at 3 years of age, while Carter at al ${ }^{70}$ reported an increased risk of becoming overweight at age 7 in children ages 3 to 5 years who slept less hours per night. Although other authors have suggested a negative relationship between sleep time and unhealthy dietary patterns, when comparing mean hours of nighttime sleep time with snack quality 
score and with the frequency of snacking while watching TV we found no association. It is possible that we found no association between sleep duration and weight category or dietary patterns because the children included in our study were still very young and our sample size was relatively small.

Misperceiving the child's weight was highly prevalent in this population, with most participants reporting their child was just the right size when the child was actually overweight or obese. It is important to note that feedback from WIC staff regarding the weight status of their child is provided during the nutrition education contact at the WIC offices. A better understanding of the common parental misperception of their child's weight is key to the success of the efforts to reduce childhood obesity. Research found that parents are willing to receive feedback on their child's weight status, and this may bring positive changes in health behaviors. ${ }^{125}$ As WIC, together with pediatrician's offices, is a place where preschool children are weighted regularly, there is potential for successful interventions to raise awareness of children's weight issues.

We examined birth weight and breastfeeding as early life risk factors for overweight and obesity. Both have been included in many studies, mostly showing a significant relationship with the risk of overweight and obesity. Birth weight was positively associated with the prevalence of overweight/obesity between the ages of 3 to under 5 years. Contradictory to most research, breastfeeding analyzed as ever breastfed or not and as breastfeeding duration, did not have a significant relationship with the prevalence of overweight/obesity in our study. Similar results were reported in a recent longitudinal study including Latino children followed until age 9, which found that a higher birth weight was significantly associated with an increased risk for obesity at 9 
years, and did not find an association between exclusive breastfeeding at 4-6 weeks and obesity. ${ }^{87}$ In a study with WIC children in New York State, breastfeeding was associated with a lower risk of obesity. ${ }^{122} \mathrm{~A}$ study by Carling et al ${ }^{126}$ showed that children with a high risk for obesity - based on maternal BMI, gestational weight gain, maternal education, smoking, social support, food insecurity during pregnancy, and stress at 1 year postpartum - and who breastfed for less than 2 months were 2.55 times more likely to belong to a rising growth trajectory then children at high risk for obesity who breastfed for more than 4 months. These are risk factors commonly seen in WIC mothers and we are not sure the reason why we could not find an association. It could be there are other risk factors associated with this population playing a more important role in the risk for overweight and obesity than breastfeeding considered independently. Given the many benefits of breastfeeding for both the mother and the child, it is important to continue promoting breastfeeding among the WIC, as well as the general, population.

Of all the potential confounding variables we studied, four had a significant correlation with weight category and were included in the logistic regression model. The risk of overweight and obesity was positively associated with the intake of SSB and with birth weight, and negatively associated with physical activity. Frequency of meals consumed away from home or daycare/preschool was not significant when included in the logistic regression model. Preschool children should not be consuming SSB at all due to the high content of sugar. Because of how prevalent the consumption of SSB is in children we evaluated the impact of consuming over 4 oz. of SSB per day and found that it almost doubles the odds of being overweight or obese. Being physically active for 60 minutes or more daily is recommended for this age group. ${ }^{62}$ In this study, preschool 
children who exercised less than one hour per day had 1.91 more chance of being overweight and obese than those who met the recommendation. Children with a low birth weight were significantly less likely to be overweight or obese. Chiasson et al ${ }^{122}$ when studying WIC children did not include SSB intake or physical activity but the authors found lower rates of obesity in children with a low or very low birth weight.

This study did not consider all potential risk factors previously referred to in the literature. Specifically those risk factors related to parental information, such as weight status, pregnancy complications, family status (i.e. single or married), education, feeding practices and activity patterns, were not included due to the nature of the study design. The environment in which a child lives may promote healthy behaviors or not. Improving dietary and lifestyle patterns will influence the risk for overweight and obesity. ${ }^{127,128}$ Environmental factors were not studied here, with the exception of childcare, which is reported elsewhere. By using a cross sectional design we might have missed any relationship that would appear over time. The sample is representative of the Broward County WIC population, but results may not be generalizable to preschool children nationally or to other age groups or races and ethnicities.

Despite the many limitations of this study, our results add to the body of literature in childhood obesity by including WIC participating children, a population at higher risk for overweight and obesity that is not often included in studies. The use of a researcheradministered questionnaire tailored for this study allowed us to obtain responses to better answer our research questions, as well as allowed us to probe respondents for any unusual responses obtained. Our findings highlight the importance of addressing habits related to an increased risk for overweight and obesity in very young children. We 
demonstrated an important relationship between SSB intake, consumption of foods prepared away from home or daycare/preschool, physical activity, and birth weight and the risk of being overweight or obese in children under 5 years. Dietary patterns seen in infancy, such as the intake of fruits and vegetables, foods high in energy density, and formula were shown to be associated with the child's diet and weight outcomes at 6 years. ${ }^{129}$ It is possible that the relationship we found may have started even before the children included in our study were 2 years of age. Children begin to form eating preferences in infancy and continue to learn about food and eating during the early childhood years. ${ }^{130}$

There is a need for more longitudinal studies accessing the risk factors for childhood overweight and obesity, mainly in young children. Studies including a large, racially and ethnically diverse population from different socio-economic levels may help elucidate the relationship of characteristics found in different groups with the risk for overweight and obesity. By gaining a better understanding of this complex problem we can target interventions tailored to specific groups with a better chance of success. Obesity prevention interventions may be particularly useful when initiated early in life, making WIC a potential environment for effective intervention programs to help reduce overweight and obesity rates in children. Additional research is needed on the effectiveness of different obesity prevention interventions with WIC clients. 


\section{References}

1. Serdula MK, Ivery D, Coates RJ, Freedman DS, Williamson DF, Byers T. Do obese children become obese adults? A review of the literature. Prev Med. 1993;22(2):167-177.

2. Cheung PC, Cunningham SA, Naryan KMV, Kramer MR. Childhood obesity incidence in the United States: A systematic review. Child Obes. 2016;12(1):1-11.

3. Simmonds M, Llewellyn A, Owen CG, Woolacott N. Predicting adult obesity from childhood obesity: A systematic review and meta-analysis. Obes Rev. 2016;17(2):95-107.

4. Cunningham SA, Kramer MR, Narayan KMV. Incidence of childhood obesity in the United States. N Engl J Med. 2014;370(5):403-411.

5. Kelsey MM, Zaepfel A, Bjornstad P, Nadeau KJ. Age-related consequences of childhood obesity. Gerontology. 2014;60(3):222-228.

6. Wang YC, McPherson K, Marsh T, Gortmaker SL, Brown M. Health and economic burden of the projected obesity trends in the USA and the UK. Lancet. 2011;378(9793):815-825.

7. Dietz WH. Health consequences of obesity in youth: Childhood predictors of adult disease. Pediatrics. 1998;101:518-525.

8. Olshansky SJ, Passaro DJ, Hershow RC, et al. A potential decline in life expectancy in the United States in the 21st century. N Engl J Med. 2005;352(11):1138-1145.

9. Swinburn BA, Sacks G, Hall KD, et al. The global obesity pandemic: Shaped by global drivers and local environments. Lancet. 2011;378(9793):804-814.

10. Levi J, Segal L, St. Laurent R, Lang A, Rayburn J. F as in fat: How obesity threatens America's future. Princeton, NJ: Trust for America's Health/Robert Wood Johnson Foundation. 2012.

http://www.rwjf.org/content/dam/farm/reports/reports/2012/rwjf401318. Accessed March $27,2018$.

11. Davison KK, Birch LL. Childhood overweight: A contextual model and recommendations for future research. Obes Rev. 2001;2(3):159-171.

12. Dev DA, McBride BA, Fiese BH, Jones BL, Cho H, on behalf of the Strong Kids Research Team. Risk factors for overweight/obesity in preschool children: An ecological approach. Child Obes. 2013;9(5):399-408.

13. Monasta L, Batty GD, Cattaneo A, et al. Early-life determinants of overweight and obesity: A review of systematic reviews. Obes Rev. 2010;11(10):695-708. 
14. Dietary Guidelines Advisory Committee. Report of the Dietary Guidelines Advisory Committee on the Dietary Guidelines for Americans, 2010, to the Secretary of Agriculture and the Secretary of Health and Human Services. Washington, DC: U.S. Department of Agriculture, Agricultural Research Service. 2010. Available at https://www.cnpp.usda.gov/sites/default/files/dietary_guidelines_for_americans/2010DG ACReport-camera-ready-Jan11-11.pdf. Accessed March 20, 2018.

15. Malik VS, Schulze MB, Hu FB. Intake of sugar-sweetened beverages and weight gain: A systematic review. Am J Clin Nutr. 2006;84(2):274-288.

16. Hu FB. Resolved: There is sufficient scientific evidence that decreasing sugarsweetened beverage consumption will reduce the prevalence of obesity and obesityrelated diseases. Obes Rev. 2013;14(8):606-619.

17. Hu FB, Malik VS. Sugar-sweetened beverages and risk of obesity and type 2 diabetes: Epidemiologic evidence. Physiol Behav. 2010;100(1):47-54.

18. Bleich SN, Vercammen KA. The negative impact of sugar-sweetened beverages on children's health: An update of the literature. BMC Obesity. 2018;5(6). doi:

10.1186/s40608-017-0178-9

19. U.S. Department of Health and Human Services and U.S. Department of Agriculture. 2015-2020 Dietary Guidelines for Americans. 8th edition. December 2015; Available at http://health.gov/dietaryguidelines/2015/guidelines/. Accessed March 20, 2018.

20. Rosinger A, Herrick K, Gahche J, Park S. Sugar-sweetened beverage consumption among U.S. youth, 2011-2014. NCHS data brief, no 271. Hyattsville, MD: National Center for Health Statistics. 2017.

21. Davis JN, Whaley SE, Goran MI. Effects of breastfeeding and low sugar-sweetened beverage intake on obesity prevalence in Hispanic toddlers. Am J Clin Nutr. 2012;95(1):3-8.

22. Davis JN, Koleilat M, Shearrer GE, Whaley SE. Association of infant feeding and dietary intake on obesity prevalence in low-income toddlers. Obesity. 2014;22(4):11031111.

23. National Academies of Sciences, Engineering, and Medicine. Strategies to limit sugar-sweetened beverage consumption in young children: Proceedings of a workshop. Washington, DC: The National Academies Press. 2017.

24. Piernas C, Popkin BM. Trends in snacking among U.S. children. Health Aff. 2010;29(3):398-404. 
25. Crowe KM, Murray E. Deconstructing a fruit serving: Comparing the antioxidant density of select whole fruit and 100\% fruit juices. J Acad Nutr Diet. 2013;113(10):13541358.

26. O'Neil CE, Nicklas TA, Zanovec M, Kleinman RE, Fulgoni VL,III. Fruit juice consumption is associated with improved nutrient adequacy in children and adolescents: The national health and nutrition examination survey (NHANES) 2003-2006. Public Health Nutr. 2012;15(10):1871-1878.

27. Crowe-White K, O'Neil CE, Parrott JS, et al. Impact of 100\% fruit juice consumption on diet and weight status of children: An evidence-based review. Crit Rev Food Sci Nutr. 2016;56(5):871-884.

28. Barba G, Troiano E, Russo P, Venezia A, Siani A. Inverse association between body mass and frequency of milk consumption in children. Br J Nutr. 2005;93(1):15-19.

29. DeBoer MD, Agard HE, Scharf RJ. Milk intake, height and body mass index in preschool children. Arch Dis Child. 2015;100(5):460-465.

30. O'Connor TM, Yang S, Nicklas TA. Beverage intake among preschool children and its effect on weight status. Pediatrics. 2006;118(4):e1010-e1018.

31. Zheng M, Rangan A, Olsen NJ, et al. Substituting sugar-sweetened beverages with water or milk is inversely associated with body fatness development from childhood to adolescence. Nutrition. 2015;31(1):38-44.

32. Zheng M, Rangan A, Allman-Farinelli M, Rohde JF, Olsen NJ, Heitmann BL. Replacing sugary drinks with milk is inversely associated with weight gain among young obesity-predisposed children. Br J Nutr. 2015;114(9):1448-1455.

33. Dietary Guidelines Advisory Committee. Scientific report of the 2015 Dietary Guidelines Advisory Committee to the Secretary of Health and Human Services and the Secretary of agriculture. Washington, DC. 2015;Available at https://health.gov/dietaryguidelines/2015-scientific-report/PDFs/Scientific-Report-of-the2015-Dietary-Guidelines-Advisory-Committee.pdf. Accessed March 20,2018.

34. Mallan KM, Fildes A, Magarey AM, Daniels LA. The relationship between number of fruits, vegetables, and noncore foods tried at age 14 months and food preferences, dietary intake patterns, fussy eating behavior, and weight status at age 3.7 years. $J$ Acad Nutr Diet. 2016;116(4):630-637.

35. Fletcher S, Wright C, Jones A, Parkinson K, Adamson A. Tracking of toddler fruit and vegetable preferences to intake and adiposity later in childhood. Matern Child Nutr. 2017;13(2). doi:10.1111/mcn.12290. 
36. Freedman MR, Fulgoni VL. Canned vegetable and fruit consumption is associated with changes in nutrient intake and higher diet quality in children and adults: National health and nutrition examination survey 2001-2010. J Acad Nutr Diet. 2016;116(6):940948.

37. Heo M, Kim RS, Wylie-Rosett J, Allison DB, Heymsfield SB, Faith MS. Inverse association between fruit and vegetable intake and BMI even after controlling for demographic, socioeconomic and lifestyle factors. Obesity facts. 2011;4(6):449-455.

38. Pendergast FJ, Livingstone KM, Worsley A, McNaughton SA. Correlates of meal skipping in young adults: A systematic review. Int J Behav Nutr Phy. 2016;13(1):125. doi: 10.1186/s12966-016-0451-1

39. Dubois L, Girard M, Potvin Kent M, Farmer A, Tatone-Tokuda F. Breakfast skipping is associated with differences in meal patterns, macronutrient intakes and overweight among pre-school children. Public Health Nutr. 2009;12(1):19-28.

40. O'Neil CE, Byrd-Bredbenner C, Hayes D, Jana L, Klinger SE, Stephenson-Martin S. The role of breakfast in health: Definition and criteria for a quality breakfast. $J$ Acad Nutr Diet. 2014;114(12):S8-S26.

41. Edefonti V, Rosato V, Parpinel M, et al. The effect of breakfast composition and energy contribution on cognitive and academic performance: A systematic review. Am J Clin Nutr. 2014;100(2):626-656.

42. Deshmukh-Taskar PR, Nicklas TA, O'Neil CE, Keast DR, Radcliffe JD, Cho S. The relationship of breakfast skipping and type of breakfast consumption with nutrient intake and weight status in children and adolescents: The national health and nutrition examination survey 1999-2006. J Am Diet Assoc. 2010;110(6):869-878.

43. Antonogeorgos G, Panagiotakos DB, Papadimitriou A, Priftis KN, Anthracopoulos M, Nicolaidou P. Breakfast consumption and meal frequency interaction with childhood obesity. Pediatr Obes. 2012;7(1):65-72.

44. Toschke AM, Thorsteinsdottir KH, von Kries R, GME Study Group. Meal frequency, breakfast consumption and childhood obesity. Int J Pediatr Obes. 2009;4(4):242-248.

45. Wijtzes AI, Jansen W, Bouthoorn SH, et al. Meal-skipping behaviors and body fat in 6-year-old children. J Pediatr. 2016;168:118-125.

46. Poti JM, Popkin BM. Trends in energy intake among US children by eating location and food source, 1977-2006. J Am Diet Assoc. 2011;111(8):1156-1164.

47. Lin B, Guthrie J. Nutritional quality of food prepared at home and away from home, 1977-2008, EIB-105, U.S. Department of Agriculture, Economic Research Service. 2012. 
48. USDA Nutrition Evidence Library. 2015 Dietary Guidelines Advisory Committee: Systematic reviews of the individual diet and physical activity behavior change subcommittee. 2015; Available at https://www.cnpp.usda.gov/sites/default/files/usda_nutrition_evidence_flbrary/2015DGA C-SR-BehaviorChange.pdf. Accessed April 16, 2018.

49. Hingle MD, Castonguay JS, Ambuel DA, Smith RM, Kunkel D. Alignment of children's food advertising with proposed federal guidelines. Am J Prev Med. 2015;48(6):707-713.

50. Lobstein T, Dibb S. Evidence of a possible link between obesogenic food advertising and child overweight. Obes Rev. 2005;6(3):203-208.

51. Goris JM, Petersen S, Stamatakis E, Veerman JL. Television food advertising and the prevalence of childhood overweight and obesity: A multicountry comparison. Public Health Nutr. 2010;13(7):1003-1012.

52. Avery A, Anderson C, McCullough F. Associations between children's diet quality and watching television during meal or snack consumption: A systematic review. Matern Child Nutr. 2017;13(4). doi:10.1111/mcn.12428.

53. Ogden J, Coop N, Cousins C, et al. Distraction, the desire to eat and food intake. towards an expanded model of mindless eating. Appetite. 2013;62:119-126.

54. Francis LA, Birch LL. Does eating during television viewing affect preschool children's intake? J Am Diet Assoc. 2006;106(4):598-600.

55. American Academy of Pediatrics. American Academy of Pediatrics announces new recommendations for children's media use. https://www.aap.org/en-us/about-the-aap/aappress-room/Pages/American-Academy-of-Pediatrics-Announces-New-

Recommendations-for-Childrens-Media-Use.aspx. Published October 21, 2016. Updated 2016. Accessed April 17, 2018.

56. Cox R, Skouteris H, Rutherford L, Fuller-Tyszkiewicz M. The association between television viewing and preschool child body mass index. J Child Media. 2012;6(2):198220.

57. Marsh S, Ni Mhurchu C, Jiang Y, Maddison R. Comparative effects of TV watching, recreational computer use, and sedentary video game play on spontaneous energy intake in male children. A randomized crossover trial. Appetite. 2014;77:13-18.

58. Zhang G, Wu L, Zhou L, Lu W, Mao C. Television watching and risk of childhood obesity: A meta-analysis. Eur J Public Health. 2016;26(1):13-18. 
59. Proctor MH, Moore LL, Gao D, et al. Television viewing and change in body fat from preschool to early adolescence: The Framingham children's study. Int J Obes Relat Metab Disord. 2003;27(7):827-833.

60. Viner RM, Cole TJ. Television viewing in early childhood predicts adult body mass index. J Pediatr. 2005;147(4):429-435.

61. Mamun AA, O'Callaghan MJ, Williams G, Najman JM. Television watching from adolescence to adulthood and its association with BMI, waist circumference, waist-to-hip ratio and obesity: A longitudinal study. Public Health Nutr. 2013;16(1):54-64.

62. Centers for Disease Control and Prevention (CDC). How much physical activity do children need? https://www.cdc.gov/physicalactivity/basics/children/index.htm. Updated 2015. Accessed April 26, 2018.

63. Fakhouri THI, Hughes JP, Brody DJ, Kit BK, Ogden CL. Physical activity and screen-time viewing among elementary school-aged children in the United States from 2009 to 2010. JAMA Pediatrics. 2013;167(3):223-229.

64. Yang X, Telama R, Viikari J, Raitakari OT. Risk of obesity in relation to physical activity tracking from youth to adulthood. Med Sci Sports Exerc. 2006;38(5):919-925.

65. Nelson JA, Carpenter K, Chiasson MA. Diet, activity, and overweight among preschool-age children enrolled in the special supplemental nutrition program for women, infants, and children (WIC). Prev Chronic Dis. 2006;3(2). Available from: http://www.cdc.gov/pcd/issues/ 2006/apr/05_0135.htm.

66. Matricciani L, Olds T, Petkov J. In search of lost sleep: Secular trends in the sleep time of school-aged children and adolescents. Sleep Med Rev. 2012;16(3):203-211.

67. National Sleep Foundation. Children and sleep. https://sleepfoundation.org/sleeptopics/children-and-sleep/. Updated 2018. Accessed April 18, 2018.

68. Jiang F, Zhu S, Yan C, Jin X, Bandla H, Shen X. Sleep and obesity in preschool children. J Pediatr. 2009;154(6):814-818.

69. Felső R, Lohner S, Hollódy K, Erhardt É, Molnár D. Relationship between sleep duration and childhood obesity: Systematic review including the potential underlying mechanisms. Nutr Metab Cardiovas. 2017;27(9):751-761.

70. Carter PJ, Taylor BJ, Williams SM, Taylor RW. Longitudinal analysis of sleep in relation to BMI and body fat in children: The FLAME study. BMJ. 2011;342:d2712. doi:10.1136/bmj.d2712 
71. Klingenberg L, Christensen LB, Hjorth MF, et al. No relation between sleep duration and adiposity indicators in 9-36 months old children: The SKOT cohort. Pediatr Obes. 2013;8(1):e14-e18.

72. Tatone-Tokuda F, Dubois L, Ramsay T, et al. Sex differences in the association between sleep duration, diet and body mass index: A birth cohort study. J Sleep Res. 2012;21(4):448-460.

73. Cappuccio FP, Taggart FM, Kandala N, et al. Meta-analysis of short sleep duration and obesity in children and adults. Sleep. 2008;31(5):619-626.

74. Spruyt K, Gozal D. The underlying interactome of childhood obesity: The potential role of sleep. Child Obes. 2012;8(1):38-42.

75. Khan MKA, Faught EL, Chu YL, Ekwaru JP, Storey KE, Veugelers PJ. Is it nutrients, food items, diet quality or eating behaviours that are responsible for the association of children's diet with sleep? J Sleep Res. 2017;26(4):468-476.

76. Landhuis CE, Poulton R, Welch D, Hancox RJ. Childhood sleep time and long-term risk for obesity: A 32-year prospective birth cohort study. Pediatrics. 2008;122(5):955960.

77. Duncan DT, Hansen AR, Wang W, Yan F, Zhang J. Change in misperception of child's body weight among parents of American preschool children. Child Obes. 2015;11(4):384-393.

78. Baughcum AE, Chamberlin LA, Deeks CM, Powers SW, Whitaker RC. Maternal perceptions of overweight preschool children. Pediatrics. 2000;106(6):1380-1386.

79. Hackie M, Bowles CL. Maternal perception of their overweight children. Public Health Nurs. 2007;24(6):538-546.

80. Chaparro MP, Langellier BA, Kim LP, Whaley SE. Predictors of accurate maternal perception of their preschool child's weight status among Hispanic WIC participants. Obesity. 2011;19(10):2026-2030.

81. Nobari TZ, Wang M, Whaley SE. Asian American mothers' perception of their children's weight: A comparison with other racial/ethnic groups in Los Angeles. Ethn Dis. 2015;25(1):52-57.

82. Ben-Joseph EP, Dowshen SA, Izenberg N. Do parents understand growth charts? A national, internet-based survey. Pediatrics. 2009;124(4):1100-1109.

83. Garrett-Wright D. Parental perception of preschool child body weight. J Pediatr Nurs. 2011;26(5):435-445. 
84. Jones AR, Parkinson KN, Drewett RF, et al. Parental perceptions of weight status in children: The Gateshead millennium study. Int J Obes. 2011;35(7):953-962.

85. Eriksson J, Forsén T, Tuomilehto J, Osmond C, Barker D. Size at birth, childhood growth and obesity in adult life. Int J Obes Relat Metab Disord. 2001;25(5):735-740.

86. Andersen LG, Holst C, Michaelsen KF, Baker JL, Sørensen TIA. Weight and weight gain during early infancy predict childhood obesity: A case-cohort study. Int J Obes. 2012;36(10):1306-1311.

87. Kjaer TW, Faurholt-Jepsen D, Medrano R, et al. Higher birthweight and maternal pre-pregnancy BMI persist with obesity association at age 9 in high risk Latino children. J Immigr Minor Healt. 2018. doi:10.1007/s10903-018-0702-0.

88. Desai M, Beall M, Ross MG. Developmental origins of obesity: Programmed adipogenesis. Curr Diabetes Rep. 2013;13(1):27-33.

89. Matthews EK, Wei J, Cunningham SA. Relationship between prenatal growth, postnatal growth and childhood obesity: A review. Eur J Clin Nutr. 2017;71(8):919-930.

90. Yu ZB, Han SP, Zhu GZ, et al. Birth weight and subsequent risk of obesity: A systematic review and meta-analysis. Obes Rev. 2011;12(7):525-542.

91. Whitaker RC, Dietz WH. Role of the prenatal environment in the development of obesity. J Pediatr. 1998;132(5):768-776.

92. Zheng M, Lamb KE, Grimes $\mathrm{C}$, et al. Rapid weight gain during infancy and subsequent adiposity: A systematic review and meta-analysis of evidence. Obes Rev. 2018;19(3):321-332.

93. Victora CG, Bahl R, Barros AJD, et al. Breastfeeding in the 21st century: Epidemiology, mechanisms, and lifelong effect. Lancet. 2016;387:475-490.

94. Yan J, Liu L, Zhu Y, Huang G, Wang PP. The association between breastfeeding and childhood obesity: A meta-analysis. BMC Public Health. 2014;14:1267.

doi:10.1186/1471-2458-14-1267

95. Wang L, Collins C, Ratliff M, Xie B, Wang Y. Breastfeeding reduces childhood obesity risks. Child Obes. 2017;13(3):197-204.

96. Ogden CL, Carroll MD, Lawman HG, et al. Trends in obesity prevalence among children and adolescents in the United States, 1988-1994 through 2013-2014. JAMA. 2016;315(21):2292-2299. 
97. Shrewsbury V, Wardle J. Socioeconomic status and adiposity in childhood: A systematic review of cross-sectional studies 1990-2005. Obesity. 2008;16:275-284.

98. Jones-Smith JC, Dieckmann MG, Gottlieb L, Chow J, Fernald LC. Socioeconomic status and trajectory of overweight from birth to mid-childhood: The early childhood longitudinal study-birth cohort. PLoS One. 2014;9(6):e100181.

doi:10.1371/journal.pone.0100181

99. Wang Y, Beydoun MA. The obesity epidemic in the United States-gender, age, socioeconomic, racial/ethnic, and geographic characteristics: A systematic review and meta-regression analysis. Epidemiol Rev. 2007;29:6-28.

100. Pan L, Freedman DS, Sharma AJ, et al. Trends in obesity among participants aged 2-4 years in the Special Supplemental Nutrition Program for Women, Infants, and Children - United States, 2000-2014. MMWR Morb Mortal Wkly Rep. 2016;65(45):12561260 .

101. Indicators - FL-WISE participation. Florida WIC - Bureau of WIC Program Services Web site.

https://floridahealth.sharepoint.com/sites/COMMUNITYHEALTH/WIC/Intranet/Indicat ors/Flwise/participation.html. Updated 2017. Accessed February 16, 2018.

102. Centers for Disease Control and Prevention (CDC). About BMI for children and teens.

http://www.cdc.gov/healthyweight/assessing/bmi/childrens_BMI/about_childrens_BMI.h tml. Updated 2015. Accessed February 6, 2018.

103. Crespi CM, Alfonso VH, Whaley SE, Wang MC. Validity of child anthropometric measurements in the special supplemental nutrition program for women, infants, and children. Pediatr Res. 2012;71(3):286-292.

104. University of California Department of Nutrition. Healthy kids checklist. Healthy Kids Web site. http://healthykids.ucdavis.edu. Accessed October 20, 2017.

105. Centers for Disease Control and Prevention (CDC). National Health and Nutrition Examination Survey. Diet, Behavior and Nutrition Questionnaire Web site. http://www.cdc.gov/nchs/data/nhanes/nhanes_13_14/DBQ_H.pdf. Published January 15, 2013. Updated 2013. Accessed October 20, 2017.

106. Rogers R. The relationship between childhood obesity, low socioeconomic status, and race/ethnicity: Lessons from Massachusetts. Child Obes. 2015;11(6):691-695.

107. Shefferly A, Scharf RJ, DeBoer MD. Longitudinal evaluation of $100 \%$ fruit juice consumption on BMI status in 2-5-year-old children. Pediatr Obes. 2016;11(3):221-227. 
108. Wojcicki JM, Heyman MB. Reducing childhood obesity by eliminating $100 \%$ fruit juice. Am J Public Health. 2012;102(9):1630-1633.

109. American Academy of Pediatrics. American Academy of Pediatrics recommends no fruit juice for children under 1 year. https://www.aap.org/en-us/about-the-aap/aap-pressroom/Pages/American-Academy-of-Pediatrics-Recommends-No-Fruit-Juice-ForChildren-Under-1-Year.aspx. Published May 22, 2017. Updated 2017. Accessed April $17,2018$.

110. Carruth BR, Skinner JD. The role of dietary calcium and other nutrients in moderating body fat in preschool children. Int J Obes Relat Metab Disord. 2001;25(4):559-566.

111. Skinner JD, Bounds W, Carruth BR, Ziegler P. Longitudinal calcium intake is negatively related to children's body fat indexes. J Am Diet Assoc. 2003;103(12):16261631.

112. Andreyeva T, Tripp AS. The healthfulness of food and beverage purchases after the federal food package revisions: The case of two New England States. Prev Med. 2016;91:204-210.

113. Chiasson MA, Findley SE, Sekhobo JP, et al. Changing WIC changes what children eat. Obesity. 2013;21(7):1423-1429.

114. Lorson BA, Melgar-Quinonez HR, Taylor CA. Correlates of fruit and vegetable intakes in US children. $J$ Am Diet Assoc. 2009;109(3):474-478.

115. Fox MK, Condon E, Briefel RR, Reidy KC, Deming DM. Food consumption patterns of young preschoolers: Are they starting off on the right path? J Am Diet Assoc. 2010;110(12 Suppl):S52-S59.

116. Roe LS, Meengs JS, Birch LL, Rolls BJ. Serving a variety of vegetables and fruit as a snack increased intake in preschool children. Am J Clin Nutr. 2013;98(3):693-699.

117. Watts $\mathrm{AW}, \mathrm{PhD}$, Valente $\mathrm{M}, \mathrm{MA}, \mathrm{Tu} \mathrm{A}, \mathrm{PhD}$, Mâsse $\mathrm{LC}, \mathrm{PhD}$. Eating away from home: Influences on the dietary quality of adolescents with overweight or obesity. Can J Diet Pract Res. 2017;78(4):166-171.

118. Bhutani S, Schoeller DA, Walsh MC, McWilliams C. Frequency of eating out at both fast-food and sit-down restaurants was associated with high body mass index in non-large metropolitan communities in Midwest. Am J Health Promot. 2018;32(1):75-83.

119. Nicklas TA, Morales M, Linares A, et al. Children's meal patterns have changed over a 21-year period: The Bogalusa heart study. J Am Diet Assoc. 2004;104(5):753-761. 
120. Dubois L, Farmer A, Girard M, Peterson K. Social factors and television use during meals and snacks is associated with higher BMI among pre-school children. Public Health Nutr. 2008;11(12):1267-1279.

121. Sisson SB, Broyles ST, Robledo C, Boeckman L, Leyva M. Television viewing and variations in energy intake in adults and children in the USA. Public Health Nutr. 2012;15(4):609-617.

122. Chiasson MA, Scheinmann R, Hartel D, et al. Predictors of obesity in a cohort of children enrolled in WIC as infants and retained to 3 years of age. J Community Health. 2016;41(1):127-133.

123. Danner FW. A national longitudinal study of the association between hours of TV viewing and the trajectory of BMI growth among US children. J Pediatr Psychol. 2008;33(10):1100-1107.

124. de Jong E, Visscher TLS, HiraSing RA, Heymans MW, Seidell JC, Renders CM. Association between TV viewing, computer use and overweight, determinants and competing activities of screen time in 4- to 13-year-old children. Int J Obes. 2013;37(1):47-53.

125. Grimmett C, Croker H, Carnell S, Wardle J. Telling parents their child's weight status: Psychological impact of a weight-screening program. Pediatrics. 2008;122(3):e682-e688.

126. Carling SJ, Demment MM, Kjolhede CL, Olson CM. Breastfeeding duration and weight gain trajectory in infancy. Pediatrics. 2015;135(1):111-119.

127. Story M, Kaphingst KM, Robinson-O'Brien R, Glanz K. Creating healthy food and eating environments: Policy and environmental approaches. Annu Rev Public Health. 2008;29:253-272.

128. Rahman T, Cushing RA, Jackson RJ. Contributions of built environment to childhood obesity. Mt Sinai J Med. 2011;78(1):49-57.

129. Rose CM, Birch LL, Savage JS. Dietary patterns in infancy are associated with child diet and weight outcomes at 6 years. Int J Obes. 2017;41(5):783-788.

130. Birch LL, Anzman SL. Learning to eat in an obesogenic environment: A developmental systems perspective on childhood obesity. Child Dev Perspect. 2010;4:138-143. 


\section{CHAPTER V: THE EFFECT OF CHILDCARE ARRANGEMENTS ON BODY WEIGHT STATUS OF WIC PRESCHOOL CHILDREN}

\section{Introduction}

There has been a significant increase in obesity prevalence observed in both adults and youth from 1999-2000 through 2015-2016 demonstrated as a linear trend. ${ }^{1}$ Combined with the serious health consequences associated with obesity, this highlights the importance of better understanding its risk factors. The latest data from the 2015-2016 National Health and Nutrition Examination Survey (NHANES) shows obesity prevalence rate of $20.6 \%$ among adolescents (12-19 years), 18.4\% among school-age children (6-11 years) and $13.9 \%$ among preschool-age children $(2-5$ years $) .{ }^{1}$ The same data shows a significantly higher prevalence of obesity among non-Hispanic black (22.0\%) and Hispanic (25.8\%) youth aged 2-19 years when compared to non-Hispanic white $(14.1 \%)$ and non-Hispanic Asian (11.0\%) youth. These obese children and adolescents are about five times more likely to be obese as adults than non-obese children and adolescents. ${ }^{2}$

Substantial evidence from current literature suggests that the early childhood period is critical to the development, and consequently the prevention, of obesity. ${ }^{3}$ The early experience with food and eating is crucial in the development of food acceptance patterns. ${ }^{4-6}$ Research has shown that the broader the exposure to foods at an early age, the higher the chances of increased liking and consumption. ${ }^{7}$ A longitudinal study by Skinner at al ${ }^{8}$ reported that a high percentage of children's food preferences are developed by the time children are as young as 2 to 3 years of age and track until the same children are in the elementary school with a correlation coefficient from 0.74 to 
0.79. Children will eat their preferred foods and they come to like and eat what is familiar, which is what is present in the environment.

The social context also plays an important role in forming eating habits in children through modeling the eating behavior of others. ${ }^{9,10}$ Parents are particularly influential in the development of eating habits in very young children because they influence both the genetic potential and the immediate environment. ${ }^{11}$ Parenting styles can influence children's eating habits; with studies demonstrating that a high level of parental control with low responsiveness to the child's needs increases the risk of obesity, ${ }^{11,12}$ as does indulgent parental feeding. ${ }^{13}$ Research has shown strong correlations between the dietary intakes of preschool children and their caregivers. ${ }^{14}$ It has been suggested that preschool experiences may also have a significant influence on eating habits, and consequently on weight status in childhood. ${ }^{3,15}$ Early childcare and education programs have been pointed out by research as being important settings for obesity prevention interventions aimed at both children and their parents. ${ }^{16,17}$

In the United States, the number of 3 and 4 year old children enrolled in preschool increased from $36.7 \%$ in 1980 to $52.7 \%$ in $2015 .{ }^{18}$ In 2016, according to the National Center for Education Statistics, $73 \%$ of children ages 3-5 not yet in kindergarten had at least one weekly nonparental care arrangement, while $27 \%$ were only under parental care. ${ }^{19}$ From those participating in a nonparental childcare setting $82 \%$ were under center-based arrangements, $32 \%$ were cared for by a relative, and $16 \%$ were cared for by a non-relative in a home-based environment (children may have multiple arrangements). ${ }^{19}$ Head Start is a federally funded program established in 1965 that promotes school readiness for children in low-income families, by offering educational, 
nutritional, health, social and other services, serving nearly one million children. ${ }^{20}$ Head Start provides preschool services mostly in center-based settings. Nevertheless, despite the evidence for an association between childcare setting and childhood overweight and obesity, studies on the influence of childcare setting in preschool children's weight status are limited and non-conclusive.

A study examining the influence of the type of childcare the year before kindergarten on the risk of overweight or obesity when entering kindergarten using a nationally representative sample found that non-Latino children in friend, family and neighbor care and in Head Start were significantly more likely to be obese at the start of kindergarten than children under parental care, while Latino children in parental care were more likely to be obese than those in Head Start or friend, family and neighbor care. ${ }^{21}$ Another study conducted primarily with preschool children from low-income urban households in the U.S. found no significant relationship between race and ethnicity and weight category, but found that children who attended a public preschool for at least one year were at an increased risk for being overweight or obese when entering kindergarten compared to children under parental care. ${ }^{22}$ Even though some studies suggest a protective effect of parental care, other studies have found that preschool children who spend more time in center-based care were less likely to be obese than children under parental care. ${ }^{23,24}$ A recent literature review compiling findings from studies examining the association of childcare arrangement and weight outcome among preschool-aged children concluded there is no consistent evidence for a relationship between childcare and the risk for obesity except for Head Start; 3 out of 8 studies demonstrated a negative relationship between Head Start and the risk for obesity, while 
no study reported a positive relationship. ${ }^{25}$ Another systematic review reported that children aged 5 years and younger who are under informal care (family, friends and neighbors) have an increased risk of childhood overweight and obesity than preschool children who are on center-based care. ${ }^{26}$

The need for parents to be out of the house working gives room for different childcare arrangements to take place. Understanding the influence of childcare setting in the prevalence of obesity in preschool children may allow new guidelines to be proposed for both the home setting and the preschool setting with the goals of preventing childhood obesity and improving the health of children. The aim of this study was to explore the types of childcare arrangements of children 3 to under 5 years of age participating in the Broward County, Florida, Special Supplementation Nutrition Program for Women, Infants and Children (WIC) and to examine their relationship to the children's body weight status.

\section{Methods}

Subject recruitment

Data for this cross-sectional study was collected from the Special Supplementation Nutrition Program for Women, Infants and Children (WIC). A convenience sample was obtained from all seven Broward County Health Department WIC clinics, in Florida. Broward County WIC is the second largest WIC agency in Florida, having served over 48 thousand clients during the 2017 fiscal year. ${ }^{27}$ WIC requires an authorized representative for the child, being a parent or guardian, to be present during the certification process. When a child is certified for WIC, his/her height 
and weight are updated on the system and a blood test for anemia is performed if due. All data is recorded into the WIC data system. Anthropometric data for children is updated every 6 months, at the certification and the mid-certification visits.

Inclusion criteria consisted of being between the ages of 3 and under 5 years, currently enrolled in the WIC program in Broward County, being present at one of the WIC clinics for a certification or mid-certification visit and having height and weight data less than 30 days old updated on the WIC data system. Exclusion criteria were any medical health condition, as indicated by medical nutritional risks by WIC codes, children under foster care, legal guardians who do not know the biological mother's pregnancy history for the child, children accompanied by an authorized representative who does not participate on the daily care of the child, children accompanied by an authorized representative who could not communicate in English or Spanish.

Recruitment flyers in both English and Spanish explaining the purpose of the study, inclusion and exclusion criteria, brief explanation of the procedures and compensation details, as well as the contact information for the researcher, were placed at participating Broward County clinics. Authorized representatives for children who would qualify for the study also were approached by the research staff while waiting to receive their WIC services and invited to participate. If interested, the authorized representative for the child met the researcher in an available location inside the WIC clinic to participate in the interview after they have finished with their WIC appointment services. Informed consent was obtained from the authorized representative allowing the interview to be conducted and providing permission to access the child's data from the WIC data system. The consent form was available in English and Spanish. The authorized 
representative for each participant received a $\$ 10$ Publix gift card to compensate for the time they spent to participate in the study.

\section{Data Collection}

Approval to conduct the study was obtained from the Florida International University Institutional Review Board (IRB) (Protocol Approval \# IRB-15-0369) and the State of Florida Department of Health IRB (Protocol Title: Meal Frequency and the Role of Snacking on Weight of Minority Preschool Children). Study protocol included secondary analysis of data accessed through the WIC data system and the use of a questionnaire to collect data not available through the WIC data system. Research Electronic Data Capture (REDCap), a secure web application for building and managing surveys and databases, was used for data collection and data management.

Data fields collected from the WIC data system included age, gender and anthropometric data (height, weight, BMI, BMI-for-age, weight-for-age, height-for-age, weight-for-length). The researcher had access to the WIC data system, and accessed all data fields to be collected from the WIC data system after the participant was dismissed.

Definition of underweight, overweight and obesity was based on the CDC

guidelines for BMI-for-age weight status categories and the corresponding percentiles: ${ }^{28}$

- Underweight: less than the $5^{\text {th }}$ percentile.

- Healthy weight: $5^{\text {th }}$ percentile to less than the $85^{\text {th }}$ percentile.

- Overweight: $85^{\text {th }}$ percentile to less than the $95^{\text {th }}$ percentile.

- Obese: equal to or greater than the $95^{\text {th }}$ percentile. 
Crespi and colleagues ${ }^{29}$ conducted a study to assess the accuracy of anthropometric measurements collected by WIC staff by comparing them to the "gold standard" measurements collected by trained research personnel at seven clinics in California $(\mathrm{n}=287)$ and concluded that height and weight data of children ages 2-5 years collected by trained WIC staff are sufficiently accurate to be used for monitoring and research purposes.

A previously validated questionnaire, adapted and tested in this population, was used to collect data during the interview with parents and guardians. The questionnaire used as reference is from a study conducted by Nelson et al, ${ }^{30}$ in which the authors used a self-administered questionnaire to explore food and beverage consumption patterns and television-viewing and physical activity habits in WIC preschool children, as well as the relationship of such patterns to each other and to overweight. Additional questions were added based on the Healthy Kids Checklist, University of California Department of Nutrition, ${ }^{31}$ and the NHANES questionnaire ${ }^{32}$ to explore the relationship between the source of food items and the child's body weight, as well as its relationship to other variables. Both research teams provided authorization to use and modify their questionnaires, while the NHANES questionnaire is publicly available online. A small pilot test with 10 subjects was conducted in one of the WIC clinics to ensure the questionnaire was relevant and appropriate for the population. Eating and physical activity habits data is published elsewhere. For this study we limited our analysis to exploring data collected on childcare arrangements and race and ethnicity. 
Childcare arrangement classification was based on the division used by the U.S. Department of Education, Institute of Education Sciences, National Center for Education Statistics: ${ }^{33}$

- Parental care only

- Nonparental care:

- Center-based care (Head Start programs, day care centers, preschools, prekindergartens, and other childhood programs),

- Nonrelative care (such as family child care in another home or sitter in child's home)

- Relative care

Children can have multiple care arrangements on a given week. On the questionnaire parents were asked to report the average number of hours per day and/or per week on each type of childcare setting the child participates in during the daytime on weekdays (12 hours/day, 60 hours/week).

Standards for the classification of Federal data on race and ethnicity by the Executive Office of the President, Office of Management and Budget (OMB), Office of Information and Regulatory Affairs were followed when collecting data on categories of race and ethnicity. ${ }^{34}$

\section{Data Analysis}

Descriptive statistics were used for sample characteristics. Chi-square test for association was used to test for the relationship between the different childcare settings and the child's body weight category combined into 2 groups, under/normal weight and 
overweight/obese. Childcare setting was considered based on 12 hours per day, 5 days per week (daytime on weekdays). Because of the small number of children found to be under nonrelative care we grouped children under nonrelative and relative care under one variable called home nonparental care. To assess the influence of race and ethnicity both were added as layers when conducting the chi-square tests. The relationship between being exclusively under parental care and age group was also tested using chi-square test.

All calculations were conducted using SPSS software version 24 (SPSS Inc.

Chicago, IL). A significance level of $\mathrm{p}<0.05$ was used for all statistical tests.

\section{Results}

From the 200 subjects who consented to participate in the study 3 extreme outliers, who reported over 10 eating episodes in one day, were excluded. Surveys have been answered mostly by mothers $(92.9 \%)$ with some fathers $(4.1 \%)$ and grandmothers (3\%). A total of 197 children were included in the data analysis. Children were between 3.0 to 4.9 years; mean age was 3.9 years $(\mathrm{SD}=0.6)$. Descriptive statistics are presented in Table 1.

Table 2 presents the distribution of children according to the type of childcare. The majority of the children (53.3\%) participated in at least one nonparental care arrangement during the week, most commonly Head Start center-based care. Younger children were more likely to be exclusively under parental care. Among the 3-year-olds, $58.9 \%$ were exclusively under parental care, in contrast with $32.2 \%$ of the 4 -year-olds (chi-square test $\mathrm{p}<0.001$ ). 
Table 1. Characteristics of study population $(\mathrm{N}=197)$.

\begin{tabular}{ll|l}
\hline Characteristic & & $\begin{array}{l}\text { Frequency } \\
\%(\mathrm{~N})\end{array}$ \\
\hline Ethnicity & Hispanic or Latino & $47.2 \%(93)$ \\
& Not Hispanic or Latino & $52.8 \%(104)$ \\
\hline Race & Black or African American & $44.7 \%(88)$ \\
& White & $48.2 \%(95)$ \\
& Asian & $2.5 \%(5)$ \\
& American Indian or Alaska Native & 0 \\
& Native Hawaiian or Pacific Islander & 0 \\
& Mixed race & $4.6 \%(9)$ \\
\hline Gender & Male & $45.7 \%(90)$ \\
& Female & $54.3 \%(107)$ \\
\hline Weight category & Underweight & $3.6 \%(7)$ \\
& Normal weight & $64.4 \%(127)$ \\
& Overweight & $16.8 \%(33)$ \\
& Obese & $15.2 \%(30)$ \\
\hline Hemoglobin status & Low & $12.2 \%(24)$ \\
& Within normal limits & $87.7 \%(171)$ \\
\hline
\end{tabular}

${ }^{\mathrm{a}}$ Mixed race indicates more than one race has been selected.

When considering the type of care the child received for most of the daytime on weekdays, $58.4 \%$ of the children were under parental care, $28.4 \%$ under center-based care, 5.1\% under home nonparental care (being relative and non-relative combined) and $8.1 \%$ of the children were under more than one type of care equally distributed. When considering the number of hours spent under each type of care, both under/normal weight and overweight/obese children spent on average 40 hours per week under parental care and 20 hours per week under some type of nonparental care. 
Table 2. Distribution of preschool children by childcare arrangements during daytime on weekdays.

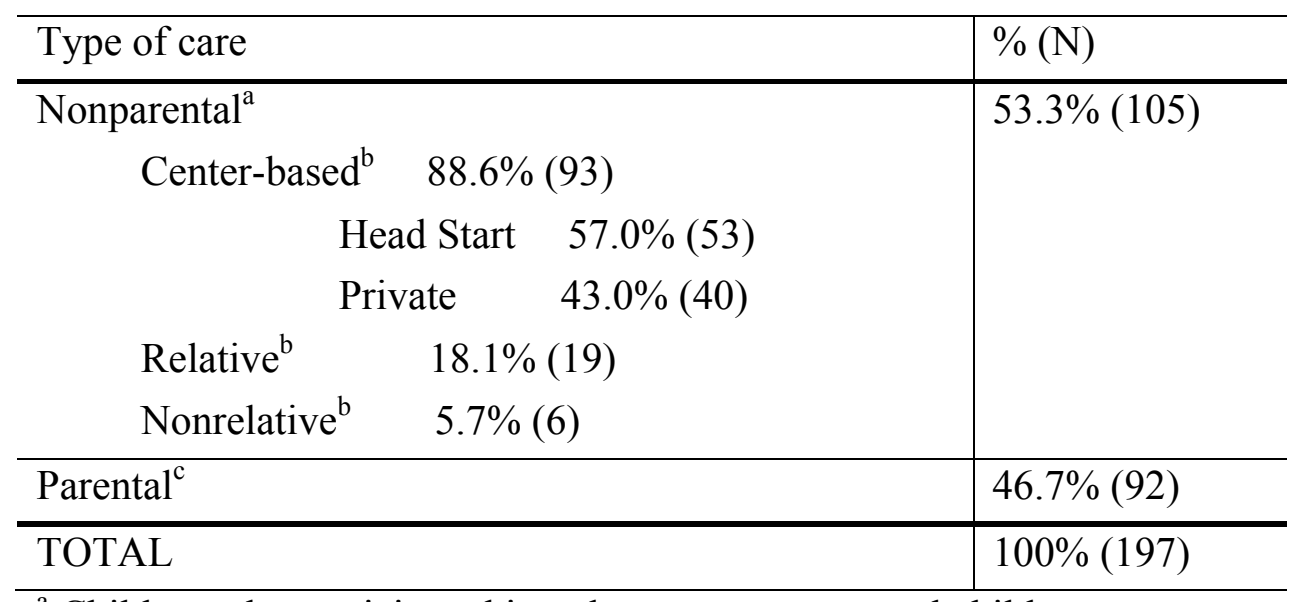

${ }^{a}$ Children who participated in at least one nonparental childcare arrangement during the week

${ }^{\mathrm{b}}$ Children may participate in multiple care arrangements on a given week.

${ }^{c}$ Children exclusively under parental care.

Performing cross tabulation, the chi-square test showed no statistically significant association between weight category combined and being exclusively under parental care or participating in at least one nonparental childcare arrangement during the week $(\mathrm{p}=0.897)$. The type of nonparental childcare setting the child participates in $(\mathrm{p}=0.685)$, the type of center-based care setting the child participates in $(\mathrm{p}=0.394)$, and the type of care the child participates in for the majority of the daytime on weekdays ( $\mathrm{p}=0.896)$ were also not statistically significant. When adding race and ethnicity as layers to the same statistical tests the only one that showed marginal significance $(p=0.071)$ was ethnicity as a factor for the association between the type of center-based care setting the child participates in and weight category combined. We found that Hispanic or Latino preschool children were more likely to be overweight or obese when in Head Start compared to in private childcare centers (Table 3). 
Table 3. Association between the type of center-based care setting and weight category combined by ethnicity.

\begin{tabular}{l|l|l|l|l|l}
\hline Ethnicity & $\begin{array}{l}\text { Type of center- } \\
\text { based care }\end{array}$ & \multicolumn{2}{|c|}{$\begin{array}{l}\text { Weight category \% (N) } \\
\text { Under/Normal } \\
\text { weight }\end{array}$} & $\begin{array}{l}\text { Total } \\
\text { Overweight/ } \\
\text { Obese }\end{array}$ & p-value \\
& & $75.9 \%(22)$ & $24.1 \%(7)$ & $100 \%(29)$ & 0.571 \\
\hline Not Hispanic & Head Start & $68.4 \%(13)$ & $31.6 \%(6)$ & $100 \%(19)$ & \\
or Latino & Private & $72.9 \%(35)$ & $27.1 \%(13)$ & $100 \%(48)$ & \\
& Total & $50 \%(12)$ & $50 \%(12)$ & $100 \%(24)$ & $0.071^{\#}$ \\
\hline Hispanic or & Head Start & $76.2 \%(16)$ & $23.8 \%(5)$ & $100 \%(21)$ & \\
Latino & Private & $62.2 \%(28)$ & $37.8 \%(17)$ & $100 \%(45)$ & \\
& Total & $64.2 \%(34)$ & $25.8 \%(19)$ & $100 \%(53)$ & 0.394 \\
\hline Total & Head Start & $72.5 \%(29)$ & $27.5 \%(11)$ & $100 \%(40)$ & \\
& Private & $67.7 \%(63)$ & $32.3 \%(30)$ & $100 \%(93)$ & \\
& Total & $6700)$ & & & \\
\hline
\end{tabular}

${ }^{\text {\# }}$ Pearson chi-square test marginally significant.

\section{Discussion}

Even though preschool children's participation at some type of nonparental care is significant, there are only a few studies exploring the relationship between childcare setting and the child's body weight and the results are non conclusive. The preschool children in our study spent on average 20 hours per week under some type of nonparental care arrangement. The U.S. Census Bureau reported that in Spring 2011 preschool children under 5 years of age with employed mothers spent an average of 26 hours per week in childcare while those with non-employed mothers spent an average of 21 hours per week in childcare, any care excluding parental care. ${ }^{35}$

Our study could not find any association between the type of childcare or the number of hours spent under parental or nonparental care per week and the child's body 
weight status. Zahir et al ${ }^{36}$ used data from a longitudinal cohort of low-income Latino children and found no association between participating in any type of childcare at age 4 , number of hours per week in childcare and the risk for overweight or obesity. Some studies have found a protective effect of being under parental care when compared to other nonparental care settings, while others have found an increased likelihood of being overweight or obese for children under parental care, although most studies either found mixed results or no association between the type of childcare and the risk for overweight and obesity. ${ }^{25}$ It has been suggested that the likelihood of childhood obesity declines with participation in center based care, including Head Start, due to the increased levels of health screening offered and the availability of healthier food choices when compared to less formal care, thus improving nutrition. ${ }^{23,37}$

The marginal significance we found for Hispanic or Latino children in Head Start being more likely to be overweight or obese than those in private childcare centers is contrary to what we expected. One other study found the opposite, with a protective effect of being in Head Start in Latino children's risk for obesity when compared to parental care. ${ }^{21}$ Other studies that evaluated the effect of Head Start on weight and nutrition found that Head Start participation increased healthy eating habits ${ }^{38}$ and reduced the prevalence of obesity. ${ }^{39,40}$ Head Start participates in the United Stated Department of Agriculture (USDA) Child and Adult Care Food Program (CACFP) to receive reimbursement for meals and snacks served, but to be eligible the childcare centers must abide by CACFP nutrition standards. ${ }^{41}$ A study by Whitaker et al ${ }^{42}$ found that most Head Start programs reported practices related to nutrition and physical activity that exceed the federal program performance standards. On the other hand, a review of 
U.S. state regulations for non-CACFP regulated childcare centers and family childcare homes found that most states had few nutrition and physical activity regulations related to obesity, with considerable variation among states. ${ }^{43}$ It has been suggested that states can improve their regulations by requiring all childcare centers to comply with CACFP standards. ${ }^{44}$ In speculating an explanation for our finding, Latino families participating in Head Start may have a particular family structure and different eating habits when at home, which affected their risk for obesity. A study by Lee et al $^{38}$ including a lowincome sample of preschool aged children described that Head Start participants tended to come from more disadvantaged backgrounds, their mothers were more likely to be younger, unmarried at birth, unemployed, foreign-born, less-educated, poor and receiving welfare benefits when compared to children in other center-based care settings. This, combined with the perception found among Latino mothers that their children are thinner than they actually are and the cultural belief that "chubby" children are healthier than skinny ones, ${ }^{45}$ may significantly influence their eating habits when not in the childcare center. Family eating behaviors are not accounted for in this study. It is also possible that Head Start staff empathizes with the Latino children and imposes fewer restrictions on the amount of food the children are allowed to consume.

Some strengths of this study include the use of a researcher-administered questionnaire, allowing the researcher to probe the responder, reducing unreliable answers or no response given, as well as the control for socioeconomic status by including only preschool children from low-income families receiving WIC benefits. Socioeconomic status has been shown to have an important inverse association with the risk for overweight and obesity in children. ${ }^{46,47}$ It has been suggested that low 
socioeconomic status plays a more significant role in the risk for obesity than race and ethnicity. $^{48}$

One of the limitations of our study is the small sample size. If we had included some of the potential confounding factors that were collected through the questionnaire we would loose power and the results would not be reliable. We also did not account for unmeasured or unobservable reasons why a child is placed in one or another type of childcare and the differences of care provided in each. Different family circumstances that lead parents to place their child in a certain type of childcare may also have a potential influence in the way this child is cared for and fed when at home. The variation found in regulations for childcare settings combined to the lack of studies evaluating if the existing regulations are being followed makes designing studies looking at the relationship between childcare participation and the risk of obesity in preschool children challenging. Our study may also be subject to reporting bias resulting from a possible inaccuracy in parent-reported childcare arrangement.

Having a better understanding of the influence of childcare on the risk of obesity is very important in guiding future interventions. So far there are no conclusive results but childcare is known to have a potential influence over a child's eating habits. Studies with larger sample sizes, taking into consideration potential confounding factors such as environmental factors, parental eating and feeding behaviors, race and ethnicity are needed to clarify the relationship, if any, of childcare settings and body weight status. Studies evaluating if the existing policies in place regulating the different types of childcare are being followed and reinforced are also needed to better understand what changes according to the type of childcare the preschooler participates on. Considering 
the substantial amount of time preschool children spend in center-based settings it is important to propose obesity prevention interventions to take place at both private and Head Start care centers. Studying the effect of such interventions may help elucidate what works to protect the future heath of overweight and obese preschool children.

\section{References}

1. Hales CM, Carroll MD, Fryar CD, Ogden CL. Prevalence of obesity among adults and youth: Unites States, 2015-2016. NCHS data brief, no 288. Hyattsville, MD: National Center for Health Statistics. 2017.

2. Simmonds M, Llewellyn A, Owen CG, Woolacott N. Predicting adult obesity from childhood obesity: A systematic review and meta-analysis. Obes rev. 2016;17(2):95-107.

3. Birch LL, Ventura AK. Preventing childhood obesity: What works? Int J Obes. 2009;33(S1):S74-S81.

4. Birch LL. The role of experience in children's food acceptance patterns. $J$ Am Diet Assoc. 1987;87(9 Suppl):S36-S40.

5. Birch LL, Fisher JO. Development of eating behaviors among children and adolescents. Pediatrics. 1998;101(Suppl):539-549.

6. Harris G. Development of taste and food preferences in children. Curr Opin Clin Nutr Metab Care. 2008;11(3):315-319.

7. Cooke L. The importance of exposure for healthy eating in childhood: A review. $J$ Hum Nutr Diet. 2007;20(4):294-301.

8. Skinner JD, Carruth BR, Wendy B, Ziegler PJ. Children's food preferences: A longitudinal analysis. J Am Diet Assoc. 2002;102(11):1638-1647.

9. Birch LL, Davison KK. Family environmental factors influencing the developing behavioral controls of food intake and childhood overweight. Pediatr Clin North Am. 2001;48(4):893-907.

10. Erinosho TO, Hales DP, McWilliams CP, Emunah J, Ward DS. Nutrition policies at child-care centers and impact on role modeling of healthy eating behaviors of caregivers. J Acad Nutr Diet. 2012;112(1):119-124. 
11. Stang J, Loth KA. Parenting style and child feeding practices: Potential mitigating factors in the etiology of childhood obesity. J Am Diet Assoc. 2011;111(9):1301-1305.

12. Thompson ME. Parental feeding and childhood obesity in preschool-age children: Recent findings from the literature. Issues Compr Pediatr Nurs. 2010;33(4):205-267.

13. Hughes SO, Power TG, Orlet Fisher J, Mueller S, Nicklas TA. Revisiting a neglected construct: Parenting styles in a child-feeding context. Appetite. 2005;44(1):83-92.

14. Acharya K, Feese M, Franklin F, Kabagambe EK. Body mass index and dietary intake among Head Start children and caregivers. J Am Diet Assoc. 2011;11(9):13141321.

15. Larson N, Ward DS, Neelon SB, Story M. What role can child-care settings play in obesity prevention? A review of the evidence and call for research efforts. $J$ Am Diet Assoc. 2011;111(9):1343-1362.

16. Story M, Kaphingst KM, French S. The role of child care settings in obesity prevention. Future Child. 2006;16(1):143-168.

17. Ward DS, Vaughn A, Story M. Expert and stakeholder consensus on priorities for obesity prevention research in early care and education settings. Child Obes. 2013;9(2):116-124.

18. U.S. Department of Education, National Center for Education Statistics. Percentage of the population 3 to 34 years old enrolled in school, by sex, race/ethnicity, and age group: Selected years, 1980 through 2015. Available at https://nces.ed.gov/programs/digest/d16/tables/dt16_103.10.asp?current=yes. Published July 2016. Accessed January 23, 2018.

19. Corcoran L, Steinley K. Early childhood program participation, from the National Household Education Surveys Program of 2016 (NCES 2017-101). Washington, DC: National Center for Education Statistics, Institute of Education Sciences, U.S. Department of Education. 2017. http://nces.ed.gov/pubsearch. Accessed January 23, 2018.

20. Office of Head Start. Head Start program facts: Fiscal year 2016. U.S. Department of Health and Human Services, Administration for Children and Families Web site. https://eclkc.ohs.acf.hhs.gov/about-us/article/head-start-program-facts-fiscal-year-2016. Published October 31, 2017. Accessed January 31, 2018.

21. Maher EJ, Li G, Carter L, Johnson DB. Preschool child care participation and obesity at the start of kindergarten. Pediatrics. 2008;122(2):322-330.

22. McGrady ME, Mitchell MJ, Theodore SN, Sersion B, Holtzapple E. Preschool participation and BMI at kindergarten entry: The case for early behavioral intervention. $J$ Obes. 2010:1-6. doi:10.1155/2010/360407. 
23. Mandal B, Powell LM. Child care choices, food intake, and children's obesity status in the United States. Econ Hum Biol. 2014;14:50-61.

24. Lumeng JC, Gannon K, Appugliese D, Cabral HJ, Zuckerman B. Preschool child care and risk of overweight in 6- to 12-year-old children. Int J Obes. 2005;29:60-66.

25. Swyden K, Sisson SB, Lora K, Castle S, Copeland KA. Association of childcare arrangement with overweight and obesity in preschool-aged children: A narrative review of literature. Int $J$ Obes. 2017;41(1):1-12.

26. Alberdi G, McNamara AE, Lindsay KL, et al. The association between childcare and risk of childhood overweight and obesity in children aged 5 years and under: A systematic review. Eur J Pediatr. 2016;175(10):1277-1294.

27. Indicators - FL-WISE participation. Florida WIC - Bureau of WIC Program Services Web site.

https://floridahealth.sharepoint.com/sites/COMMUNITYHEALTH/WIC/Intranet/Indicat ors/Flwise/participation.html. Updated 2017. Accessed February 16, 2018.

28. Centers for Disease Control and Prevention (CDC). About BMI for children and teens.

http://www.cdc.gov/healthyweight/assessing/bmi/childrens_BMI/about_childrens_BMI.h tml. Updated 2015. Accessed February 6, 2018.

29. Crespi CM, Alfonso VH, Whaley SE, Wang MC. Validity of child anthropometric measurements in the Special Supplemental Nutrition Program for Women, Infants, and Children. Pediatr Res. 2012;71(3):286-292.

30. Nelson JA, Carpenter K, Chiasson MA. Diet, activity, and overweight among preschool-age children enrolled in the special supplemental nutrition program for women, infants, and children (WIC). Prev Chronic Dis. 2006;3(2). Available from: http://www.cdc.gov/pcd/issues/2006/apr/05_0135.htm.

31. University of California Department of Nutrition. Healthy Kids Checklist. Healthy Kids Web site. http://healthykids.ucdavis.edu. Accessed October 20, 2017.

32. Centers for Disease Control and Prevention (CDC). National Health and Nutrition Examination Survey. Diet, Behavior and Nutrition Questionnaire Web site. http://www.cdc.gov/nchs/data/nhanes/nhanes_13_14/DBQ_H.pdf. Published January 15, 2013. Updated 2013. Accessed October 20, 2017.

33. Mamedova S, Redford J. Early childhood program participation, from the National Household Education Surveys Program of 2012. Washington, DC: National Center for Education Statistics, Institute of Education Sciences, U.S. Department of Education. 2013;NCES 2013-029. http://nces.ed.gov/pubsearch. Accessed July 9, 2017. 
34. The White House. Revisions to the standards for the classification of federal data on race and ethnicity. Office of Management and Budget Web site.

https://www.whitehouse.gov/wp-content/uploads/2017/11/Revisions-to-the-Standardsfor-the-Classification-of-Federal-Data-on-Race-and-Ethnicity-October30-1997.pdf. Published October 30, 1997. Accessed March 20, 2018.

35. Laughlin L. Who's minding the kids? Child care arrangements: Spring 2011. Current population reports, P70-135. U.S. Census Bureau, Washington, DC. 2013.

https://www2.census.gov/library/publications/2013/demo/p70-135.pdf. Accessed January $30,2018$.

36. Zahir N, Heyman MB, Wojcicki JM. No association between childcare and obesity at age 4 in low-income Latino children. Pediatr Obes. 2013;8(2):e24-e28.

37. Belfield CR, Kelly IR. Early education and health outcomes of a 2001 U.S. birth cohort. Econ Hum Biol. 2013;11(3):310-325.

38. Lee R, Zhai F, Han W, Brooks-Gunn J, Waldfogel J. Head Start and children's nutrition, weight, and health care receipt. Early Child Res Q. 2013;28(4):723-733.

39. Frisvold DE, Lumeng JC. Can increasing the daily duration of Head Start reduce childhood obesity? J Hum Resour. 2011;46(2):373-402.

40. Lumeng JC, Kaciroti N, Sturza J, et al. Changes in body mass index associated with Head Start participation. Pediatrics. 2015;135(2):e449-e456.

41. Child and adult care food program (CACFP) child day care centers. US Department of Agriculture, Food and Nutrition Service Web site. http://www.fns.usda.gov/cacfp/child-day-care-centers. Updated 9/7/2017. Accessed January $31,2018$.

42. Whitaker RC, Gooze RA, Hughes CC, Finkelstein DM. A national survey of obesity prevention practices in Head Start. Arch Pediatr Adolesc Med. 2009;163(12):1144-1150.

43. Benjamin S, Slining M, Walker E, Cradock A, Gillman M. Obesity prevention in child care: A review of U.S. state regulations. BMC Public Health. 2008;8(188). doi:10.1186/1471-2458-8-188.

44. Benjamin Neelon SE, Briley ME. Position of the American Dietetic Association: Benchmarks for nutrition in child care. J Am Diet Assoc. 2011;111(4):607-615.

45. Chaparro MP, Langellier BA, Kim LP, Whaley SE. Predictors of accurate maternal perception of their preschool child's weight status among Hispanic WIC participants. Obesity. 2011;19(10):2026-2030.

46. Shrewsbury V, Wardle J. Socioeconomic status and adiposity in childhood: A systematic review of cross-sectional studies 1990-2005. Obesity. 2008;16:275-284. 
47. Jones-Smith JC, Dieckmann MG, Gottlieb L, Chow J, Fernald LC. Socioeconomic status and trajectory of overweight from birth to mid-childhood: The early childhood longitudinal study-birth cohort. PLoS One. 2014;9(6):e100181.

doi:10.1371/journal.pone.0100181

48. Rogers R. The relationship between childhood obesity, low socioeconomic status, and race/ethnicity: Lessons from Massachusetts. Child Obes. 2015;11(6):691-695. 


\section{CHAPTER VI: SUMMARY AND CONCLUSIONS}

\section{The relationship of eating frequency and body weight status}

Most children consumed 3 meals (97.5\%) and 2 to 3 snacks per day $(33.0 \%$ and $37.1 \%$ respectively). The mean number of snacks consumed per day on the weekend was significantly higher than mean number of snacks on weekdays $(2.78 \pm 1.20$ vs. $2.67 \pm$ 1.08 respectively, $\mathrm{p}=0.001)$. The number of eating episodes per day did not present a significant correlation with body weight status. The fact that most children included in this study had between 5 and 6 eating episodes on a day may not have allowed the statistical tests performed to detect any significant difference. Our results suggest that the young age of participants may be an advantage in terms that they still engage in small and frequent eating occasions.

\section{The role of snack quality on body weight status}

The most frequently consumed snacks were milk, 100\% fruit juice and fresh fruits. Normal/under weight children consumed WIC approved cereals and breads more often than overweight/obese children. This indicates a possible protective effect of WIC foods on a child's diet. There was no significant difference in the frequency of intake of more nutritious or nutrient-poor snacks by body weight status. Snack items in the more nutritious group were the ones most often consumed by $66 \%$ of the preschool children included in this study. Nevertheless, sweet and savory snacks were consumed often, on average 3 to 4 times per week, with a preference for savory snacks over sweet snacks, independent of weight status. 


\section{The impact of known risk factors for childhood obesity on body weight status}

The intake of sugar-sweetened beverages (SSB) was significantly higher in overweight/obese children when compared to normal/underweight. Meal skipping was prevalent, with $30 \%$ of the children skipping at least one meal per week, independent of weight status. Forty five percent of the participating children frequently consumed snacks while watching TV. Children who ate snacks frequently while watching TV had a higher intake of SSB, a lower intake of vegetables, and spent more time in front of a screen compared to those who consumed snacks infrequently while watching TV. On average, the children spent 2.3 hours in front of a screen and 38 minutes being physically active on a day. The time spent exercising was significantly greater in normal/under weight children when compared to the overweight/obese group. Mean birth weight for overweight/obese children was significantly higher. Multivariate analyses revealed a significant positive association between the intake of SSB and birth weight, and negative association between physical activity and the risk of overweight and obesity. NonHispanic or Latino and Black or African American preschool children included in this study presented behaviors that may place them at an increased risk of obesity.

\section{The effect of different childcare arrangements on body weight status}

The preschool children in our study spent on average 20 hours per week under some type of nonparental care arrangement. There was no association between the type of childcare or the number of hours spent under parental or nonparental care per week and the child's body weight status. 


\section{CHAPTER VII - STRENGTHS AND LIMITATIONS}

This study included a population that is at increased risk for overweight and obesity and added to the limited body of research with WIC participating preschool children. One of the strengths of this study was the use of a researcher-administered questionnaire, providing virtually no unanswered questions and allowing the researcher to probe as necessary. Another strength is the reliance on measured and not self-reported anthropometric data. In addition, the inclusion of a sample consisted of WIC participants granted control for socioeconomic-status. Lastly, to our knowledge, this is the first study to explore the relationship of eating frequency and snack quality, in combination with obesity risk factors, with body weight status of children 3 to under 5 years from lower socioeconomic status including different racial and ethnic minority groups.

Possibly the greatest limitation of this study was the small sample size for the amount of variables included in the analyses. The limited amount of time, limited resources to compensate participants, and only one researcher who had access to the WIC clinics to collect data were some of the constraints that did not allow us to have a larger sample size. In some cases where there was no statistical significance, a trend that could potentially be significant on a larger sample size was found. Secondly, we did not collect information as to how long the subjects have been participating in the WIC program, which could make a difference considering the amount of nutrition education they have already received. Having collected poverty level we could have explored differences depending on how poor the families were. Another limitation is the use of a food frequency questionnaire, which did not allow to access portion sizes. This was a cross- 
sectional study and we did not examine energy and nutrient intake. Additionally, potential biases due to underreporting or over reporting of food and beverage intake may be present. Furthermore, this study included a convenience sample and results are not generalizable. Despite its many limitations, this study provides valuable data that can aid in better understanding the role of snacking in childhood obesity. 


\section{CHAPTER VIII - FUTURE RESEARCH}

The relationship between eating frequency and body weight status in young children needs to be studied further. Randomized controlled trials would be beneficial in establishing a causal relationship between eating frequency and body weight in children, but they are not practical. Healthy snacking between the three main meals may potentially improve the quality of food intake, but more research is needed to understand the role of snacking on weight of preschool children. The use of a more uniform snack foods and beverages classification system is necessary to increase comparability of the studies. This would also facilitate the design for new studies.

Larger studies including a racially and ethnically diverse sample of preschool children from low socioeconomic status families could help elucidate the results from our study. There is a need for more longitudinal studies accessing the risk factors for childhood overweight and obesity, mainly in young children. By gaining a better understanding of this complex problem we can propose interventions tailored to specific groups with a better chance of success. Obesity prevention interventions may be particularly useful when initiated early in life, making WIC a potential environment for effective intervention programs to help reduce overweight and obesity rates in children. Additional research is needed on the effectiveness of different obesity prevention interventions with WIC clients. Longitudinal studies including WIC preschool children to evaluate the changes that happen in their dietary intake after they turn 5 years of age and become ineligible to continue receiving WIC benefits would provide extremely valuable data. 
APPENDIX 1 - Recruitment flyer 


\section{MEAL FREQUENCY AND THE ROLE OF SNACKING ON WEIGHT OF MINORITY PRESCHOOL CHILDREN}

You are cordially invited to participate in a study conducted by Andrea Charvet, Nutrition Educator at WIC and a PhD candidate at Florida International University, in conjunction with Florida International University, Department of Dietetics and Nutrition.

Criteria to enroll:

- Be the authorized representative of a child between 3 and 5 years of age, currently enrolled at one of the Broward County WIC clinics, with no medical condition.

- You must agree to answer a questionnaire about your child's eating habits, physical activity and day care participation.

- You must agree that the researcher accesses your information on the WIC data system.

Results from this study will help us better understand the risk factors for childhood overweight and obesity. This will allow us to plan interventions aimed at increasing the number of WIC participating children with a healthy body weight, improving the health of our children.

The entire process takes place in a single contact, which should take about 40 minutes of your time. The researcher will clarify any questions you may have about the study.

\section{PARTICIPATION IN THIS STUDY IS VOLUNTARY AND WILL NOT IMPACT YOUR WIC ELIGIBILITY.}

You will receive a $\$ 10$ Publix gift card to compensate for your time spent to provide us the necessary information.

For additional information please contact Andrea Charvet at achar065@fiu.edu or 786$908-4615$ 
APPENDIX 2 - IRB Approved consent forms 


\begin{tabular}{|l|l|}
\hline FIU IRB Approval: & $10 / 10 / 2015$ \\
\hline FIU IRB Expiration: & $10 / 10 / 2016$ \\
\hline FIU IRB Number: & IRB-15-0369 \\
\hline
\end{tabular}

Version 1 of 1

\title{
FIU] UNIVERSITY
}

\author{
PARENTAL CONSENT TO PARTICIPATE IN A RESEARCH STUDY
}

Meal Frequency and the Role of Snacking on Weight of Minority Preschool Children

\section{PURPOSE OF THE STUDY}

You are being asked to give your permission for your child to be in a research study. The purpose of this study is to examine the influence of the number of meals and the types of snacks consumed on the weight of preschool-aged children participating in the Broward County WIC Program. We will also be exploring the importance other risk factors for childhood obesity in this group of participants.

\section{NUMBER OF STUDY PARTICIPANTS}

If you agree to allow your child to participate in this study, he/she will be one of 180 people in this research study.

\section{DURATION OF THE STUDY}

Your child's participation will require 40 minutes of your time.

\section{PROCEDURES}

If your child participates in this study, we won't ask your child to do anything. You will be requested to:

1. Participate in an interview with the researcher in which you will be asked questions related to the eating, sleeping and exercising habits of your child. This will be a one-time contact.

2. Authorize the researcher to access your child's information in the WIC data system after the interview is completed.

\section{RISKS AND/OR DISCOMFORTS}

There are no risks associated with your child's participation in this study. You may feel pressured to participate in the study in fear that it may interfere with your eligibility to receive WIC benefits. Please be reassured that participation is voluntary and will not impact your WIC eligibility.

\section{BENEFITS}

Results from this study will help us understand better the risk factors for overweight and obesity in preschool-aged children participating in the WIC program. This way we can develop recommendations to help increase the number of WIC children at a healthy weight, improving the health of our children. There are no anticipated direct benefits to the participants.

\section{CONFIDENTIALITY}

The records of this study will be kept private and will be protected to the fullest extent provided by law. In any sort of report we might publish, we will not include any information that will make it possible to identify your child as a subject. Research records will be stored securely and only the researcher team will have access to the records. However, authorized University or other agents who will be bound by the same provisions of confidentiality may review your child's records for audit purposes. 


\begin{tabular}{|l|l|}
\hline FIU IRB Approval: & $10 / 10 / 2015$ \\
\hline FIU IRB Expiration: & $10 / 10 / 2016$ \\
\hline FIU IRB Number: & IRB-15-0369 \\
\hline
\end{tabular}

Version 1 of 1

\section{COMPENSATION \& COSTS}

You will receive a payment of $\$ 10$ in the format of a Publix gift card for your child's participation. You will not be responsible for any costs for your child to participate in this study.

\section{RIGHT TO DECLINE OR WITHDRAW}

Your child's participation in this study is voluntary. Your child is free to participate in the study or withdraw his/her consent at any time during the study. Your child's withdrawal or lack of participation will not affect any benefits to which he/she is otherwise entitled. The investigator reserves the right to remove your child from the study without your consent at such time that they feel it is in the best interest.

\section{RESEARCHER CONTACT INFORMATION}

If you have any questions about the purpose, procedures, or any other issues relating to this research study you may contact Andrea Charvet, (786) 908-4615, achar065@fiu.edu or Dr. Fatma G. Huffman, (305) 348-2878, huffmanf@fiu.edu.

\section{IRB CONTACT INFORMATION}

If you want to talk with someone independent of the research team for questions, concerns, or complaints about the research; questions about your rights; to obtain information; or to offer input, you can contact the Florida Department of Health Institutional Review Board (IRB). An IRB is a group of people who review research to ensure participants are protected and the research is conducted in an ethical way. You can contact the IRB at: 850-245-4585.

If you would like to talk with someone about your child's rights of being a subject in this research study or about ethical issues with this research study, you may also contact the FIU Office of Research Integrity by phone at 305-348-2494 or by email at ori@fiu.edu.

\section{PARTICIPANT AGREEMENT}

I have read the information in this consent form and agree to allow my child to participate in this study. I authorize the researcher to access my child's information in the WIC data system. I have had a chance to ask any questions I have about this study, and they have been answered for me. I understand that I will be given a copy of this form for my records.

Signature of Parent/Guardian

Printed Name of Parent/ Guardian

Printed Name of Child Participant

$\overline{\text { Signature of Person Obtaining Consent }}$
Date

Date

Page 2 of 2 


\section{\begin{tabular}{|l|l|}
\hline FIU IRB Approval: & $10 / 10 / 2015$ \\
\hline FUU IRB Expration: & $10 / 10 / 2016$ \\
\hline
\end{tabular} FIU IRB Expiration: $10 / 10 / 2016$

FIU IRB Number: 1 IRB-15-0369 FLORIDA
INTERNATIONAL
UNIVERSITY \\ Version 1 of 1}

\section{CONSENTIMIENTO DE LOS PADRES PARA PARTICIPAR EN UN ESTUDIO DE INVESTIGACIÓN}

Frecuencia de Comidas y el Papel de Snacking en el Peso de la Minoría de Preescolares

\section{PROPÓSITO DEL ESTUDIO}

Se le pide dar su permiso para que su hijo participe en un estudio de investigación. El propósito de este estudio es examinar la influencia del número de comidas y los tipos de snacks que se consumen en el peso de los niños en edad preescolar que participan en el Programa WIC del Condado de Broward. También vamos a explorar la importancia de otros factores de riesgo de la obesidad infantil en este grupo de participantes.

\section{NÚMERO DE PARTICIPANTES DE ESTUDIO}

Si está de acuerdo para permitir que su hijo participe en este estudio, él / ella será una de 180 las personas en este estudio de investigación.

\section{DURACIÓN DEL ESTUDIO}

La participación de su hijo requerirá 40 minutos de su tiempo.

\section{PROCEDIMIENTOS}

Si su hijo participa en este estudio, no vamos a pedirle a su hijo hacer nada. Se le pedirá que:

1. Participar en una entrevista con el investigador en el que se le harán preguntas relacionadas con el comer, dormir y ejercicio hábitos de su hijo. Esto se hará una sola vez.

2. Autorizar al investigador a acceder a la información de su hijo en el sistema de datos de WIC una vez finalizada la entrevista.

\section{RIESGOS Y / O MOLESTIAS}

No existen riesgos asociados con la participación de su hijo en este estudio. Es posible que se sienta presionado a participar en el estudio con el temor de que pueda interferir con su elegibilidad para recibir beneficios de WIC. Por favor, este seguro de que la participación es voluntaria y no afectará su elegibilidad WIC.

\section{BENEFICIOS}

Los resultados de este estudio nos ayudarán a entender mejor los factores de riesgo de sobrepeso y obesidad en niños en edad preescolar que participan en el programa WIC. De esta manera podemos elaborar recomendaciones para ayudar a aumentar el número de niños de WIC en un peso saludable, mejorar la salud de nuestros hijos. No hay beneficios directos anticipados para los participantes.

\section{CONFIDENCIALIDAD}

Los registros de este estudio se mantendrán en privado y estarán protegidos en toda la medida prevista por la ley. En cualquier tipo de informe que podríamos publicar, no vamos a incluir ninguna información que permita identificar a su hijo. Registros de la investigación serán almacenados de forma segura y sólo el equipo de investigación tendrá acceso a los registros. Sin embargo, personal autorizado de la Universidad u otros agentes que estarán vinculados por las mismas disposiciones de confidencialidad puede revisar los registros de su hijo para fines de auditoría. 


\begin{tabular}{|l|l|}
\hline FIU IRB Approval: & $10 / 10 / 2015$ \\
\hline FIU IRB Expiration: & $10 / 10 / 2016$ \\
\hline FIU IRB Number: & IRB-15-0369 \\
\hline
\end{tabular}

Version 1 of 1

\section{COMPENSACIÓN Y COSTOS}

Usted recibirá un pago de $\$ 10$ en forma de una tarjeta de regalo de Publix por la participación de su hijo. Usted no será responsable de los gastos por la participación de su hijo en este estudio.

\section{DERECHO A RECHAZAR O RETIRAR}

La participación de su hijo en este estudio es voluntaria. Su hijo/hija es libre de participar en el estudio o retirar el consentimiento en cualquier momento durante el estudio. La retiro de su hijo/hija o la falta de participación no afectará a ningún beneficio al cual él / ella tiene derecho de otra manera. El investigador se reserva el derecho de retirar a su hijo/hija del estudio sin su consentimiento en el momento en que ellos sienten que es en el mejor interés.

\section{INFORMACIÓN INVESTIGADOR DE CONTACTO}

Si usted tiene alguna pregunta sobre el propósito, procedimientos o cualquier otra cuestión relacionada con este estudio de investigación puede comunicarse con Andrea Charvet, (786) 908 a 4615, achar065@fiu.edu o el Dr. Fatma G. Huffman, (305) 348 -2878, huffmanf@fiu.edu.

\section{IRB INFORMACIÓN DE CONTACTO}

Si quieres hablar con alguien independiente del equipo de investigación para las preguntas, inquietudes o quejas sobre la investigación; preguntas sobre sus derechos; para obtener información; u ofrecer su opinion, puede ponerse en contacto con el Departamento de la Junta de Revisión Institucional de Salud de Florida (IRB). IRB es un grupo de personas que revisan la investigación para asegurar que los participantes están protegidos y la investigación se lleva a cabo de una manera ética. Puede ponerse en contacto con el IRB en: 850-245-4585.

Si a usted le gustaría hablar con alguien acerca de los derechos de ser un participante en este estudio de investigación o sobre cuestiones éticas con este estudio de investigación de su hijo, también puede comunicarse con la Oficina de Integridad en la Investigación en FIU por teléfono al 305-348-2494 o por correo electrónico en ori@fiu.edu.

ACUERDO DEL PARTICIPANTE

He leído la información de este formulario de consentimiento y estoy de acuerdo con permitir que mi hijo/hija participe en este estudio. Autorizo al investigador a acceder a la información de mi hijo/hija en el sistema de datos de WIC. He tenido la oportunidad de formular todas las preguntas que tengo acerca de este estudio, y que han sido contestadas por mí. Entiendo que se me dará una copia de esta forma para mis archivos.

Impreso Nombre del Padre/Madre/Guardián

Impreso Nombre del Niño Participante

$\overline{\text { Firma de la persona que obtiene el consentimiento }}$ 
APPENDIX 3 - Researcher-administered questionnaire 
We want to ask you a few questions about the child you brought with you today for WIC services. The information you share will help us improve services. THANK YOU!

1. What is your relationship to this child? $\quad \square_{1}$ Mother $\quad \square_{2}$ Father $\quad \square_{3}$ Other

2. Do you participate on the daily care for this child?

$\square_{1}$ Yes $\quad \square_{2}$ No

If NO, please stop filling out this survey. Thank you for your interest.

3. How many cups (about $80 z$ ) of the following drinks does your child usually drink each day or each week? Write 0 (zero) if your child never drinks it.

\begin{tabular}{|l|l|l|}
\hline \multicolumn{2}{|c|}{ Number of cups } \\
\hline a. Plain milk (include milk used on cereal) & Each day & \multicolumn{1}{c|}{ OR week } \\
\hline b. Flavored milk (such as chocolate or strawberry) or Pediasure & & \\
\hline c. Soy or other milk substitute & & \\
\hline d. Fruit drink (such as Sunny D, lemonade or Kool-Aid) & & \\
\hline e. Fruit juice (no sugar added or 100\% fruit juice) & & \\
\hline f. Flavored sweetened iced tea (such as Arizona teas) & & \\
\hline g. Sports Drinks (such as Gatorade or Powerade) & & \\
\hline h. Soda (such as Coke or Sprite) & & \\
\hline i. Water & & \\
\hline
\end{tabular}

4. What kind of milk does your child drink most often?
$\square$ Whole milk
$\square_{3} 1 \%$ milk
$\square_{2} 2 \%$ milk
$\square_{4}$ Fat free or skim milk
$\square_{5}$ Soy or other milk substitute
$\square_{6}$ Other What kind?

5. How many times a day does your child eat on average on a weekday?

Number of meals (breakfast, lunch, dinner):

Number of snacks (any foods or beverages except water outside of the 3 meals above):

6. How many times a day does your child eat on average on a weekend?

Number of meals (breakfast, lunch, dinner):

Number of snacks (any foods or beverages except water outside of the 3 meals above):

7. How many times a week does your child skip meals?

Which meal is skipped (mark all that apply): $\quad \square_{1}$ Breakfast $\quad \square_{2}$ Lunch $\quad \square_{3}$ Dinner

8. How many times are your child's meals cooked from scratch each day or week? each day OR each week

9. How many times does your child usually eat fast food or pizza each day or week? each day OR each week

10. How many times does your child eat foods prepared at home each day or week? each day OR each week

11. How many times does your child eat foods prepared at daycare/preschool each day or week? each day

OR each week

12. How many times does your child eat foods prepared away from home or daycare each day or week? (Include take out, drive thru and delivery food eaten at home) each day OR each week 
13. How many servings of fruit (not including juice) does your child usually eat each day or week? each day

OR each week

14. How many servings of vegetables (not including French fries) does your child usually eat each day or week? each day each week

15. How many times a week does your child eat the following snacks:

\begin{tabular}{|c|c|c|c|c|c|}
\hline $\mathrm{Chips}_{6}$ & $\square$ Less than 1 & $\square 1-2$ times & $\square$ 3-4 times & $\square$ 5-6 times & $\square 7$ or more \\
\hline Chocolate/Candy bars $_{9}$ & $\square$ Less than 1 & $\square 1-2$ times & $\square$ 3-4 times & $\square$ 5-6 times & $\square 7$ or more \\
\hline Cookies $_{5}$ & $\square$ Less than 1 & $\square 1-2$ times & $\square$ 3-4 times & $\square 5-6$ times & $\square 7$ or more \\
\hline Donuts $_{5}$ & $\square$ Less than 1 & $\square 1-2$ times & $\square$ 3-4 times & $\square 5-6$ times & $\square 7$ or more \\
\hline French fries ${ }_{10}$ & $\square$ Less than 1 & $\square 1-2$ times & $\square$ 3-4 times & $\square$ 5-6 times & $\square 7$ or mor \\
\hline Ice cream $_{5}$ & $\square$ Less than 1 & $\square 1-2$ times & $\square$ 3-4 times & $\square$ 5-6 times & $\square 7$ or more \\
\hline Puddings, flan $_{5}$ & $\square$ Less than 1 & $\square 1-2$ times & $\square$ 3-4 times & $\square$ 5-6 times & $\square 7$ or more \\
\hline Muffins, cakes or cupcakes ${ }_{5}$ & $\square$ Less than 1 & $\square 1-2$ times & $\square$ 3-4 times & $\square$ 5-6 times & $\square 7$ or more \\
\hline Animal or Graham crackers ${ }_{5}$ & $\square$ Less than 1 & $\square 1-2$ times & $\square$ 3-4 times & $\square$ 5-6 times & $\square 7$ or more \\
\hline Pastries or sweet rolls & $\square$ Less than 1 & $\square 1-2$ times & $\square$ 3-4 times & $\square$ 5-6 times & $\square 7$ or more \\
\hline Pizza/Hot Pockets $_{10}$ & $\square$ Less than 1 & $\square 1-2$ times & $\square$ 3-4 times & $\square$ 5-6 times & $\square 7$ or more \\
\hline Popcorn $_{6}$ & $\square$ Less than 1 & $\square 1-2$ times & $\square$ 3-4 times & $\square 5-6$ times & $\square 7$ or more \\
\hline Fresh fruits ${ }_{4}$ & $\square$ Less than 1 & $\square 1-2$ times & $\square$ 3-4 times & $\square$ 5-6 times & $\square 7$ or more \\
\hline Canned fruits $_{4}$ & $\square$ Less than 1 & $\square 1-2$ times & $\square$ 3-4 times & $\square$ 5-6 times & $\square 7$ or more \\
\hline Dried Fruits ${ }_{4}$ & $\square$ Less than 1 & $\square 1-2$ times & $\square$ 3-4 times & $\square$ 5-6 times & $\square 7$ or more \\
\hline Fruit juice (100\% fruit) $)_{1}$ & $\square$ Less than 1 & $\square 1-2$ times & $\square$ 3-4 times & $\square$ 5-6 times & $\square 7$ or more \\
\hline Vegetables $_{4}$ & $\square$ Less than 1 & $\square 1-2$ times & $\square$ 3-4 times & $\square$ 5-6 times & $\square 7$ or more \\
\hline Cheese $_{3}$ & $\square$ Less than 1 & $\square 1-2$ times & $\square$ 3-4 times & $\square$ 5-6 times & $\square 7$ or more \\
\hline Yogurt $_{3}$ & $\square$ Less than 1 & $\square 1-2$ times & $\square$ 3-4 times & $\square 5-6$ times & $\square 7$ or more \\
\hline WIC breakfast cereal ${ }_{7}$ & $\square$ Less than 1 & $\square 1-2$ times & $\square$ 3-4 times & $\square$ 5-6 times & $\square 7$ or more \\
\hline Non-WIC breakfast cereal & $\square$ Less than 1 & $\square 1-2$ times & $\square$ 3-4 times & $\square 5-6$ times & $\square 7$ or more \\
\hline Cereal bars/Granola bars ${ }_{7}$ & $\square$ Less than 1 & $\square 1-2$ times & $\square$ 3-4 times & $\square 5-6$ times & $\square 7$ or more \\
\hline Milk (any kind) ${ }_{3}$ & $\square$ Less than 1 & $\square 1-2$ times & $\square$ 3-4 times & $\square$ 5-6 times & $\square 7$ or more \\
\hline Sweetened beverages $_{2}$ & $\square$ Less than 1 & $\square 1-2$ times & $\square$ 3-4 times & $\square$ 5-6 times & $\square 7$ or more \\
\hline Peanut butter $_{8}$ & $\square$ Less than 1 & $\square 1-2$ times & $\square$ 3-4 times & $\square$ 5-6 times & $\square 7$ or more \\
\hline WIC breads $_{7}$ & $\square$ Less than 1 & $\square 1-2$ times & $\square$ 3-4 times & $\square$ 5-6 times & $\square 7$ or more \\
\hline Non-WIC breads & $\square$ Less than 1 & $\square 1-2$ times & $\square$ 3-4 times & $\square$ 5-6 times & $\square 7$ or more \\
\hline Crackers $_{6}$ & $\square$ Less than 1 & $\square 1-2$ times & $\square$ 3-4 times & $\square$ 5-6 times & $\square 7$ or more \\
\hline Pretzels $_{6}$ & $\square$ Less than 1 & $\square 1-2$ times & $\square$ 3-4 times & $\square 5-6$ times & $\square 7$ or more \\
\hline Nuts and seeds 8 & $\square$ Less than 1 & $\square 1-2$ times & $\square$ 3-4 times & $\square 5-6$ times & $\square 7$ or more \\
\hline Hot $\operatorname{dog}_{10}$ & $\square$ Less than 1 & $\square 1-2$ times & $\square$ 3-4 times & $\square$ 5-6 times & $\square 7$ or more \\
\hline Hamburger/Cheeseburger $_{10}$ & $\square$ Less than 1 & $\square 1-2$ times & $\square$ 3-4 times & $\square 5-6$ times & $\square 7$ or more \\
\hline
\end{tabular}

16. How often does your child eat snacks while watching TV?

$\square_{1}$ Rarely $\quad \square_{2}$ Some days $\quad \square_{3}$ Most days $\quad \square_{4}$ Almost every day $\quad \square_{5}$ Every day

17. Have you heard of My Plate? $\quad \square_{1}$ Yes $\quad \square_{2}$ No

18. Have you looked up My Plate plan on the internet? $\quad \square_{1}$ Yes $\quad \square_{2}$ No

19. Have you tried to follow the recommendations in the My Plate plan? $\square_{1}$ Yes $\quad \square_{2}$ No

20. Do you read the nutrition or health information about foods you buy? $\square_{1}$ Yes $\quad \square_{2}$ No 
21. If yes, do you use the information in deciding which foods to buy? $\quad \square_{1}$ Yes $\quad \square_{2}$ No

22. How many days per week does your child play actively or exercise enough to make him or her breathe hard? (Include running or climbing stairs) days

23. On days your child plays actively or exercises, how many minutes or hours does your child play actively or exercise? minutes $O R$ hours

24. About how many minutes or hours a day does your child sit and watch TV or videos or use a computer or play computer or tablet/smartphone games? minutes $O R$ hours

25. What time does your child usually goes to bed: $\mathrm{pm}$

26. What time does your child usually gets up: am
27. Do you feel your child is:
$\square_{1}$ Just the right size
$\square_{2}$ Too big
$\square_{3}$ Too little

28. Is your child exclusively under parental care (mother or father)?

$\square_{1}$ Yes

$\square_{2}$ No

29. If no, how many hours on average during daytime, per day or week, is your child under: Parental care (mother or father): hours per day OR hours per week

Nonparental care:

a) Center-based care (preschool) hours per day OR

b) Nonrelative care (baby sitter or nanny, friend) hours per day OR

c) Relative care (family member) hours per day OR hours per week hours per week hours per week

30. If your child goes to center-based care, is it: $\quad \square_{1}$ Head Start $\square_{2}$ Private

31. Do you consider your child to be Hispanic or Latino? $\square_{1}$ Yes $\quad \square_{2}$ No

32. What race do you consider your child to be? (Please mark all that apply):
$\square_{1}$ Black or African American
$\square_{4}$ American Indian or Alaska Native
$\square_{2}$ White
$\square_{5}$ Native Hawaiian or Other Pacific Islander
$\square_{3}$ Asian
$\square_{6}$ Other What? 
STUDY ID:

Collected by:

Date:

WIC Site: (check one)

$\square$ Oakland Park

$\square_{2}$ South Regional

$\square_{3}$ North Regional

Current Age: years months

Gender: $\square_{1}$ Male

$\square_{2}$ Female

\section{ANTHROPOMETRIC DATA}

\begin{tabular}{|c|c|c|c|c|c|c|c|c|c|c|c|}
\hline \multirow[t]{2}{*}{ Date } & \multicolumn{2}{|c|}{ Age } & \multicolumn{2}{|c|}{ Height } & \multicolumn{2}{|c|}{ Weight } & \multirow[t]{2}{*}{ BMI } & \multirow[t]{2}{*}{ BMI/Age } & \multirow{2}{*}{ Wt/Age } & \multirow[t]{2}{*}{$\mathrm{Ht} / \mathrm{Age}$} & \multirow[t]{2}{*}{ Wt/Lgth } \\
\hline & Years & Months & In. & $1 / 16$ & Lbs. & $\mathrm{Oz}$. & & & & & \\
\hline & & & & & & & & & & & \\
\hline & & & & & & & & & & & \\
\hline & & & & & & & & & & & \\
\hline & & & & & & & & & & & \\
\hline & & & & & & & & & & & \\
\hline & & & & & & & & & & & \\
\hline
\end{tabular}

Premature: $\square_{1}$ Yes $\quad \square_{2}$ No

Completed weeks of gestation:

Birth weight: Ibs

$\mathrm{OZ}$

\section{BIOCHEMICAL DATA}

\begin{tabular}{|l|l|l|}
\hline Date of Blood work & Hemoglobin & Hematocrit \\
\hline & & \\
\hline & & \\
\hline & & \\
\hline & & \\
\hline
\end{tabular}

\section{RACE \& ETHNICITY}

Race:

$\square_{1}$ Black or African American

$\square_{2}$ White

$\square_{3}$ Asian

$\square_{4}$ American Indian or Alaska Native

$\square_{5}$ Native Hawaiian or Other Pacific Islander

$\square_{6}$ Other What?

Ethnicity:

$\square_{1}$ Hispanic or Latino $\quad \square_{2}$ Not Hispanic or Latino

\section{BREASTFEEDING}

Was this child ever breastfed?

If yes, for how long?

$\square_{1}$ Yes

$\square_{2}$ No Months 
APPENDIX 4 - IRB Forms 


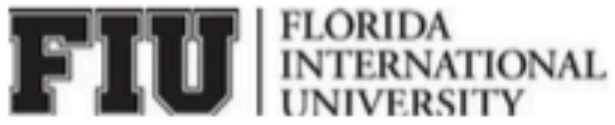

Office of Research Integrity

Research Compliance, MARC 414

\title{
MEMORANDUM
}

\author{
To: Dr. Fatma Huffman \\ CC: File \\ From: Maria Melendez-Vargas, MIBA, IRB Coordinator \\ Date: October 9, 2017 \\ Protocol Title: "Meal Frequency and the Role of Snacking on Weight of Minority \\ Preschool Children"
}

The Health Sciences Institutional Review Board of Florida International University has re-approved your study for the use of human subjects via the Expedited Review process. Your study was found to be in compliance with this institution's Federal Wide Assurance $(00000060)$.
IRB Protocol Approval \#:
IRB-15-0369-CR02
TOPAZ Reference \#: 103703
$\begin{array}{ll}\text { IRB Approval Date: } & 10 / 07 / 17 \\ \text { IRB Expiration Date: } & 10 / 10 / 18\end{array}$

As a requirement of IRB Approval you are required to:

1) Submit an IRB Amendment Form for all proposed additions or changes in the procedures involving human subjects. All additions and changes must be reviewed and approved by the IRB prior to implementation.

2) Promptly submit an IRB Event Report Form for every serious or unusual or unanticipated adverse event, problems with the rights or welfare of the human subjects, and/or deviations from the approved protocol.

3) Utilize copies of the date stamped consent document(s) for obtaining consent from subjects (unless waived by the IRB). Signed consent documents must be retained for at least three years after the completion of the study.

4) Receive annual review and re-approval of your study prior to your IRB expiration date. Submit the IRB Renewal Form at least 30 days in advance of the study's expiration date.

5) Submit an IRB Project Completion Report Form when the study is finished or discontinued.

Special Conditions: N/A.

For further information, you may visit the IRB website at http//research.fiu.edulirb.

$\mathrm{MMV} / \mathrm{em}$ 
Mi ssion:

To probet, promoles 8 improve the hedh a dilpeapla in Flonda heugh integated tate courty 4 commuity aftes.

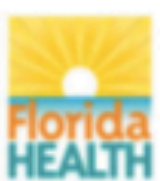

Rick S cott Governar

Celeste Phillp, MD, MPH Sugeen Genara 8 Secalary

Vision: To bethe Heartiest seve in the Natol

November 14, 2017

To: Andrea Charvet

Protocol Title: Meal Frequency and the Role of Snacking on Weight of Minority Preschool

Children

Submission Type: Continuing Review

Review Type: Expedited Procedures

Continuing Review Approval Date: November 14, 2017

Expiration Date: November 13, 2018

The Department of Health Institutional Review Board has reviewed and approved your application to continue research.

Please keep in mind:

- Apply for continuing review at least 60 days prior to expiration, even if your study is dosing.

- Report all problems listed below as soon as possible, but no later than five working days.

- If you need to make changes to your study, complete the modification application.

- If you have to make a change to eliminate hazard to human subjects and there is not fime to submit a modification, notify the IRB as soon as possible but no later than five working days.

If you have questions, want to offer suggestions, or talk with someone about this or other projects, please contact Rotanye Bryan or Bonnie Gaughan-Bailey at the Department of Health IRB at (850) 245-4585 or toll-free in Florida (866) 433-2775.

Thank you for your cooperation with the IRB.

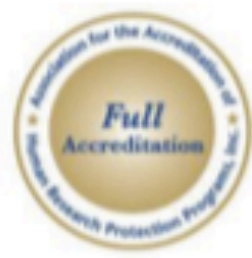

Sincerely,

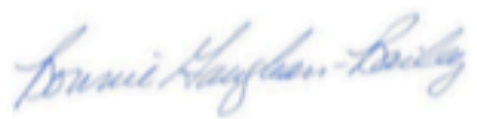

Bonnie Gaughan-Bailey, MPA, ASQ-CQIA

Administrator

Biomedical Research Section

Public Health Research

Federal Wide As surance\#: 00004682

Forida Department of Health

Dision of Comminty Healh Promation

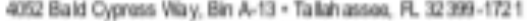

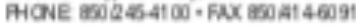

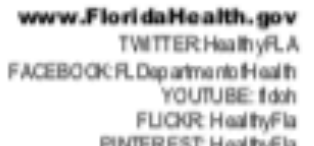

PNTEREST Had HFf 


\section{Reportable Events}

Report the following problems to IRB Staff, as soon as possible, but within five business days:

- Adverse events and adverse outcomes which in the opinion of the principal irvesfigator are both unexpected and related and suggest that the research places subjects or others at a greater risk of harm than was previously known or recognized.

- Any interim analysis or safety monitoring report indicating the frequency or magnitude of harms or benefits may be different than initially presented to the IRB.

- Arry breach of confidentiality.

- Arry change in FDA labeling or withdrawal from marketing of a drug, device, or biologic used in a research protocol.

- Arry change to the protocol taken without prior IRB review to eliminate an apparent immediate hazard to a research participant.

- Any incarceration of a participant in a protocol not approved to enroll prisoners.

- Amy event that requires prompt reporting to the sponsor.

- Any sponsor imposed suspension for risk.

- Arry protocol violation (meaning an accidental or unintentional change to the IRB approved protocol) that harmed participants or others or that indicates participants or others may be at increased risk of harm or has the potential to recur.

- Ary unanficipated adverse device effect.

- Arry non-compliance identified by Department of Health audit or monitoring.

- Arry invesfigation by FDA or OHRP or other federal agency of research (not just including this study) by any researcher on the study.

- Arry loss of license or hospital privileges by any researcher on the study.

Contact IRB staff to obtain answers to questions, express concerns, and convey suggestions regarding the HRPP by emailing irb@fihealth.gov or calling 850-245-4585.

For ida Department of Health Division of Community Health Promotion

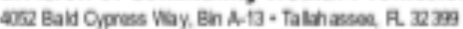

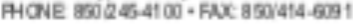

For idaHealth gov
Accredited Health Department PHAB Aublic Heath Accreditation Board 
APPENDIX 5 - Translation Affirmation Form 


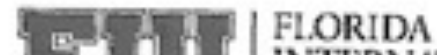 [I] IINTERNATIONAL UNIVERSITY \\ Institutional Review Board \\ Consent Doeument Translation Affirmation Form}

Principle Investigater Name: Antrea Charves

Preject Titk: Meal Frequensy and the Roie of Snadsinz on Weidtt of Mivorily Presched Childret

Langaage of Translated Consent (e.g. Spanish): Saanigh

This seb̀missice is for approvel et:

$\bigotimes \quad$ The initial suhalssice of a consent document

A modification to an airady approved consent bocument datod

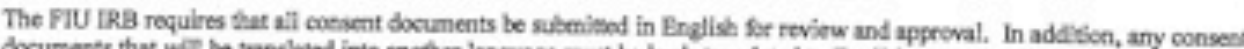

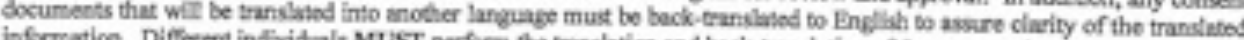
information. Different individals MUST perSorm the traskation and back-translation of be consent docsment. The PI cas perform the transiation bot carnot perform te back-transiation. Is adesion the back-ranslabor must perform the beckranslation withost first seeing the original Eeglish version of the coesent dooument.

You are required to submit:

$\checkmark$ The Englist version of the consent dooument in distribution-ready format (FIU iectertead)

$\checkmark$ The trasalated version of the consent document in distributionectaly formas (FIU lettertead)

$\checkmark$ The beck-translyted vernion of the consent doeument (indicuse "Back-translation" at the top of page)

$\checkmark$ This sigeed form with the signatures of bot traslatios

\section{Step 1: Initial Translation:}

I affirm that I have performed the intial trandation of the conseas document for the feferencod projoct.

Printed Name of Traaslator: Oustawo Zartel

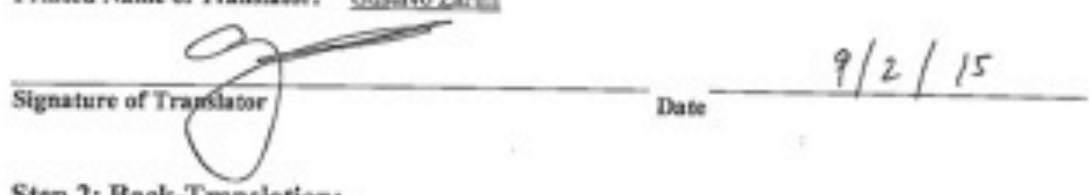

\section{Step 2: Back-Translation:}

I affirm that I have perfirmed the bock-tunsiation of the attached consent docummt for the refereobed project.

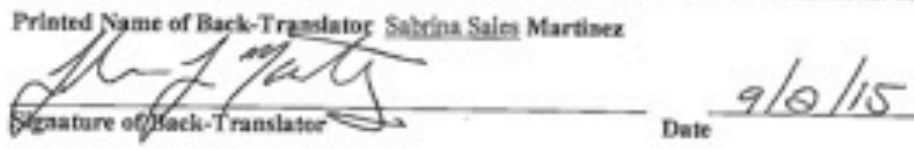


VITA

ANDREA CHARVET

Born, Curitiba, Parana, Brazil

1994-1998

B.S., Dietetics and Nutrition

Recipient of the "Professor Nilo Cairo" Award

Universidade Federal do Parana, Brazil

1996-1998

PIBIC/CNPQ Research Fellow

Universidade Federal do Parana, Brazil

2002-2007

M.S., Dietetics and Nutrition

Florida International University, Miami, Florida

2009-2011

Registered Dietitian, private practice

Curitiba, Parana, Brazil

2011-2013

Nutrition Educator, Broward County WIC Program

Fort Lauderdale, Florida

2013-2014

Ph.D. student and Teaching Assistant

Florida International University, Miami, Florida

2014-2018

Ph.D. student and Research Assistant

Florida International University, Miami, Florida

2014-2018

NIGMS RISE Fellow

Florida International University, Miami, Florida

2016

Recipient of the Student Government Association

Scholarship

Florida International University, Miami, Florida

2017

Dietetic Internship

Florida International University, Miami, Florida

\section{PUBLICATIONS AND PRESENTATIONS}

Charvet A., Brogan Hartlieb K., Yeh Y., Jen C. A comparison of snack serving sizes to USDA guidelines in healthy weight and overweight minority preschool children enrolled in Head Start. BMC Obesity. 2016;3:36. 
Charvet A., Rocco C., Mendonca D., Bruck I., Antoniuk S. Dieta Cetogenica - Uma Visao Basica (Ketogenic Diet - A Basic Understanding). O Dendrito. 1998;4(3):59-61.

Charvet A., Brogan Hartlieb K., Yeh Y., Jen K-L C. Head Start Program Preschool Children's Snack Intake and its Implications on Weight Status, oral presentation at the MARC U*STAR \& MBRS RISE Student Research Mini-Symposium, Miami, FL, October 10th, 2014.

Charvet A., Brogan Hartlieb K., Yeh Y., Jen K-L C. Preference for Energy Dense Snack Foods in Healthy and Overweight Minority Preschool Children, oral presentation at the Experimental Biology Annual Conference, Boston, MA, March 30th, 2015.

Charvet A., Brogan Hartlieb K., Yeh Y., Jen K-L C. Elevated Intake of Energy Dense Snack Foods in Healthy and Overweight Minority Preschool Children, oral presentation at the FIU Graduate Student Appreciation Week Scholarly Forum, Miami, FL, April 7th, 2015.

Charvet A., Huffman F. Meal Frequency and the Role of Snacking on Weight of Minority Preschool Children, poster presentation at the MARC U*STAR \& MBRS RISE Student Research Mini-Symposium, Miami, FL, October 2nd, 2015.

Charvet A., Huffman F. Meal Frequency and the Role of Snacking on Weight of Minority Preschool Children, Public Health Association Annual Educational Conference, Orlando, FL, July 27th \& 28th, 2016.

Charvet A., Huffman F. Meal Frequency and the Role of Snacking on Weight of Minority Preschool Children, oral presentation at the MARC U*STAR \& NIGMS RISE Student Research Mini-Symposium, Miami, FL, October 4th, 2016.

Charvet A., Huffman F. Eating Frequency and the Role of Snacking on Weight of Minority Preschool Children, oral presentation at the $19^{\text {th }}$ Annual Biomedical and Comparative Immunology (BCI) Symposium, Miami, FL, March 31st, 2017.

Charvet A., Huffman F. Eating Frequency and the Role of Snacking on Weight of Minority Preschool Children, poster presentation at the Experimental Biology Annual Conference, Chicago, IL, April 23rd, 2017.

Charvet A., Huffman F. The Impact of Beverage Intake on Weight of Minority Preschool Children, oral presentation at the MARC U*STAR \& NIGMS RISE Student Research Mini-Symposium, Miami, FL, October 13th, 2017.

Charvet A., Huffman F. Beverage Intake Among Minority Preschool Children and its Relationship to Body Weight, oral presentation at the $20^{\text {th }}$ Annual Biomedical and Comparative Immunology (BCI) Symposium, Miami, FL, March 9th, 2018. 